$$
U \subset R h-\mp D-121046
$$

\title{
Potential Long-Term Chemical Effects of Diesel Fuel Emissions on a Mining Environment: A Preliminary Assessment Based on Data from a Deep Subsurface Tunnel at Rainer Mesa, Nevada Test Site
}

\author{
Contributing Authors: \\ A. Meike, W. L. Bourcier, and M. Alai \\ Lawrence Livermore National Laboratory \\ D. L. Haldeman, P. S. Amy, and T. Lagadinos \\ University of Nevada at Las Vegas \\ L. Hersman \\ Los Alamos National Laboratory

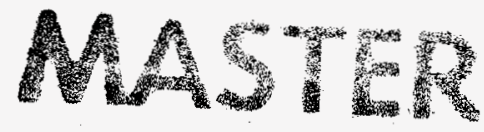

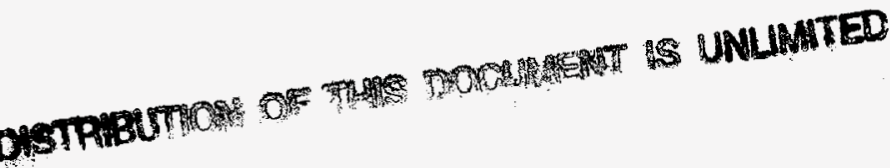

September 1995

This report was submitted to fulfill the requirements of Yucca Mountain Project Milestone No. MOL73, "Progress Report on the Stability of Organic Compounds." 


\section{DISCLAIMER}

This report was prepared as an account of work sponsored by an agency of the United States Government. Neither the United States Government nor any agency thereof, nor any of their employees, make any warranty, express or implied, or assumes any legal liability or responsibility for the accuracy, completeness, or usefulness of any information, apparatus, product, or process disclosed, or represents that its use would not infringe privately owned rights. Reference herein to any specific commercial product, process, or service by trade name, trademark, manufacturer, or otherwise does not necessarily constitute or imply its endorsement, recommendation, or favoring by the United States Government or any agency thereof. The views and opinions of authors expressed herein do not necessarily state or reflect those of the United States Government or any agency thereof. 


\section{DISCLAMMER}

Portions of this document may be illegible in electronic image products. Images are produced from the best available original document. 


\section{Contents}

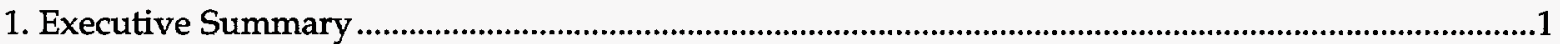

2. Diesel Emissions in the Context of Long-Term Disposal of Radioactive Waste .....................................

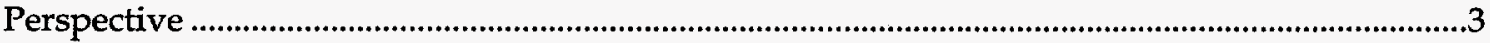

Factors that Determined the Approach to This Investigation .............................................................4

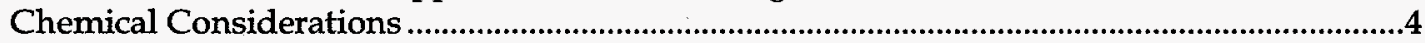

Chemical Mobility Considerations ...................................................................................................

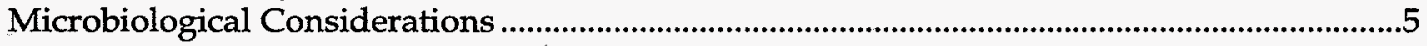

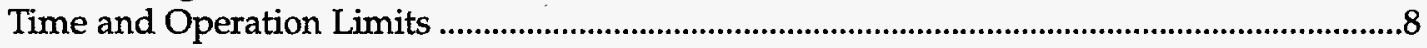

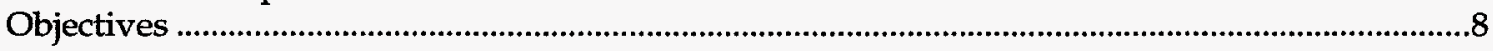

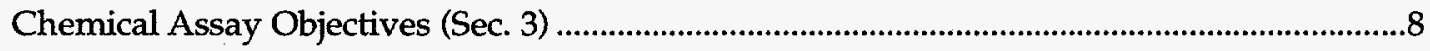

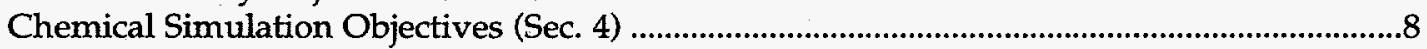

Microbial Assay Objectives (Sec. 5) ............................................................................................

Reconnaissance Survey of N-Tunnel and Resultant Sampling Decisions .........................................9

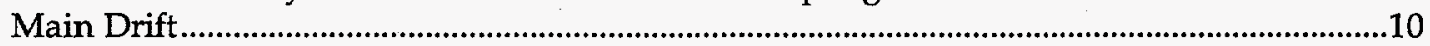

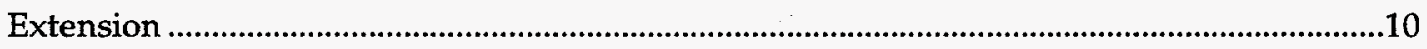

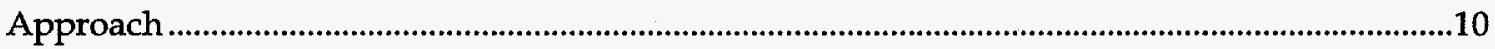

3. Chemical Assay of N-Tunnel: Sampling and Data Interpretation.....................................................13

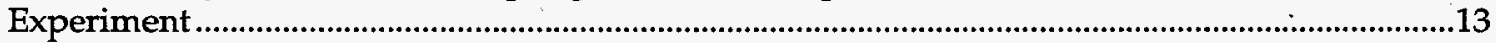

Diesel Exhaust Composition ...................................................................................................13

Sampling Procedures and Postcollection Sample Treatments ....................................................14

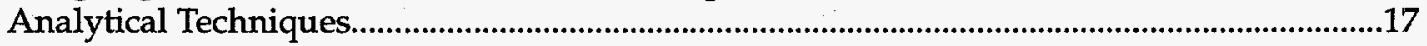

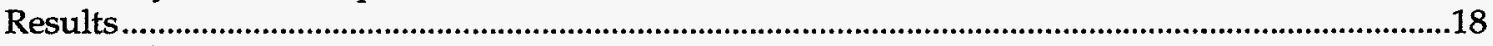

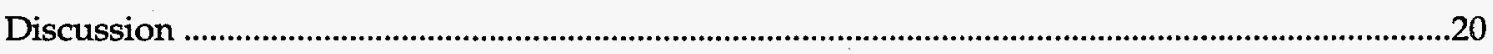

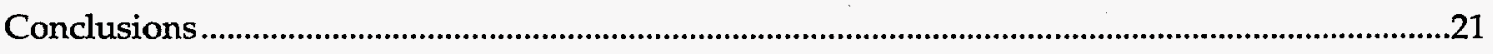

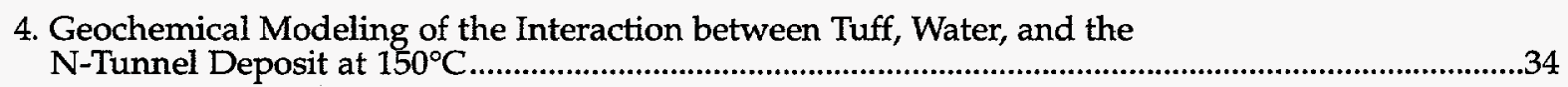

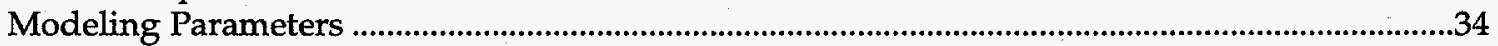

Modeling Tuff-Groundwater-Rock Deposit Interactions.............................................................35

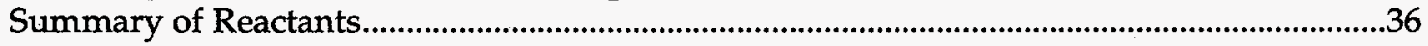

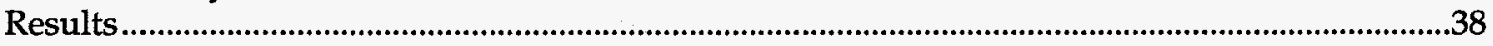

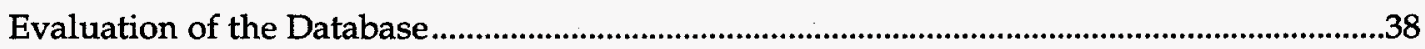

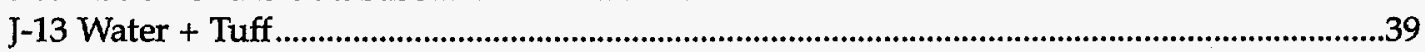

J-13 Water + Tuff + Deposit .....................................................................................................

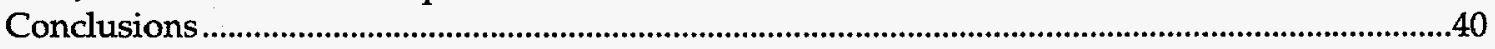

5. Effects of Diesel Exhaust on the Microbiota in a Tuffaceous Tunnel System .......................................46

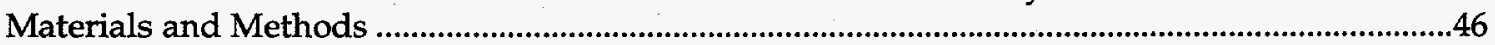

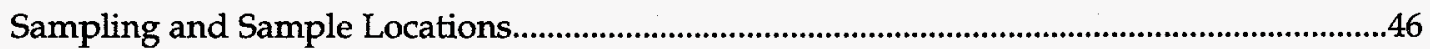

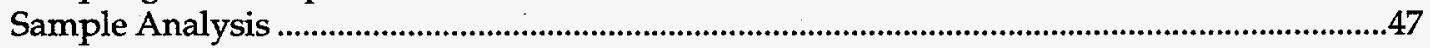

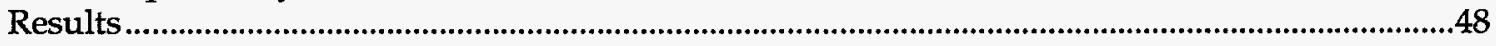

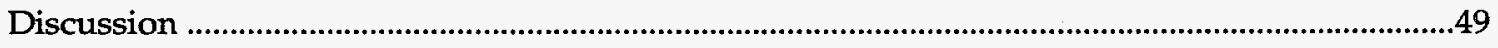

Summary and Future Directions .......................................................................................................51

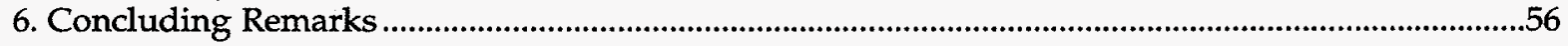

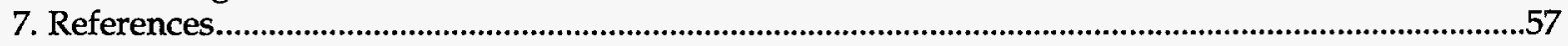

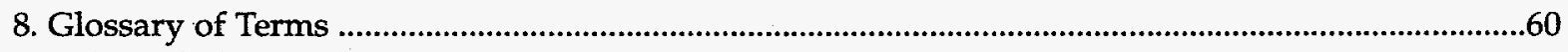

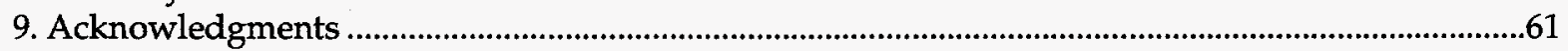




\title{
1. Executive Summary
}

\author{
A. Meike
}

The general purpose of the Yucca Mountain Site Characterization Project (YMSCP) Introduced Materials Task is to understand and predict potential long-term modifications of natural water chemistry related to the construction and operation of a radioactive waste repository that may significantly affect performance of the waste packages. The present study focuses on diesel exhaust. Although chemical information on diesel exhaust exists in the literature, it is either not explicit or incomplete, and none of it establishes mechanisms that might be used to predict longterm behavior. In addition, the data regarding microbially mediated chemical reactions are not well correlated with the abiotic chemical data. To obtain some of the required long-term information, we chose a historical analog: the U12n tunnel at Rainier Mesa, Nevada Test Site. This choice was based on the tunnel's extended (30-year) history of diesel usage, its geological similarity to Yucca Mountain, and its availability. The sample site within the tunnel was chosen based on visual inspection and on information gathered from miners who were present during tunnel operations. The thick layer of dark deposit at that site was assumed to consist primarily of rock powder and diesel exhaust.

Surface samples and core samples were collected with an intent to analyze the deposit and to measure potential migration of chemical components into the rock. X-ray diffraction $(\mathrm{XRD})$, x-ray fluorescence (XRF), scanning electron microscopy (SEM) with energy dispersive spectra (EDS) analysis, secondary-ion mass spectrometry (SIMS), and Fourier transform infrared (FTIR) analysis were used to measure both spatial distribution and concentration for the wide variety of chemical components that were expected based on our literature survey.

Concentrations of $\mathrm{Ba}, \mathrm{Ti}, \mathrm{S}$, and $\mathrm{Ca}$ increased in the surface deposit with respect to analyses of the rock at depth $(\sim 2.5 \mathrm{~cm}$ from the tunnel surface). Although all of these elements are related to diesel exhaust in the literature, increases in $\mathrm{S}$ and $\mathrm{Ca}$ may also be related to tunnel respiration (the process in which dissolved species are transported in pure fluids to the tunnel wall where evaporation occurs, leaving a precipitate). Other metals that have been associated with diesel exhaust analyses in the literature ( $\mathrm{As}, \mathrm{Cu}, \mathrm{Pb}, \mathrm{Bi}, \mathrm{Mo}, \mathrm{Mn}$, $\mathrm{Pt}$, and $\mathrm{P}$ ) were also detected in some surface samples but not in others. This variability in the analyses is related to the extremely low concentrations, but it also suggests heterogeneity of the exhaust deposit and, in some cases, a source other than diesel exhaust (e.g., detergent, minute paint spatters, flakes of coating materials). Other elements detected ( $\mathrm{Si}, \mathrm{Fe}, \mathrm{Zn}, \mathrm{Nb}, \mathrm{Rb}, \mathrm{K}$ ) did not show an arguable trend beyond the analytical error. The measured concentrations of $\mathrm{Cr}$ and $\mathrm{Ni}$, also associated with diesel exhaust, increase at depth. However, with the exception of $\mathrm{Ba}$, the absolute concentrations of elements that can be directly associated with diesel exhaust are quite low. Some increase in hydrocarbon content was detected, as was an increase in total organic carbon (TOC). Given the age of the deposit, we expect that for the purpose of test interference analysis, these analyses may be considered a minimum value. Further identification and characterization of the hydrocarbons were not within the scope of the present study.

Preliminary computer chemical simulations were conducted using the $\mathrm{EQ} 3 / 6$ geochemical modeling code and a simplified version of the chemical analysis of the surface deposit. The other modeling exercise originally planned, using analyses from the literature, proved to be impossible because the information was incomplete. However, one objective of the Introduced Materials Task is to expand the EQ3/ 6 database into the areas that will be necessary to model introduced materials. Comparison of the database with the literature demonstrated the lack of some gaseous species (e.g., $\mathrm{NO}_{\mathrm{x}}$ species) for which data exist in the literature but have been omitted from the database because they have not been required for normal geochemical analysis. In the case of the $\mathrm{NO}_{\mathrm{x}}$ species, the database has been modified.

Given the time and database restrictions for the present study, and thus the inability to conduct a full spectrum of simulations, we assumed an open system and that all the carbon was present as elemental, and most probably amorphous, carbon with the potential of being converted to carbonate. As might be expected under these 
conditions, $\mathrm{pH}$ was considerably affected, which ultimately affected the identity of the phases predicted to dissolve and to precipitate. These results are considered to represent one extreme bound for the potential chemical modification of natural waters by a deposit similar to the U12n tunnel composition.

The analysis of the abundance and distribution of microbiota that may be affected by diesel fuel and diesel exhaust provides a first step toward obtaining data related to microbially mediated chemistry in a form that is consistent with the present YMSCP framework for predicting abiotic chemical reactions. Total cell counts and numbers of aerobic heterotrophic, sulfatereducing, nitrate-reducing, citrate-utilizing, and diesel-degrading bacteria were obtained. Samples were taken from three depths into the walls and invert (floor), using methods that will be developed for future quality-affecting investigations in the Exploratory Studies Facility (ESF). The potential for microbial contamination of the tunnel wall during sampling was determined to be negligible by monitoring the distribution of latex spheres (1 $\mu \mathrm{m}$ diam), labeled with fluorescent dyes, that were used as tracers in all microbial sampling.

In general, the tunnel invert, a perturbed environment, demonstrates a greater abundance of specific bacterial types than does the tunnel wall. However, the trends recorded in culturable counts of aerobic heterotrophic bacteria with depth in the wall and the invert were the inverse of each other. The counts increased with depth into the wall and decreased with depth into the invert. TOC content decreased with depth in both the wall and the invert. Thus, it is no surprise that where a negative correlation was observed between TOC content and numbers of culturable microorganisms in the wall samples, a positive correlation was observed in the invert samples. Microbes capable of using diesel fuel and diesel combustion products were determined to be present in both the tunnel wall and the invert, based on the disappearance of total petroleum hydrocarbons measured from experimental microcosms that contained subsurface materials to which diesel fuel had been added.

The results of this historical analog study emphasize the need for further investigation into the potential modification of the natural chemistry of the subsurface by diesel exhaust. This study also provides a template for the type of integrated approach, using both microbiological and chemical tools, that the YMSCP Introduced Materials Task requires to determine and predict the longterm chemical consequences of the presence of introduced materials in a repository environment. 


\title{
2. Diesel Emissions in the Context of Long-Term Disposal of Radioactive Waste
}

\author{
A. Meike
}

\section{Perspective}

During the design and construction of a radioactive waste repository, the use of many types of materials and construction techniques must be considered. As for any mining operation, these decisions are commonly interdependent and include such factors as economics, health and safety, and the available technology. The longterm chemical implications for the repository materials must also be considered in the design (Meike 1994); these considerations include the effects of construction and operation, exposure to elevated temperatures, and possibly, depending on repository design, radiolysis. One design and construction decision that could have a major impact on other decisions and might affect the types of materials that remain in the repository for long periods of time is the type of power used in motorized vehicles and power generators.

This study was undertaken to provide supporting data for deciding which type of power should be used in haulage vehicles in the Exploratory Studies Facility (ESF) and, of course, will support similar decisions for emplacement vehicles should a repository be developed. Two possibilities are being considered: diesel and electric. When this study was begun, diesel power was favored because of economic and technological considerations. However, the potential longterm chemical effects of diesel use in a repository environment are not well known. Therefore, we have developed this short study on one aspect of diesel-powered-vehicle use to determine whether adverse effects are observed that would suggest using an alternative power source such as electricity. Two categories of potential chemical consequences of using diesel fuel in a mining environment can be distinguished: the effects of diesel spills and of accumulated diesel-emission deposits.

Diesel spills can be expected to occur occasionally because of human error and machine malfunction. The long-term stability of diesel fuel in a repository environment, the formation of colloids from the organic components of diesel fuel, and the reactivity of diesel fuel breakdown products, although potentially important, are being pursued under other activities within the Introduced Materials Task and are not covered in this report. For preliminary information on the hydrous pyrolysis of diesel fuel, the reader is referred to Jackson and Carroll (1994). For a general perspective on the impact of introduced materials on the formation of colloids and their sorption properties, the reader is referred to Meike and Wittwer (1994).

The second category of potential chemical consequences has to do with the effects of accumulated diesel-emission deposits, which are the result of normal use during mining construction and operation. Because this kind of deposit is related to the conditions of engine use (e.g., engine wear, load, idle time, and run time), the diesel exhaust deposits should be more easily bounded than, for example, an unexpected spill. Consequently, the chemical effects should be more easily predicted. To conduct a relatively short-term assay of long-term chemical effects of diesel deposits, we sought a tunnel location that had been exposed to diesel emissions over a relatively extended period of time. We chose tunnel U12n ("N-Tunnel"), located at Rainier Mesa on the Nevada Test Site (NTS), because it has a history of intermittent diesel emission exposure since its excavation in 1964. We have undertaken the present study of a single historical analog supported by geochemical simulations to determine whether these or other potentially deleterious chemical effects on a repository environment can be identified in a less than full scale study.

Like any historical analog, N-Tunnel represents a collection of experimental factors that in many ways are representative of mining operations, but do not necessarily represent the range of variables in an experimentally controlled fashion. In fact, some factors are not quantifiable. There is a substantive advantage to the investigation of historical analogs, however, even in the face of these drawbacks. That is, with the careful selection of the analog or analogs to be investigated, the variable of time can be addressed. This variable is often inaccessible for most experimental work, for which a normal "long-term" laboratory experiment may extend to several months or, at most, a few years. With regard to a radioactive. 
waste repository, these experimental durations are far too short to determine whether the processes under consideration are the processes that will be important over the long term (currently 10,000 years). In addition to time, historical analogs offer a complex combination of factors that may be consistently and implicitly omitted during laboratory experiments. For example, materials degradation, geochemical transport, and radionuclide transport in laboratory experiments are commonly conducted without regard for (or, more often, with a direct attempt to minimize the effects of) microbial influence on the experiments.

\section{Factors that Determined the Approach to This Investigation}

Three major considerations determined our approach in this investigation of diesel exhaust accumulations. The first two considerations involved addressing the potential chemical consequences that may compromise the short- or longterm interests of the Yucca Mountain Site Characterization Project (YMSCP). The short-term interests include identifying the potential effects of diesel exhaust deposits on geochemical monitoring at sample sites in the ESF; the long-term interests include identifying the potential chemical effects of exhaust deposited during construction of a radioactive waste repository. Direct and coupled chemical effects, and microbial effects, must all be considered. The third consideration involved time limitations related to meeting the schedule of design decisions. All of these considerations are outlined below.

\section{Chemical Considerations}

The chemical components of diesel exhaust include the products of combustion and partial combustion of diesel fuel. Perfect combustion is unlikely in a real setting; thus, diesel emissions may contain a wide range of hydrocarbons. Heavy metals, sulfur compounds, and nitrogen compounds are also present (see Tables 2.1 and 2.2). Possible chemical effects of the diesel emissions span a wide range. For example, the inorganic gases component (carbon monoxide, carbon dioxide, nitric oxide, nitrogen dioxide, and sulfur dioxide) could increase the acidity of any water present. Generally, silicate minerals become more soluble with increasing acidity, which may increase the porosity of the repository horizon rock. The ability of the rock-water system at Yucca Mountain to neutralize an increase in acidity from the diesel fuel exhaust is limited; therefore, local chemical effects may be significant. Introduced materials, such as cement, may act locally as buffers. If hydrologic connections and gradients are sufficient, contaminated water interacting with rock and water may affect the composition of water samples collected for geochemical analysis at locations far removed from the deposit site. As another example, diesel fuel exhaust contains elemental carbon as particulate matter, and uncombusted or partially combusted organic components. Some of these exhaust components and the products of their degradation over time may have the potential to be involved in organometallic complexes and in the formation of colloids. These possibilities are being investigated under separate activities of the Introduced Materials Task.*

To predict the potential occurrence of the effects described above, we must have an exact understanding of the chemical components of diesel fuel and its combustion products. Many studies attest to the variability of diesel emissions with engine load and engine efficiency (e.g., Khatri et al. 1979). These factors are not known for the present study, either for the N-Tunnel equipment or for the intended use in the ESF. Our assessment of the literature found very few analyses of the chemical components of diesel fuel emissions that were either complete or detailed enough to suit the present needs of the Introduced Materials Task. Furthermore, a database adequate for the simulation needs of the Introduced Materials Task has not yet been developed. The simulations presented here should therefore be considered more of a method of systems analysis than a realistic simulation of chemical behavior in a repository or mining drift environment. The rarity of complete chemical speciation data is understandable for a number of reasons. First, the need for complete chemical speciation information, which is often time-consuming and costly, has not been apparent. For regulatory purposes, for example, incomplete speciation or

\footnotetext{
*For the status of the Hydrous Pyrolysis of Diesel Fuel investigation, see Jackson and Carroll (1994); for the status of the Colloids investigation, see Meike and Wittwer (1994); and for the status of the Organometallic Complex investigation, see Meike (1994).
} 
elemental analyses (e.g., Tables 2.1 and 2.2) are far more common. Second, as discussed in Sec. 3 , the chemical composition of diesel fuel emissions is expected to vary as a function of many factors and is therefore case-specific to the particular study type.

Environmental safety and health (ES\&H) standards for tunnel environments can be used to estimate maximum concentrations of some diesel exhaust components (particularly those known to be carcinogens) as a function of diesel use brake horsepower (BHP). An analysis of this type was conducted before initiating the present work (CRWMS M\&O Contractor 1993; see Tables 2.3 and 2.4). However, chemical components of concern for health and safety standards may not be identical to those significant to the long-term stability of radioactive waste packages. In addition, the relation between the chemical composition of diesel emissions and the composition of a solid deposit is not clear. Furthermore, in a mining environment such as N-Tunnel or the ESF, the more complex chemical relations between diesel emissions and rock powder, such as the condensation or sorption of diesel exhaust constituents onto particles of rock dust, also require elucidation. Thus, the value of the calculations of the CRWMS M\&O Contractor (1993), which reflect the data in the literature, is limited.

\section{Chemical Mobility Considerations}

Studies of soil contamination indicate that the hydrocarbon components of diesel fuel have varying degrees of mobility (see Table 2.5 ). We do not expect to be able to apply these numbers directly to the tuffaceous rock unit of the present study. However, we expect that the hydrocarbon components of diesel deposits may not migrate into the rock as a single front, and perhaps relative mobilities may be similar. To this end, studies should be conducted to evaluate chemical composition with depth into the wall of the tunnel.

\section{Microbiological Considerations}

The potential effect of microbes on the longterm degradation and corrosion of nuclear waste packages has been recognized (Bachofen 1991; Birch and Bachofen 1990; Gadd 1990; West et al. 1985). However, it is less often explicitly recognized that microbiological activity could modify the chemical environment differently than, or at a different rate than, non-microbially mediated chemical reactions. Thus, the design of a radioactive waste repository must determine
Table 2.1. Emission factors for diesel engines.

\begin{tabular}{lc}
\hline Type of emission & $\begin{array}{c}\text { Emission factor } \\
(\mathbf{l b} / 1000 \text { gal })\end{array}$ \\
\hline Aldehydes & 10 \\
Benzo(a)pyrene & $0.4 \mathrm{~g} / \mathbf{1 0 0 0}$ gal \\
Carbon monoxide & 60 \\
Hydrocarbons & 180 \\
Oxides of nitrogen & 222 \\
Oxides of sulfur & 40 \\
Ammonia & Not available \\
Organic acids & 31 \\
Particulates & 110 \\
\hline
\end{tabular}

Source: American Industrial Hygiene Association 1972, p. 23.

a $2 \mathrm{lb} / 1000$ gal for gasoline engines.

whether microbially mediated chemical reactions may significantly modify predicted chemical reactions that are based on non-biochemical considerations alone. As for any study intended to determine the potential significance of standard chemical reactions, we must understand the biochemical cycling of elements, especially the interactions between microbiota and materials introduced into the near-field environment. Unlike these standard reactions, the survival and environmental sensitivities of the microbial populations also affect reaction rate.

Table 2.2. Estimated diesel contaminant emission rates.

\begin{tabular}{lc}
\hline Contaminant & $\begin{array}{c}\text { Emission rate } \\
\text { (lb/short ton, } \\
\text { fuel burned) }\end{array}$ \\
\hline Particulates & 34 \\
Oxides of sulfur & 10 \\
Oxides of nitrogen & 49 \\
Acids (e.g., acetic) & 10 \\
Aldehydes (e.g., formaldehyde) & 5 \\
Other organics & \\
(including hydrocarbons) & Not available \\
\hline Source: American Industrial Hygiene Association \\
1972, p. 21. \\
a 141 lb/short ton for gasoline engines.
\end{tabular}


Table 2.3. Compendium of diesel exhaust constituents.

\begin{tabular}{|c|c|c|c|c|c|c|c|}
\hline Source & $\mathrm{CO}(\%)$ & $\mathrm{HC}(\%)$ & NO (\%) & $\mathrm{NO}_{2}(\%)$ & $\mathrm{CO}_{2}(\%)$ & $\mathrm{SO}_{2}(\%)$ & $\begin{array}{c}\mathrm{DPM}^{a} \\
\left(\mathrm{mg} / \mathrm{m}^{3}\right)\end{array}$ \\
\hline Alcock (1977) & 0.07 & 0.05 & 0.07 & 0.01 & 11.8 & - & - \\
\hline Hartman (1992) & $0.02-0.15$ & $0.003-0.015$ & $0.048-0.054$ & $0.007-0.008$ & $3.0-9.50$ & - & $0.021-0.2^{b}$ \\
\hline $\begin{array}{l}\text { Williams et al. } \\
\text { (1987) }\end{array}$ & $0.02-0.25$ & - & $0.05-0.10$ & $0.0012-0.002$ & $0.8-1.0$ & - & - \\
\hline $\begin{array}{l}\text { Dainty et al. } \\
\text { (1986) }\end{array}$ & 0.03 & - & 0.07 & 0.0048 & - & 0.008 & 75 \\
\hline $\begin{array}{l}\text { Watts (1987); } \\
\text { Steward et al. } \\
\text { (1976) }\end{array}$ & $0.0-0.01$ & - & $0.0-0.01$ & $0.0-0.0008$ & $0.03-7.0$ & $0.0095-0.0098$ & $96.7-111.6$ \\
\hline $\begin{array}{l}\text { Doyle-Coombs } \\
\text { (1987) }\end{array}$ & $0.0114-0.0513$ & - & $0.0225-0.0735$ & $0.0036-0.0084$ & $6.1-7.2$ & - & - \\
\hline McClure (1992) & - & - & - & - & - & - & $45-118$ \\
\hline $\begin{array}{l}\text { Baumgard and } \\
\text { Bickel (1987) }\end{array}$ & - & - & - & - & - & - & $50-100$ \\
\hline Zeller (1990) & - & - & - & - & - & - & 4-115 \\
\hline
\end{tabular}

Source: CRWMS M\&O Contractor 1993.

a DPM = diesel particulate matter.

b In wt\%.

Table 2.4. Worst-case scenario ${ }^{\mathrm{a}}$ diesel exhaust constituents.

\begin{tabular}{|c|c|c|c|c|c|c|c|}
\hline & $\mathrm{CO}$ & $\mathrm{HC}$ & No & $\mathrm{NO} 2$ & $\mathrm{CO} 2$ & $\mathrm{SO} 2$ & DPM \\
\hline \multicolumn{8}{|c|}{ Highest value } \\
\hline $\mathbf{f t}^{3} / \mathrm{bhp} \cdot \mathbf{h r}$ & 0.486 & 0.097 & 0.194 & 0.0162 & 22.9 & 0.0194 & $649.6^{b}$ \\
\hline $\mathrm{m}^{3} / \mathbf{k W} \cdot \mathbf{h r}$ & 0.0185 & 0.0037 & 0.0074 & 0.0006 & 0.8696 & 0.00074 & $(484.4)^{\mathrm{b}}$ \\
\hline \multicolumn{8}{|c|}{ Product produced per bhp.hr } \\
\hline ppme & 48.6 & 9.7 & 19.4 & 1.6 & 2290 & 1.9 & $2.3^{d}$ \\
\hline ppme $^{e}$ & 38.9 & 7.8 & 15.5 & 1.3 & 1832 & 1.5 & $1.8^{d}$ \\
\hline \multicolumn{8}{|l|}{$\mathrm{H}_{2} \mathrm{O}$ vapor: } \\
\hline $0.216 \mathrm{~kg} / \mathrm{b}$ & & & & & & & \\
\hline
\end{tabular}

Source: CRWMS M\&O Contractor 1993.

a Results from the assumptions BSFC $=0.48 \mathrm{lb}$ fuel/bhp.hr, SLF $=60 \%$, and CPE $20 \%$ above high average, where BSFC = brake specific fuel consumption, SLF = shift load factor, CPE = concentration products of exhaust,

b In mg/bhp·hr (mg/kW.hr).

c Concentration in underground atmosphere with dilution rate of $100 \mathrm{~cm} / \mathrm{bhp}$, where $\mathrm{cfm}=$ cubic feet per minute.

d In $\mathbf{~ m g} / \mathbf{m}^{3}$.

e Concentration in underground atmosphere with dilution rate of $125 \mathrm{cfm} / \mathrm{bhp}$. 
Table 2.5. Mobility of distillate oil constituents.

\begin{tabular}{llc}
\hline Chemical & $\begin{array}{c}\text { Solubility in water, } \\
S_{\mathrm{w}}(\mathrm{mg} / \mathrm{L})\end{array}$ & $\begin{array}{c}\text { Retardation coefficient } \\
\boldsymbol{R}_{\mathrm{d}}\end{array}$ \\
\hline Low mobility $\left(\boldsymbol{R}_{\mathrm{d}}>\mathrm{100}\right)$ & 1.9 & - \\
Fluorene & 1.6 & 1097.2 \\
Phenanthene & 0.16 & - \\
Pyrene & 0.0057 & 24,601 \\
Benzanthracene & 0.0030 & 67,801 \\
Benzo(a)pyrene & 0.265 & - \\
Fluoranthene & & \\
Medium mobility $\left(100>R_{\mathrm{d}}>10\right)$ & 31 & $\mathbf{8 7 . 9 4}$ \\
Napthalene & 160 & 60.91 \\
Dimethylbenzene, 1,3-(m-xylene) & 200 & 54.39 \\
Dimethylbenzene, 1,4-(p-xylene) & 180 & 23.26 \\
Dimethylbenzene, 1,2-(o-xylene) & 150 & 53.92 \\
Ethylbenzene & 520 & 30.40 \\
Toluene & & \\
High mobility $\left(R_{\mathrm{d}}<10\right)$ & 1800 & 8.80 \\
Benzene & 60,000 & 5.16 \\
Quinoline & 26,000 & 4.78 \\
Cresol (m-) & 25,000 & 4.21 \\
Cresol (p-) & 26,000 & 2.32 \\
Cresol (o-) & 67,000 & 2.09 \\
Phenol & & \\
\hline
\end{tabular}

Source: Calabrese and Kostecki 1991.

a Retardation coefficient represents the rate of migration of the chemical constituent in comparison with that of groundwater (e.g., $R_{\mathrm{d}}=\mathbf{1 0 0}$ indicates constituent moves $\mathbf{1 0 0}$ times slower than water). The following values were used to determine $R_{\mathrm{d}}$ : fugacic oxygen capacity $=0.01$, porosity $=0.35$, bulk density $=1.5 \mathrm{~g} / \mathrm{cm}^{3}$.

Geological and technological similarities between the Rainier Mesa N-Tunnel and the Exploratory Studies Facility suggested that microbiological investigations in the former location could provide analogs in two important areas of interest to the YMSCP: (1) microbial effects and (2) microbial sample collection protocol. In previous studies, Rainier Mesa provided an opportunity to sample for autochthonous subsurface microbiology at depth from extant tunnel systems and to avoid the costs and concerns associated with drilling operations (Amy et al. 1992; Haldeman and Amy 1993; Haldeman et al. 1995). Viable microbes have been recovered from depths to $450 \mathrm{~m}$ in the volcanic tuffs of Rainier Mesa (Amy et al. 1992; Haldeman and Amy 1993; Haldeman et al. 1993; Kieft et al. 1993).
In the present study, we consider the impact of human intervention. Perturbations of natural conditions increase the abundance and stimulate the activity of subsurface microbial communities simply because physical redistribution of materials may make compounds essential for bacterial resuscitation or growth more available to the microbial populations (Brockman et al. 1992; Fredrickson et al. 1995; Haldeman et al. 1994, 1995). In addition to the autochthonous populations, microbial populations are expected to be transported into a tunnel environment through the ventilation system and through human transport. Substances may be introduced that serve as bacterial nutrients or inhibitors (e.g., water, oxygen, fuel exhaust). Hydrocarbons and other emission constituents are potential sources of 
nutrients that may result in a microbiological plume of preexisting or introduced microbiota. Because microbiological activity could modify the chemical environment and the rates of chemical reactions, it is essential to document the presence of microbes that have the potential to use the components of diesel fuel.

\section{Time and Operation Limits}

The samples for this study were obtained and analyzed and the data were interpreted within a four-month period. The reasons for the time limitation are discussed in the Objectives section below. The chosen tunnel was open for inspection on the first Tuesday of each month. We restricted our entry into the tunnel to those days because of budgetary constraints. Given the time limitation, our sampling mission was limited to a reconnaissance survey and a sampling expedition, conducted during two consecutive months. During the reconnaissance survey, a sampling location was chosen, sampling procedures were finalized, and tunnel-use information was obtained from staff who had a history of work experience connected with the tunnel. During the sampling expedition, suites of samples were taken for later study. A limited water supply and the absence of electricity had a severe impact on our ability to obtain rock core samples, which compromised our ability to assess the mobility of diesel components into the rock.

\section{Objectives}

The intention of the proposed investigation was to assess samples collected from $\mathrm{N}$-Tunnel at the Nevada Test Site, which has experienced intermittent use of diesel haulage equipment since its construction in 1964. The geochemical modeling code EQ3/ 6 was intended to simulate rock-water-introduced material interactions over a range of geochemical environments likely to occur during construction. Analyses of N-Tunnel rock surfaces were intended to provide information on the penetration of diesel fuel exhaust into the repository walls and on the resulting degradation or perturbation of the repository rock that had been exposed to diesel fuel emissions for an extended but unquantified period of time.

The duration of our investigation was limited by the need to provide input for an August 1994 decision regarding the type of haulage vehicle to be used at the ESF. Therefore, the results of this investigation are preliminary and limited in scope. Because it is likely that this question will recur in the context of the actual repository design, issues that remain unresolved in this study must be pursued by the Introduced Materials Task. A secondary function of this work stems from the fact that a complete analysis of the effects of hydrocarbon exhaust deposits involves an analysis of microbial activity. Therefore, we tested techniques for sampling microbial cultures that will ultimately be developed into quality assurance procedures for the ESF.

The specific objectives outlined below were undertaken based on the considerations described above. They are discussed in detail in Secs. 3-5, as indicated.

\section{Chemical Assay Objectives (Sec. 3)}

- Identify deposit constituents, if present.

- Compare measured deposit constituents with published exhaust constituent data.

- Determine the depth to which diesel components have migrated into the tunnel wall.

- Compare chemistry of samples with chemical simulations.

- Identify modifications of wall rock, if any, as a function of depth.

\section{Chemical Simulation Objectives (Sec. 4)}

- Compare results with actual analyses from tunnel.

- Assess the adequacy of the EQ3/6 database in the required area.

- Assess ability to simulate systems containing these organic components.

- Identify future directions for improving chemical simulations in this area.

\section{Microbial Assay Objectives (Sec. 5)}

- Characterize the functional categories of species that are growing in association with diesel deposits.

- Compare these populations with what is known or can be ascertained about the autochthonous population.

- Assess factors that may affect the potential for survival of diesel deposit-loving microbes under intermittent wetting and elevated temperature conditions (e.g., formation of coatings, potential nutrient sources other than diesel).

- Identify and evaluate diesel fuel components as nutrient sources for microbes.

- Identify microbial composition of water originating from fractures. 
- Assess the potential chemical modifications, particularly $\mathrm{pH}$, of water resulting from the presence of these microbes.

- Identify possible chemical environments that might promote or hinder the growth of these microbes.

Clearly, time and budget limitations did not allow us to address all of these issues. However, we find a broad approach to a historical analog to be most productive, because characteristics of the site will often limit the objectives that can be accomplished.

\section{Reconnaissance Survey of N-Tunnel and Resultant Sampling Decisions}

Discussions with NTS staff revealed that the main drift of N-Tunnel was excavated in 1964 with an alpine miner. This drift terminates at the water/gas-impermeable bulkhead, just beyond 19+00 ft (U12n designation: $(19 \times 100)+0=$ $1900 \mathrm{ft}$ ). Two rock units are designated locally for mining purposes as $\mathrm{Tbt}$ and $\mathrm{T} t 2$. In this study, these designators are useful only to distinguish between the nonzeolitized unit Tbt and the zeolitized $\mathrm{T} t 2$. The main drift is excavated through a gentle syncline ( $\mathrm{Tbt})$, which is located toward the opening, and an anticline ( $\mathrm{Tt} 2$ ) toward the rear of the main drift. The N-Tunnel extension was mined in the early 1980s. The entrance was mined with an alpine miner. At roughly $2+00 \mathrm{ft}$, where the tunnel boring machine-mined tunnel begins, a flat-bottomed floor was excavated for rail with an alpine miner. Both tunnels are accessible only on foot because they are blocked by wooden barriers.

Diesel locomotives were used in the main drift for hauling equipment and personnel over a 30-year period. Exact dates and types of use were unknown at the time this report was written, so we cannot realistically estimate the amount of time the tunnel walls were exposed to diesel emissions. However, discussions with miners and drillers at N-Tunnel and at the ESF revealed a number of important details. The locomotives emitted exhaust toward the left side of the tunnel ("left hand" and "right hand" refer to the inbound perspective) and close to the floor (approximately $6 \mathrm{in}$. from the tunnel floor). Before scrubbers were installed, the exhaust appeared to sink to the floor (we assume that the visible fraction contained larger soot particles than the postscrubbed emission, and that the exhaust gases were blown toward the floor).
The right-hand side of the tunnel is faced with lagging that can easily be removed by two people and was thus more accessible than the left side, on which all of the piping and cables are installed. Unfortunately, given the configuration of the locomotive exhaust system, the diesel deposit would be most likely to accumulate on the left side of the tunnel. The obstructions on the left side, which include one drainage pipe at floor level that cannot be removed, impaired our ability to observe potential deposits. These same obstructions may also have limited the deposition of diesel deposits on the wall. However, this prescrubber type of emission may have produced what appears to be an intermittent band of darkcolored deposit along the left side of the tunnel. The varying density of the deposit at any specific location would have depended on the idle time of the diesel-powered vehicle and on the presence of obstructions.

At a time that could not be recalled by the NTS staff, scrubbers were installed onto the exhaust systems of the vehicles because of air quality concerns for miners working in the tunnel. The scrubbers consisted of tanks filled with a common laundry detergent through which the diesel exhaust was bubbled. At present, the components that would have been removed or modified by the scrubbers have not been identified. According to witnesses, soapy water from the scrubbers frequently formed large pools on the tunnel floor. As will be discussed later with respect to the microbial assay, the biota observed on the tunnel floor may have been radically affected.

With the installation of the scrubbers, according to eye witnesses, the exhaust appeared to be dispersed upward and to fill the air in the tunnel. Here, it seems that although the scrubbers may have reduced the total fraction of particulate matter, the scrubbing also served to disperse the emissions over a larger air volume. The implication for our studies is that the mechanism for dispersal and thus the type and location of deposits are affected and to some extent determined by the exhaust/emission system. A request was made to determine the approximate date that scrubbers were installed and thus the actual deposition period that might be attributed to the dark band observed on the left wall. However, this information was not obtained by the deadline for completing this report. The dates of scrubber installation and of the use and operation of the diesel-powered vehicles within the tunnel, if 
obtained in the future, will give us a better perspective on whether the results of this report are applicable to the ESF or to a radioactive waste repository.

The following features, observed between $9+00$ and $19+00 \mathrm{ft}$ within the main drift, were of particular interest to the Introduced Materials Task but were not found in association with the dark deposits deemed most likely to contain remnants of diesel exhaust.

- "Mine Guard," a sprayed resin coating used to consolidate the rock wall, was visible on the right wall. A combination of Fibercrete, rockbolt, and shotcrete is now substituted for these applications.

- Some areas of the wall have been painted with water-based latex paint to increase illumination in the tunnel. This was also visible on the right wall.

- Water seepage was visible overhead. Its origin was not visible but appeared to be somewhere near the crown of the tunnel. The seepage was not extensive enough to contact a location. that appeared to have the potential to contain measurable amounts of diesel exhaust deposit.

- The area near the bulkhead was covered with grout. We have been told that the seal is airtight. This suggests that the fractures also may be extensively filled with grout.

We considered four locations in the N-Tunnel main drift and one location in the N-Tunnel extension for various types of sampling. The candidate locations were as follows:

\section{Main Drift}

$3+40 \mathrm{ft}$. This location, in the nonzeolitized Tbt unit, was near the entrance. We were informed that diesel-powered locomotives idled here during warm-up and loading, especially during the winter. The left-hand side of the tunnel was not accessible, and the right side showed limited evidence of carbon deposit. The lack of apparent deposit in this location was not surprising because of the near-normal ventilation.

$9+00 \mathrm{ft}$. Access to the right side was better at this location because only the lagging needed removal, which could be done on the day of sampling. The restricted ventilation is also expected to have enhanced the prospect of obtaining an adequate perturbation resulting from diesel exhaust. Furthermore, this location was well within the zeolitized Tt 2 unit, which, although somewhat different mineralogically from the Topopah Spring Tuff (Tpt), is easier to sample and is similar to that previously studied by Haldeman and Amy (1993). By restricting our microbial sampling to the zeolitized rock units, we were able to compare our results with those of previous studies. The carbon deposit may have been covered to some extent by dust, but appeared to be limited at this location.

$12+40 \mathrm{ft}$. This location was subject to extensive Fibercrete, rockbolts, and wire mesh screening that was said to have been installed after the tunnel was opened. These materials were installed to consolidate an area that was continually spalling, which may be related to later events. The date of Fibercrete emplacement is not yet known.

$18+50$ to $19+00 \mathrm{ft}$. This location is the present limit of the main drift. It was also an area where locomotives idled for extended periods of time. The ventilation would have been much poorer here than closer to the entrance of the tunnel. An approximately 18-in.-wide band of dark deposit is evident on the left-hand wall of the tunnel, running close to the tunnel floor. The location is accessed by climbing between the pipes. The deposit is thick and appears to flake from the surface like dried mud. The history of rock spalling at this location was not established, so the actual age of the deposit is unknown. Sampling this deposit would require consolidation and sectioning. We were informed that the gravel floor in this section is more recent than that in the rest of the tunnel and that the old floor was excavated before the present gravel was placed. However, the original floor appears to have been preserved behind the pipes and could serve as a location for floor samples.

\section{Extension}

$2+80 \mathrm{ft}$. The tunnel wall was consolidated with rockbolts, wire mesh, and Fibercrete. There is a seep in this tunnel farther in than we went. However, a band of wall near the floor on both sides, roughly 10 inches wide, is damp. The tunnel on the opening side of the Fibercreted area is in the nonzeolitized Tbt unit. The Fibercreted area terminates within the zeolitized Tt2 unit.

\section{Approach}

The location between $18+50$ and $19+00 \mathrm{ft}$ was selected as the sampling location because it represented the best combination of historical circumstances for the accumulation of a deposit and 
because the darkness and thickness of the observed deposit far exceeded the other sampling locations. Of general interest to the Introduced Materials Task was the litter observed between the pipes and the wall at the sampling locations: a rubber band, a potato chip bag, plastic cup lids, a newspaper, Styrofoam cups, a reclosable plastic bag, a screwdriver, and a wooden pole for inserting dynamite. No water was observed near the sampling site or in direct contact with the diesel deposits anywhere in the tunnel, which rendered the planned aqueous sampling and analyses impossible.
Samples were taken in the lower four feet of the tunnel wall and from the tunnel floor. Microbial assay samples (Fig. 2.1) and chemical assay samples (Fig. 2.2) were taken at locations adjacent to, but at a distance from one another to avoid contamination of the microbial sampling. The tunnels are not electrified; the lack of a generator on the day of sampling severely curtailed our ability to obtain core samples. The sample collection, analytical methods, and results of the preliminary chemical and microbial studies are presented in Secs. 3 and 5, respectively. A preliminary geochemical modeling exercise is described in Sec. 4. 


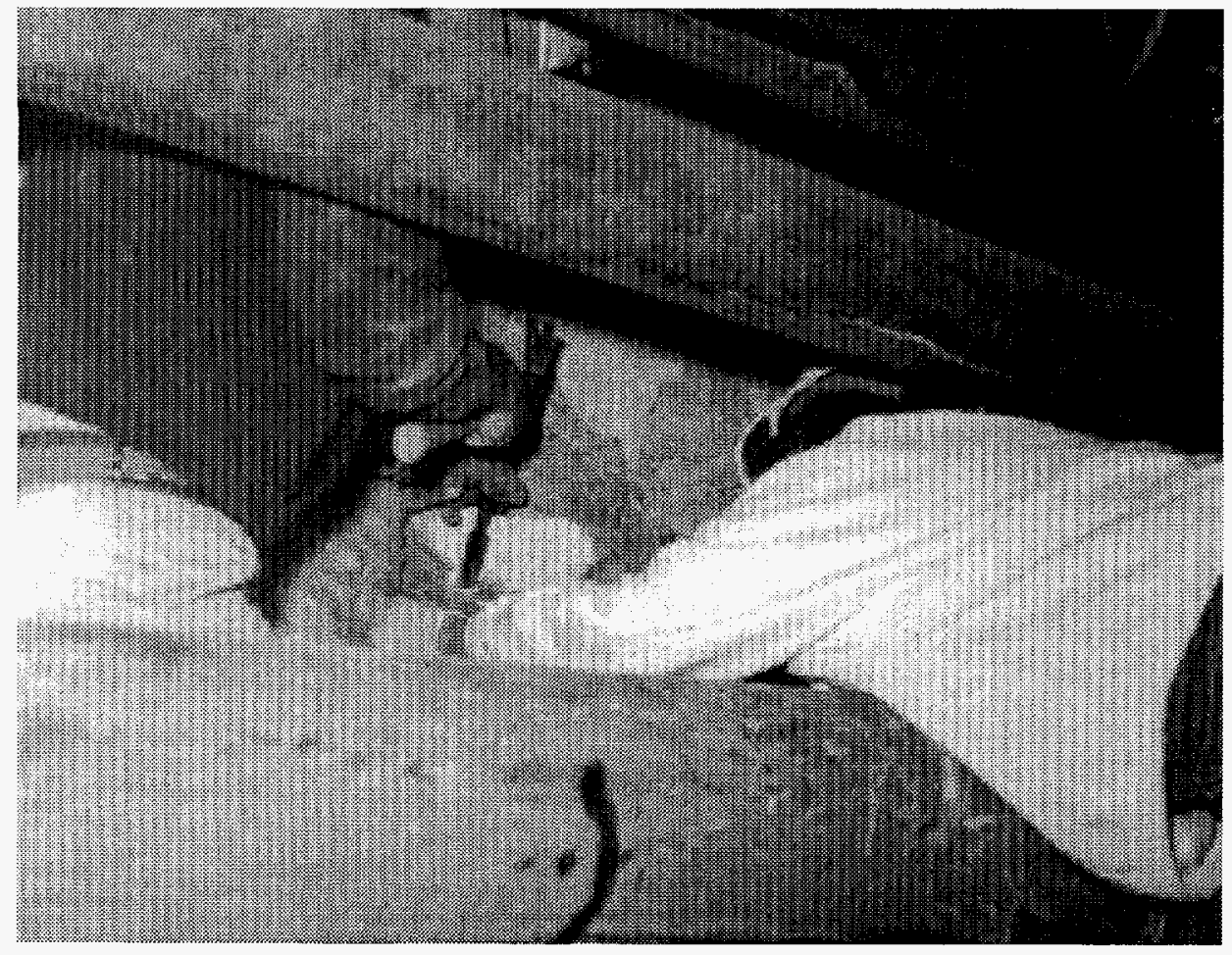

Figure 2.1. Sterile sample collection techniques for microbial assay described in Sec. 5 .

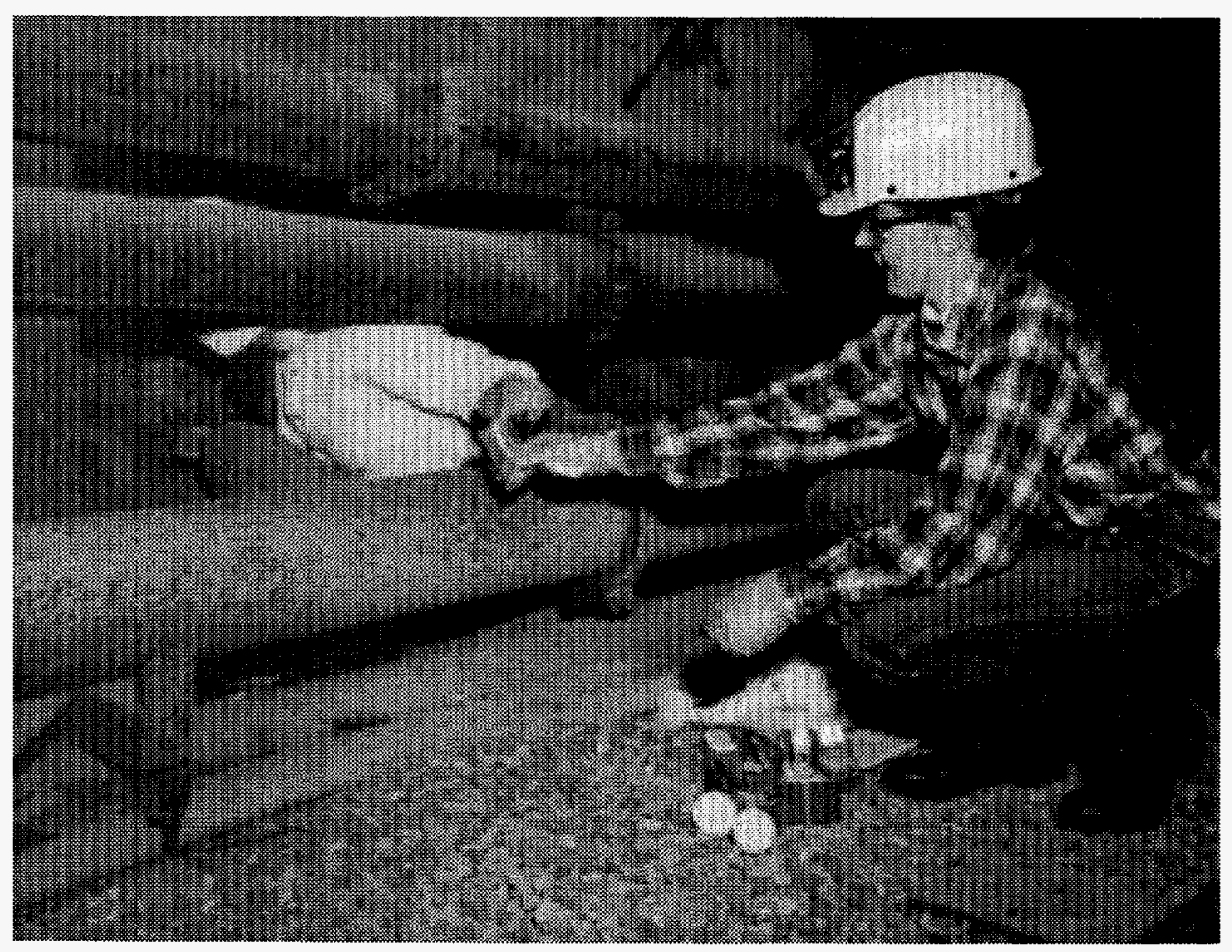

Figure 2.2. Sample collection for chemical assay described in Sec. 3 . 


\title{
3. Chemical Assay of N-Tunnel: Sampling and Data Interpretation
}

\author{
A. Meike and M. Alai
}

\begin{abstract}
The chemical assay described in this section provides some insight into the potential chemical modifications caused by diesel exhaust deposits that might be present in a mining environment. The data are also used as the foundation for the computer chemical simulations (Sec. 4) and the microbial assay (Sec. 5). Various sampling methods were developed for this chemical assay for several reasons: (1) only a single opportunity for sampling was available; (2) some of the sampling methods were in an early stage of development; and (3) a wide variety of analytical methods was required, given the chemical components that could be present and the mutually exclusive nature of some of the collection requirements. Considerations that indicated the range of potential chemical species that could be present as a result of a diesel exhaust deposit are described below.
\end{abstract}

\section{Experiment}

\section{Diesel Exhaust Composition}

The compositions of diesel emissions depend, in part, on the composition of the original diesel fuel, which is a complex mixture of the intermediate distillates from crude oil. A general diesel fuel composition is approximately $40 \%$ n-alkanes; $40 \%$ iso- and cycloalkanes; $20 \%$ aromatic hydrocarbons; and a few percent isoprenoids, sulfur, nitrogen, and oxygenated compounds (Lipkea et al. 1979).

At least three kinds of diesel fuel are defined in Lipkea et al. (1979, p. 18). The most volatile distillate of fuel oil is designed for diesel-powered car engines. A heavier, less volatile distillate of fuel oil is used in industrial and heavy mobile service vehicles. The fuel oil intended for lowand medium-speed engines is the most viscous. Of the components in diesel fuels, compounds of lower molecular mass tend to evaporate and degrade more readily, leaving the higher molecular mass components over time (Lee et al. 1992). This observation suggests that more hydrocarbons will be present in the exhaust deposits of the engines that use heavier diesel fuels than those that use lighter fuels. The heavier, more viscous fuels also produce emissions that contain more sulfur and ash. The heavier fuel is expected to be used for haulage at the ESF and is assumed to have been used in the haulage locomotives in N-Tunnel.

The composition of a given diesel fuel can vary from source to source and even from the same source over time, depending on several factors, including the source of the crude oil, the degree of chemical modification during cracking or re-forming, and the separation method. Diesel fuels may also contain several "quality enhancer" additives-ignition improvers, stability improvers, corrosion inhibitors, multipurpose additives, and surfactants (Lee et al. 1992).

Table 3.1 lists two sample diesel compositions obtained from the literature.

A detailed relation between diesel fuel and the range of possible combustion products is not well established for a number of reasons. First, the available analyses of diesel fuel and diesel emissions are frequently incomplete and are given in units that are difficult, if not impossible to compare. Second, factors beyond the original composition of the diesel fuel affect the composition of the exhaust emissions. These factors include the load the engine is bearing and the temperature of the engine. None of these factors could be controlled or quantified for the present study.

However, a survey of the literature suggests that some organic and inorganic compounds can be expected. The diesel exhaust particulate may. contain metals such as $\mathrm{Ba}, \mathrm{Mn}$ (Lipkea et al. 1979); Ca, Zn (Hare et al. 1979); Fe, Al, and S (Springer and Baines 1979) that may derive from diesel fuel, additives, and engine wear. The exhaust may also contain nitrogen oxides and sulfur oxides (Hare et al. 1979; Lipkea et al. 1979; Springer and Baines 1979) that derive from the combustion or partial combustion of hydrocarbons. Table 3.2 compares the polycyclic aromatic hydrocarbon (PAH) analyses of diesel exhaust particulates from three published reports and a broader range organic component analysis of diesel fuel.

It is important to note that the composition of diesel emissions, which are widely available from 
Table 3.1. Hydrocarbon class analysis for petroleum diesels.

\begin{tabular}{lcc}
\hline Compound class & $\begin{array}{c}\text { Sample 1 } \\
(w t \%)\end{array}$ & $\begin{array}{c}\text { Sample 2 } \\
(w t \%)\end{array}$ \\
\hline Paraffins & 42.70 & 41.70 \\
Cycloparaffins & & \\
Mono & 23.40 & 18.80 \\
Di & 8.00 & 9.30 \\
Tri & 2.00 & 2.80 \\
Total & 33.40 & 30.90 \\
Aromatics & & \\
Alkylbenzenes & 9.70 & 8.40 \\
Indans + tetralins & 4.80 & 5.30 \\
Dinaphthenobenzenes & 1.30 & 1.10 \\
Alkylnapthalenes & 5.30 & 7.60 \\
Biphenyls, etc. & 1.30 & 2.50 \\
Fluorenes, etc. & 0.70 & 1.10 \\
Tricyclic aromatics & 0.80 & 1.40 \\
Benzene & $(47.00)^{\mathrm{a}}$ & - \\
Totalb & 23.90 & 27.40 \\
\hline
\end{tabular}

Source: Calabrese and Kostecki 1991.

a In vol. ppm.

b Not including benzene.

the literature, may differ markedly from the composition of an actual diesel deposit. The fraction and composition of the emission that actually becomes a solid from a liquid deposit depend on environmental factors, such as temperature, relative humidity, and the amount of dust in the environment, as well as engine wear and "tuning." Therefore, many of the analyses in the literature are inappropriate to the present application.

\section{Sampling Procedures and Postcollection Sample Treatments}

The field sampling was conducted near the left rib located at $19+00 \mathrm{ft}$, in N-Tunnel, which has been excavated into Rainier Mesa at the Nevada Test Site. In this location, the surface of the tunnel is coated with a dark layer that could contain components of diesel exhaust. Samples were taken in the lower four feet of the tunnel wall and from the tunnel floor as shown in Fig. 3.1. Several techniques were used to peel the deposit from the surface of the rock. Other techniques were used to consolidate the surface and attach it firmly to the underlying rock. Powder samples were taken from the floor between the pipes and the wall, and at the contact between the floor and the wall where a dark band of material was observed. Attempts were made to obtain cores using a battery-powered drill and water as a lubricanit. This method was less than effective, although a few cores were obtained. A large rock weighing about $30 \mathrm{lb}$ was also removed and transported in one piece. The sample collection procedures and any postcollection laboratory treatment or preparation are described below. Table 3.3 lists the sample analysis techniques used.

Wall Tape Peels. (Bar code SPC00503828) Six surface peels were taken from the tunnel wall surface. We used a butyl-rubber, inorganic-filler, phenolic-resin "air dam" tape made by SchneeMorehead to obtain surface peels of the diesel exhaust on the tunnel wall. Two pieces of the tape were applied side by side to the wall surface. These two pieces were then removed and placed face to face so that the surface material was protected. The samples were placed in a reclosable plastic bag for protection and storage. This process was performed two more times for a total of six sandwiched samples. The peels were later prepared as scanning electron microscope (SEM) mounts. One-half of each set of peel duplicates was given a carbon coat, and the other half a gold coat, in order to differentiate between the chemical signature of the coating (used for imaging purposes) and that of the sample. Silver paint used along the edge of the mount to increase conductivity did not appear to dissolve the tape.

Wall Paraffin Peels. (SPC00503828) Four pieces of paraffin wax ( $1 / 4$ in. diam, 2 in. long) were pressed lengthwise onto the surface of the tunnel wall and were removed with the surface material imbedded in the wax. These samples were placed in individual plastic bottles to minimize alteration of the sample surface.

Wall-Deposit Filter Particulate. (SPC00503828) Borosilicate fiberglass filters were cut in half and moistened with Milli-Q water. These damp filters were then wiped on the tunnel wall surface, which caused the wall surface material to cover the filter. The filter was then placed in a reclosable plastic bag for storage. The filters were later dried overnight in an oven at $50^{\circ} \mathrm{C}$. Four of these samples were taken.

Wall Deposit Consolidated with Water Glass. (SPC00503828) Liquid potassium silicate ("water-glass") was applied to the surface of the tunnel wall with a small artist's brush to protect 
Table 3.2. Hydrocarbon components and volatile organics observed in diesel exhaust particulates and in diesel fuel.

\begin{tabular}{|c|c|c|c|c|}
\hline \multirow[b]{2}{*}{ Polycyclic aromatic hydrocarbons } & \multicolumn{3}{|c|}{ In diesel exhaust particulates } & \multirow{2}{*}{$\begin{array}{c}\text { In diesel } \\
\text { fuel (ppm)e }\end{array}$} \\
\hline & $(\mu \mathrm{g} / \mathrm{km})^{\mathrm{a}, \mathrm{b}}$ & $(\mu \mathrm{g} / \mathrm{km})^{a, c}$ & $(p p m)^{d}$ & \\
\hline 2-Methyl-9H-fluorene & NA & NA & 4171.93 & NA \\
\hline 2-Methylfluorene & NA & $<0.04$ & 0.00 & NA \\
\hline Dibenzothiophene & NA & NA & 379.27 & NA \\
\hline Phenanthrene & 80.00 & 29.00 & 113400.76 & 1500 \\
\hline Anthracene & 6.90 & $\mathbf{3 . 3 0}$ & 33249.05 & NA \\
\hline 4-Methyldibenzothiophene & NA & NA & 4677.62 & NA \\
\hline 3-Methyldibenzothiophene & NA & NA & 1896.33 & NA \\
\hline 3-Methylphenanthrene & NA & NA & 75979.77 & NA \\
\hline 3-Methylanthracene & 43.00 & 30.00 & 0.00 & NA \\
\hline 2-Methylanthracene & 53.00 & 40.00 & 84829.33 & NA \\
\hline 4\&9-Methylphenanthrene & 48.00 & 48.00 & 46649.81 & NA \\
\hline 1-Methylphenanthrene & 43.00 & 41.00 & 59165.61 & NA \\
\hline Fluoranthene & 45.00 & 17.00 & 188622.00 & ND-37 \\
\hline Pyrene & 54.00 & 11.00 & 165865.99 & ND-41 \\
\hline 1-Methyl-7-isopropyl-phenanthrene & 3.30 & NA & 2907.71 & NA \\
\hline Benzo[a]fluorene & 8.30 & 2.40 & 14032.87 & NA \\
\hline 2-Methylpyrene & 11.00 & 2.00 & 15802.78 & NA \\
\hline 1-Methylpyrene & 6.40 & 0.75 & 11630.85 & NA \\
\hline Benzo[ghi]fluoranthene & 5.50 & 1.50 & 46776.23 & NA \\
\hline Cyclopenta[cd]pyrene & 3.00 & 0.18 & 5689.00 & NA \\
\hline Benz[a]anthracene & 4.10 & 0.47 & 20353.98 & $0.001-1.2$ \\
\hline Chrysene/triphenylene & 0.10 & 2.80 & 37800.25 & $1.4 / 2.2$ \\
\hline Benzo[b\&k]fluoranthene & 1.10 & 0.29 & 21491.78 & NA \\
\hline Benzo[e]pyrene & 1.70 & 0.15 & 14032.87 & $<0.1$ \\
\hline Benzo[a]pyrene & NA & $<0.06$ & 5309.73 & $0.001-0.6$ \\
\hline Perylene & $\mathbf{N A}$ & $<0.01$ & 884.96 & NA \\
\hline Indeno[ $1,2,3-c d]$ fluoranthene & NA & $<0.09$ & 252.84 & NA \\
\hline Indeno[1,2,3-cd]pyrene & 0.076 & $<0.04$ & 6447.53 & NA \\
\hline Picene & 0.19 & 0.010 & 0.00 & NA \\
\hline Benzo[ghi]perylene & 0.26 & $<0.13$ & 14791.40 & NA \\
\hline Coronene & NA & $<0.01$ & 2654.87 & NA \\
\hline 2-Methylnaphthalene & NA & NA & NA & 6700 \\
\hline Naphthalene & NA & $\mathbf{N A}$ & NA & 2730 \\
\hline Phenol & NA & NA & NA & 6.8 \\
\hline Cresol & $\mathbf{N A}$ & NA & NA & 54.3 \\
\hline Quinoline & NA & NA & NA & 9.2 \\
\hline \multicolumn{5}{|l|}{ Volatile organics } \\
\hline Benzene & NA & NA & NA & $6-82$ \\
\hline Ethylbenzene & NA & NA & NA & $100-800$ \\
\hline Toluene & NA & NA & NA & $100-800$ \\
\hline Xylene & NA & NA & NA & $100-800$ \\
\hline
\end{tabular}

a The engine was run on a chassis dynamometer. NA = not analyzed.

b Westerholm and Li (1994), pp. 965-972. (One of eight diesel fuels analyzed, Swedish summer commercial fuel.)

c Westerholm et al. (1991), pp. 332-338.

d Converted to parts per million from the reported microgram amounts. Mason et al. (1992), pp. 1635-1638.

e Calabrese and Kostecki (1991). ND = not detected. 
Table 3.3. Analysis scheme for the chemical assay samples collected in N-Tunnel.

\begin{tabular}{|c|c|c|c|c|c|}
\hline \multirow[b]{2}{*}{ Sample } & \multirow[b]{2}{*}{ No. of samples } & \multicolumn{2}{|c|}{ Analysis 1} & \multicolumn{2}{|c|}{ Analysis 2} \\
\hline & & Method & Objective & Method & Objective \\
\hline Floor powder & 2 & $\begin{array}{l}\text { FTIR } \\
\text { SIMS }\end{array}$ & $\begin{array}{l}\text { Organic } \\
\text { compounds }\end{array}$ & & \\
\hline Floor powder & 2 & XRF & $\begin{array}{l}\text { Elemental } \\
\text { analysis }\end{array}$ & XRD & Mineralogy \\
\hline Filter particulate & 4 & XRF & $\begin{array}{l}\text { Elemental } \\
\text { analysis }\end{array}$ & & \\
\hline Wall cores & $\begin{array}{c}2 \text { cores }= \\
10 \text { samples }\end{array}$ & XRF & $\begin{array}{l}\text { Elemental } \\
\text { analysis }\end{array}$ & $\begin{array}{l}\text { FTIR } \\
\text { SIMS }\end{array}$ & $\begin{array}{l}\text { Organic } \\
\text { compounds }\end{array}$ \\
\hline Water-glass & 1 core $=4$ slides & Thin sections & Mineralogy & & \\
\hline Water-glass & 2 cores & SEM & $\begin{array}{c}\text { Elemental/ } \\
\text { distribution } \\
\text { analysis }\end{array}$ & & \\
\hline Tape & 6 & SEM & $\begin{array}{l}\text { Elemental } \\
\text { analysis }\end{array}$ & & \\
\hline Large wall rock & 1 & XRD & Mineralogy & & \\
\hline Large wall rock & 3 & $\begin{array}{c}\text { Total carbon } \\
\text { analysis }\end{array}$ & $\begin{array}{l}\text { Total carbon, } \\
\text { total inorganic } \\
\text { carbon }\end{array}$ & & \\
\hline Paraffin & $\begin{array}{l}\text { Not scheduled } \\
\text { for analysis }\end{array}$ & & & & \\
\hline Chiseled samples & $\begin{array}{l}\text { Not scheduled } \\
\text { for analysis }\end{array}$ & & & & \\
\hline
\end{tabular}

the diesel-exhaust-coated wall surface from alteration during sampling and analysis. Three surfaces (each $\sim 2$ in. diam) were covered with the liquid and allowed to dry. Several coats were applied, and each coat was allowed to dry between applications. The rock surrounding the three water-glass coatings was chipped away from the tunnel wall, and a solid piece of rock ( $\sim 8$ in. high, 6 in. wide, and 2 in. thick) containing the three coated surfaces was removed. These three water-glass samples were later dry cored out of the solid piece of rock using a 1.5-in. drill bit. These cores were $1.5 \mathrm{in}$. in diameter and 2 in. in length. Cross sections were cut from the cores across the deposit and underlying tuff (see Fig. 3.2a). SEM mounts were prepared from onehalf of each core for SEM optical and chemical analysis. The other half of each core was prepared as thin sections for optical microscope analysis and ultimately microprobe analysis, as necessary.

Wet-Drilled Wall Cores. (SPC00503825) Two rock cores were obtained by using a 1.5-in. drill bit and drilling $\sim 2$ in. deep into the tunnel wall.
Water was used as a coolant to reduce heat generated by the friction between the drill bit and the rock. During postcollection treatment, the two wall cores were cut in half lengthwise. One-half of each core was set aside as a backup, and the other half was cut every 0.25 in. down the length of the core. This resulted in five 0.25 -in. sections that represented increasing depth into the tunnel wall for each core (Fig. 3.2b).

Large Wall Rock. (SPC00503828) A portion of the wall rock $\sim 2 \mathrm{ft}$ long, $1 \mathrm{ft}$ wide, and $0.5 \mathrm{ft}$ thick was removed from the tunnel. A fracture had already loosened the rock, so the sample was easily separated from the wall. This rock was covered with the black layer suspected to be diesel exhaust. Samples were later taken from the rock both by breaking off bulk pieces of it and by scraping off surface material. If necessary, this rock will be sliced lengthwise to obtain a chemical profile as a function of rock depth.

Floor Powder. (SPC00503829) Powdered material from the tunnel floor was collected into glass vials. The first sample was taken on the 
tunnel floor near the wall. The second sample was taken on the tunnel floor at the junction between the tunnel wall and floor.

Chiseled Floor Samples. (SPC00503829) Several pieces of rock were removed from the tunnel floor with a chisel. These samples were placed in reclosable bags for storage.

\section{Analytical Techniques}

A variety of techniques was used to perform qualitative analyses on the samples. Several of these techniques provided similar information that was useful as both cross-checks and backup analyses. The samples were analyzed as described in Table 3.3. The analytical methods are outlined below.

SEM. A Hitachi S-800 SEM equipped with a Kevex 8000 energy-dispersive $x$-ray spectrometer (EDS) was used to perform electron optical imaging and spatial-distribution elemental analysis on the samples. Each sample was characterized in at least 30 places. Data were taken for each area that showed new elemental constituents or a particularly high or low elemental $x$-ray energy peak.

Spurious EDS analyses can be generated from two sources. The first potential source is any material located on the interior of the sample chamber. The second potential source is the overlapping spectral fingerprint of another element. Both of these potential errors were eliminated by careful interpretation and use of baseline analyses. The samples were analyzed with both gold and carbon coatings to maximize the number of elements detectable (e.g., to observe trace quantities of $\mathrm{Rb}$, for which the K $\alpha$ peak overlaps the $\mathrm{Au}$ $\mathrm{L} \gamma$ peak). Analysis was also made of the chamber scatter and materials that were included in preparing the sample. Figure 3.3 illustrates an analysis of a gold-coated tape mount, which can be compared with the data given below to discriminate between actual elemental spectra generated by the sample and those generated by other sources.

Attempts to use x-ray mapping on the samples for the heavy elements of interest produced a very low signal-to-noise ratio. Backscatter imaging, which is sensitive to atomic number $Z$, proved to be a more valuable technique to search for heavy metal components. The elements with higher $Z$ values appear brighter in the image. Particulates that showed contrast differences in the backscatter image mode were analyzed.

Fourier Transform Infrared (FTIR) Spectroscopy. FTIR spectroscopy was used to deter- mine the organic, $\mathrm{NO}_{x}$, and $\mathrm{SO}_{x}$ compounds. Because traces of organic hydrocarbons are present everywhere in the environment, including the laboratory in which they are analyzed, samples can be easily contaminated in handling and preparation. The local contamination effects of hydrocarbon contamination of optical surfaces of the spectrometer are minimized by normalizing a reference spectrum to the sample spectrum. The reference spectrum, however, is not taken contemporaneously with the sample spectrum and is usually used for a series of samples. Long-chain hydrocarbons are characterized in FTIR by absorption bands at 2926 and $2855 \mathrm{~cm}^{-1}$. These bands arise from the stretching of methylene group $\left(-\mathrm{CH}_{2}\right) \mathrm{C}-\mathrm{H}$ bonds. The detection limit for hydrocarbons is at best $500 \mathrm{ppm}$; a typical limit is $1000 \mathrm{ppm}$.

A Secondary Ion Mass Spectrometer (SIMS). We used a SIMS to detect aromatics. A small portion of the sample was heated at $20^{\circ} \mathrm{C} / \mathrm{min}$. Longchain hydrocarbons have characteristic fragment ions at 43,57 , and 71 amu in their mass spectra. A realistic detection limit for hydrocarbons using SIMS is believed to be $\sim 1000 \mathrm{ppm}$.

X-Ray Fluorescence Spectrometry (XRF). We used $X R F$ conducted with a Siemens 303 wavelength dispersive spectrometer, to perform elemental analysis. A qualitative scan for each sample was processed using the fundamental parameters method to give semiquantitative results. This method can have errors up to $30 \%$ relative to reported weight percent values, but results are usually accurate to $10 \%$ relative. However, because the method used only one standard, and not in the same medium as the sample, the more conservative $30 \%$ error bars are used in our analysis of the data. Table 3.4 lists the detectable elements and their respective minimum reporting limits. Therefore, although the results for each element are given in three significant figures, the minimum detection level is much higher: $0.01 \%$ at best, but typically $0.03 \%$. The significance of these detection limits to the present study will be discussed in the Results subsection of this section. Because the results are corrected for background, negative values may appear for some elements. Elements lighter than $\mathrm{Na}$ are not included, so the results of a given analysis may not add to $100 \%$.

X-Ray Diffraction (XRD). We used XRD to determine the mineralogy of the samples. All of our studies used $\mathrm{Cu} \mathrm{K} \alpha$ radiation. In combination with an elemental analysis, XRD assists in determining whether the elements detected through 
Table 3.4. Concentrations below which elements were not detectable by XRF.

\begin{tabular}{|c|c|c|c|}
\hline \multicolumn{3}{|c|}{ Concentration } & \multirow{2}{*}{$\begin{array}{c}\text { Concentration } \\
(w t \%)\end{array}$} \\
\hline Element & (wt\%) & Element & \\
\hline $\mathbf{F}$ & 0.3 & Fe & 0.04 \\
\hline $\mathbf{N a}$ & 0.03 & Co & 0.02 \\
\hline $\mathbf{M g}$ & 0.02 & $\mathbf{N i}$ & 0.02 \\
\hline Al & 0.04 & $\mathrm{Cu}$ & 0.01 \\
\hline Si & 0.05 & $\mathbf{Z n}$ & 0.01 \\
\hline $\mathbf{P}$ & 0.05 & $\mathrm{Ga}$ & 0.01 \\
\hline $\mathbf{S}$ & 0.02 & $\mathrm{Ge}$ & 0.01 \\
\hline $\mathrm{Cl}$ & 0.02 & As & 0.02 \\
\hline $\mathbf{K}$ & 0.02 & Se & 0.01 \\
\hline $\mathrm{Ca}$ & 0.03 & $\mathbf{B r}$ & 0.01 \\
\hline Sc & 0.05 & $\mathbf{R} \mathbf{b}$ & 0.01 \\
\hline $\mathrm{Ti}$ & 0.04 & Sr & 0.01 \\
\hline $\mathbf{V}$ & 0.03 & $\mathbf{Y}$ & 0.01 \\
\hline $\mathrm{Cr}$ & 0.03 & $\mathbf{Z r}$ & 0.01 \\
\hline $\mathbf{M n}$ & 0.03 & $\mathrm{Sm}$ & 0.05 \\
\hline $\mathbf{N b}$ & 0.01 & Gd & 0.06 \\
\hline Mo & 0.01 & Dy & 0.03 \\
\hline $\mathbf{R h}$ & 0.02 & $\mathbf{H f}$ & 0.04 \\
\hline $\mathbf{A g}$ & 0.03 & $\mathrm{Ta}$ & 0.04 \\
\hline $\mathrm{Cd}$ & 0.03 & $\mathbf{W}$ & 0.04 \\
\hline In & 0.05 & $\mathbf{P t}$ & 0.02 \\
\hline Sn & 0.06 & $\mathbf{A u}$ & 0.02 \\
\hline $\mathrm{Sb}$ & 0.12 & $\mathrm{Hg}$ & 0.02 \\
\hline $\mathrm{Te}$ & 0.1 & Tl & 0.02 \\
\hline Cs & 0.1 & $\mathbf{P b}$ & 0.03 \\
\hline $\mathbf{B a}$ & 0.12 & $\mathbf{B i}$ & 0.03 \\
\hline $\mathbf{L a}$ & 0.08 & Th & 0.02 \\
\hline $\mathrm{Ce}$ & 0.05 & $\mathbf{U}$ & 0.02 \\
\hline Nd & 0.05 & & \\
\hline
\end{tabular}

other analytical methods are mineralogical components of the rock or originate from another source, such as diesel exhaust particulate.

Total Carbon (TC) and Carbon Present as Carbonates. To determine total organic carbon (TOC), we measured TC and carbon present as carbonates. Total carbon was determined with a Leco induction furnace. Carbonate carbon was determined by titration of $\mathrm{CO}_{2}$ from an acid digest of the sample, and TOC was determined by subtraction of carbonate carbon from total carbon. The detection limits for both total carbon and carbon present as carbonate are a few parts per million.

\section{Results}

$\mathrm{XRF}$ was the most useful technique for obtaining the inorganic analyses of the samples. The raw results, given in weight percent of sample, were converted to moles per kilogram of sample for chemical modeling (Sec. 4). In the absence of multiple core samples of respectable length, the data are sparse with which to interpret the potential mobility of any chemical species. However, these results can be viewed as a preliminary exercise to steer further investigations, and as a tool to assess our various sampling methods. An approximation of possible chemical trends within the first few inches of the tunnel wall as a function of depth was obtained from a composite of the analyses. An analysis of the pure deposit, labeled wall deposit (WD), was plotted with the analyses of the core samples (WC1 and WC2) and filter samples (F1-F4). As a consequence, the $x$ axis is not plotted to a scale directly proportional to depth in the rock but is greatly expanded toward the wall surface. The data cluster around four different magnitudes and, for clarity, are presented on four figures on different scales (Figs. 3.4-3.6).

In Figs. 3.4-3.6, the filter analyses were plotted to correspond with the core surface, labeled surface (S). By comparing the filter and core surface analyses with each other and with the trend of values with depth, we can assess the two sampling methods for each element at that location. These two methods yielded less accurate analyses of some elements at the "surface" level because the water used in core drilling removed much of the surface deposit on the cores, and the chemical composition of the filter fiber is included in the filter analyses, which may also favor more soluble components. For example, the filters do not yield good results for $\mathrm{Na}$ or $\mathrm{Ca}$, but they yield results that are much more consistent with other data for the analyses of elements such as $\mathrm{Cu}, \mathrm{Al}$, and $\mathrm{Cr}$.

Subtle chemical trends with depth can be seen for $\mathrm{Ca}$ and $\mathrm{S}$, and may be indicated for $\mathrm{Ti}$, $\mathrm{Na}$, and $\mathrm{Cl}$ (Figs. 3.4-3.6). These results would be consistent with a tunnel respiration cycle created 
by the excavation of the tunnel system. The water migration to the tunnel wall and evaporation at the wall could have resulted in the net transportation of dissolved chemical species and precipitation of secondary minerals at the tunnel wall. In this investigation, the core analyses $3-5$ are taken as representative of the average rock chemistry and its variability. However, upon further study, in which samples are taken at greater depth, it may become clear that the entire sample area represents a chemically altered zone created by the excavation of the tunnel drift. Comparison of XRD spectra of the rock matrix and the surface coating (Fig. 3.7) suggests that a major constituent of the surface deposit is pulverized rock. Heavier mineral constituents of the rock matrix, such as quartz and feldspar, have a reduced intensity in the surface deposit, which is consistent with an airborne rock powder composed of the less dense rock constituents. Mineral constituents of the surface coating that are not repeated in the rock matrix were not evident. No gypsum was detected using the heating method to detect the gypsum $\rightarrow$ anhydrite transition.

A general comparison between the chemistry of the surface deposits and the interior rock is more illuminating at this preliminary stage of our understanding of the complex system of tunnel, rock, and introduced materials.

Certain elements were observed only in the samples obtained from the tunnel surface. Although elements such as $\mathrm{As}, \mathrm{Pb}$, and $\mathrm{Cd}$ are present in measurable quantities in some surface samples, extreme variability exists from sample to sample. This variation suggests that the distribution of these elements within the deposit is spatially heterogeneous. Barium, however, appears very clearly in the XRF analysis of the wall sample and (together with S) is detected frequently in the EDS of samples described below.

SEM analyses based on backscattered imaging (in which elements of higher atomic weight scatter more strongly) proved to be the best SEM technique for this application. By using EDS, Ba was observed most frequently in the tape samples (Fig. 3.3), but $\mathrm{Pb}$ was not observed. S, Ti, V, Mn, and $\mathrm{Ni}$ were observed in the surface samples or toward the surface edge of the water-glass samples, and not in the host rock. This result is not surprising given the low concentrations detected using XRF. Occurrences of $\mathrm{Ba}$ and $\mathrm{S}$ did not coincide. SEM analyses of the water-glass cross sections support the observation that $\mathrm{Ba}$ particulates
Table 3.5. Total organic carbon analysis of wall surface deposit. C1-3 are splits of the same sample.

\begin{tabular}{cccc}
\hline $\begin{array}{c}\text { Sample } \\
\text { ID }\end{array}$ & $\begin{array}{c}\text { Total carbon } \\
\text { (wt\%) }\end{array}$ & $\begin{array}{c}\text { Carbonate } \\
\text { (wt\%) }\end{array}$ & $\begin{array}{c}\text { TOCb }^{\mathbf{b}} \\
\text { (wt\%) }\end{array}$ \\
\hline C1 & 1.45 & 0.38 & 1.07 \\
C2 & 1.29 & 0.39 & 0.90 \\
C3 & 1.55 & 0.68 & 0.87 \\
C5 & 2.94 & 1.59 & 1.35 \\
\hline
\end{tabular}

a Calculated as carbon.

b Total organic carbon.

occur sporadically and in connection with the surface deposits (Fig. 3.8). Efforts to map Ba and $S$ or other elements in the outer few millimeters of the rock surface proved fruitless owing to the poor signal for those elements. In FTIR analyses, nitrates were detected in the outer portion of one sample, but no sulfates were detected.

The above analyses are unable to detect elemental carbon, assumed to be one of the major constituents of diesel particulate matter (DPM), or hydrocarbons.

Total organic carbon analysis of the wall surface deposit clearly shows that a significant amount of carbon is present in forms other than carbonate (Table 3.5). By comparing the analysis of the three splits from one sample $(\mathrm{C} 1, \mathrm{C} 2$, and C3), we can estimate the analytical error inherent in this technique. Analyses of the wall rock as a function of depth show a distinct trend. It is clear that the organic carbon constituent that appears in the surface coating (Table 3.5) disappears at depth in the rock wall and in the invert (Tables 3.6 and 3.7). Although TOC analysis does not distinguish between elemental carbon and hydrocarbons, infrared data can put a maximum value on the hydrocarbons that were present in the surface coating.

Table 3.6. Total organic carbon analysis of floor samples (see Sec. 5).

\begin{tabular}{cccc}
\hline & \multicolumn{3}{c}{ Total organic carbon $(w t \%)$ at } \\
\cline { 2 - 4 } Sample ID & $3-5 \mathrm{~cm}$ & $6-9 \mathrm{~cm}$ & $11-14 \mathrm{~cm}$ \\
\hline Core A & 0.75 & 0.69 & 0.037 \\
Core B & 0.64 & 0.51 & 0.055 \\
Core C & 0.67 & 0.044 & 0.080 \\
\hline
\end{tabular}


Table 3.7. Total organic carbon analysis of wall samples (see Sec. 5).

\begin{tabular}{cccc}
\hline & \multicolumn{3}{c}{ Total organic carbon (wt\%) at } \\
\cline { 2 - 4 } Sample ID & $0-1 \mathrm{~cm}$ & $1-2 \mathrm{~cm}$ & $2-3 \mathrm{~cm}$ \\
\hline Wall A & 0.082 & 0.053 & 0.019 \\
Wall B & 0.116 & 0.026 & 0.016 \\
Wall C & 0.126 & 0.062 & 0.028 \\
\hline
\end{tabular}

Aromatic hydrocarbons were detected in the FTIR analyses of the outer core samples (Core 1-1, 1-2, and 2-1). Figure 3.9 illustrates the FTIR signature of the samples, in the area of the spectrum where aromatics are detected, superimposed on the background signature. The hydrocarbon peak adsorbances (Table 3.8) demonstrate that the samples register roughly three times the background measurement. However, this signal was not judged to be sufficiently above the detection limit to accurately measure a change with depth into the rock. Nonetheless, because the FTIR detection limit is $\sim 500 \mathrm{ppm}$, a significant amount of the TOC analysis may be due to the presence of hydrocarbons. An FTIR analysis of the surface deposit is not yet available. SIMS analyses of the core surfaces (Fig. 3.9) detected characteristic fragment ions for long-chain hydrocarbons at 43 , 57 , and $71 \mathrm{amu}$. Similarly, we observed that analyses above the detection limit ( $1000 \mathrm{ppm}$ ) support the argument that a portion of the TOC analysis can be attributed to hydrocarbons.

\section{Discussion}

Chemical analyses of diesel emissions from the literature, such as the examples given in this section and in Sec. 2, are made in a rarefied, ideal environment. Few comparisons (if any) are made between these ideal analyses and an actual diesel

Table 3.8. FTIR hydrocarbon peak adsorbances.

\begin{tabular}{lcc}
\hline Sample ID & $2926 \mathrm{~cm}^{-1}$ & $2855 \mathrm{~cm}^{-1}$ \\
\hline Core 1-1 & 0.0291 & 0.0158 \\
Core 1-2 & 0.0215 & 0.0116 \\
Core 2-1 & 0.0318 & 0.0179 \\
Blank KBr & 0.0091 & 0.0054 \\
\hline
\end{tabular}

deposit in a non-ideal environment. In a nonideal environment, factors such as the ventilation, the complex chemistry of the depositional environment, and the engine wear ultimately determine the characteristics of the physical deposit. It is therefore instructive to compare the analyses of the supposed diesel deposit on the surface of the $\mathrm{N}$-Tunnel to analyses from the literature for correlations that might point to characteristic effects of a tunnel environment.

From the results of fresh diesel exhaust PAH analysis (Table 3.2), one could expect a far higher concentration of aromatics in the diesel deposit than was actually observed by FTIR or SIMS. We suggest that these aromatic components were either never deposited on the tunnel wall (but were in fact removed through the tunnel ventilation system, or deposited on the tunnel floor), or that they were deposited, but were volatilized or consumed by microbial activity during the intervening 30 years. Hydrous pyrolysis experiments (Jackson and Carroll 1994) suggest that the chemical degradation of diesel fuel by abiotic process is very slow.

Without more specific elemental analyses of the actual diesel particulate matter, it is impossible to compare the inorganic components. Indeed, because much of the metal component is supposed to be due to engine wear, much of the elemental composition is extremely site-specific. However, all of the metals that were observed would be expected from diesel emissions. The observation of nitrate compounds and sulfur suggests that further investigation is required as to the fraction of volatile compounds that condense and ultimately form solid deposits in a tunnel environment.

The observations made in this study must be considered in light of the fact that the actual usage history of the tunnel is unknown at this time. However, during the tunnel's 30-year history, improvements have been made in emission standards, dispersion of emissions, and ventilation standards. Therefore, if usage of hauling locomotives in the ESF is comparable to that in the N-Tunnel, then over a similar time period and for comparable usage, we expect diesel emissions should have less evident chemical consequences than we observed in N-Tunnel. Detailed comparisons of locomotive usage should be conducted to verify this assertion. Further complications and coupled effects are considered in the concluding remarks (Sec. 6). 


\section{Conclusions}

Evidence that any inorganic and hydrocarbon components could have migrated into the rock is not available owing to inadequate core samples. The apparent migration of inorganic components could only be tracked for a few centimeters.

However, significant chemical differences were observed between the surface layer and the rock at $2-3 \mathrm{~cm}$ depth. Of the inorganic elements whose concentrations change with depth, $\mathrm{Ba}$ and $\mathrm{S}$ are the most significant with respect to their possible association with diesel emissions. Other metals commonly associated with diesel emissions, such as $\mathrm{Pb}, \mathrm{As}, \mathrm{Mn}, \mathrm{Mo}, \mathrm{Bi}$, and $\mathrm{Cd}$, also occurred in measurable quantities, however. The TOC in the first few centimeters of rock drops sharply. This is reflected in the FTIR and SIMS analyses, in which hydrocarbons were measured in the outermost portions of the core samples. Other remarks are postponed until the remaining data are presented in the sections that follow. 


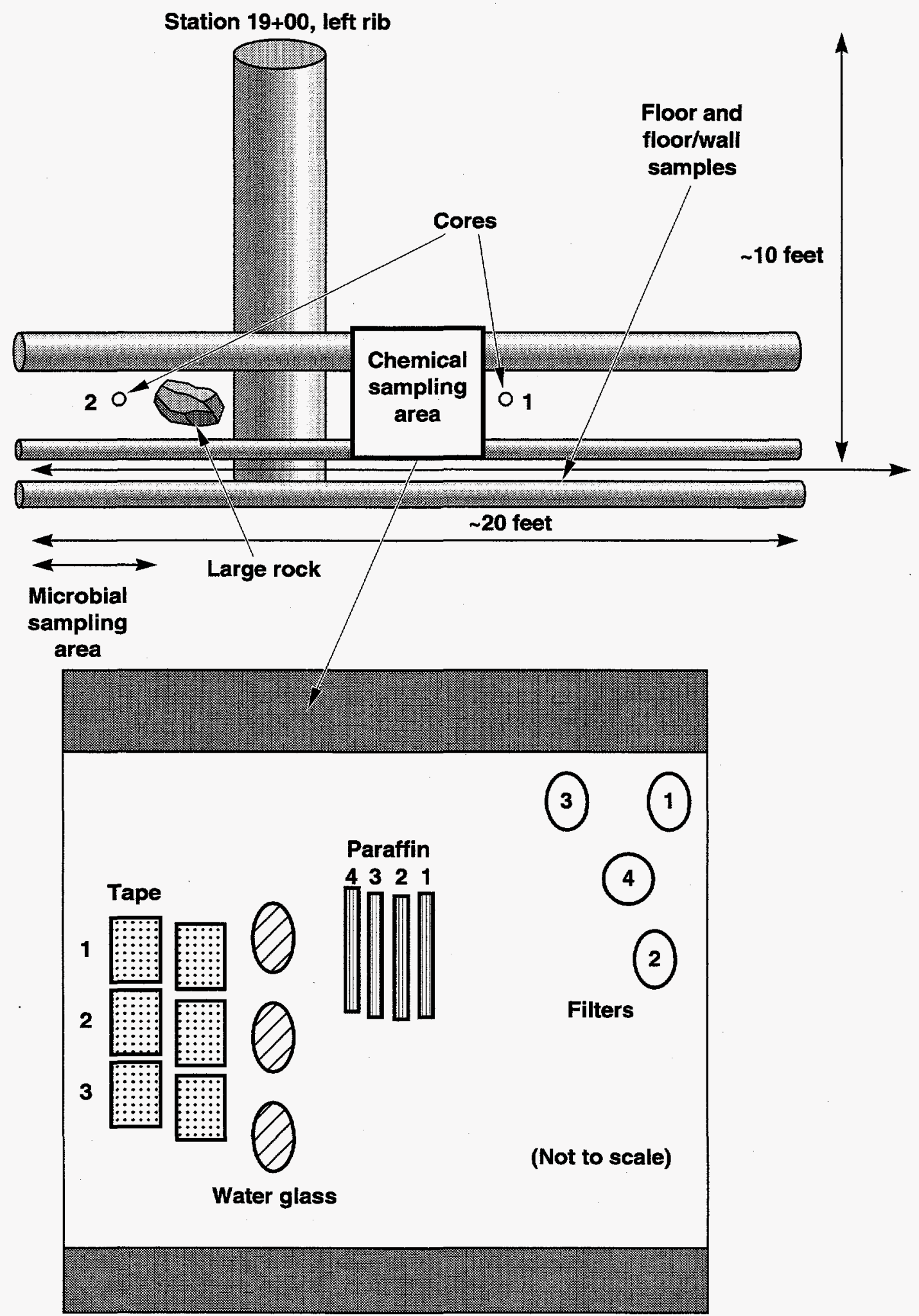

Figure 3.1. Relative location of samples taken for chemical analysis at station $19+00$, left wall, N-Tunnel, Rainier Mesa. 
(a)

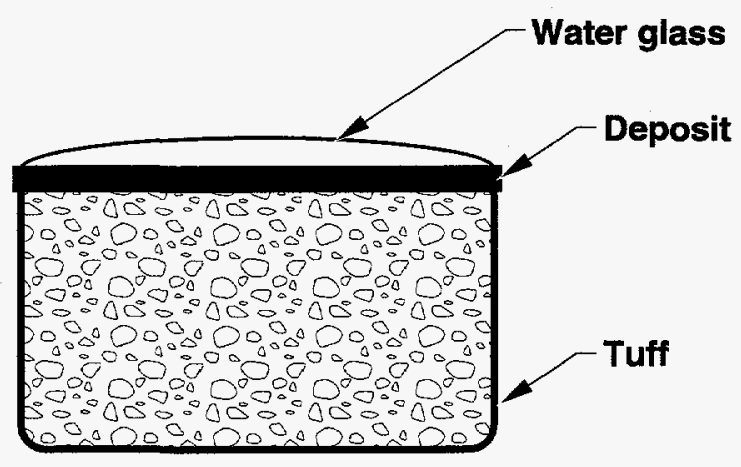

(b)
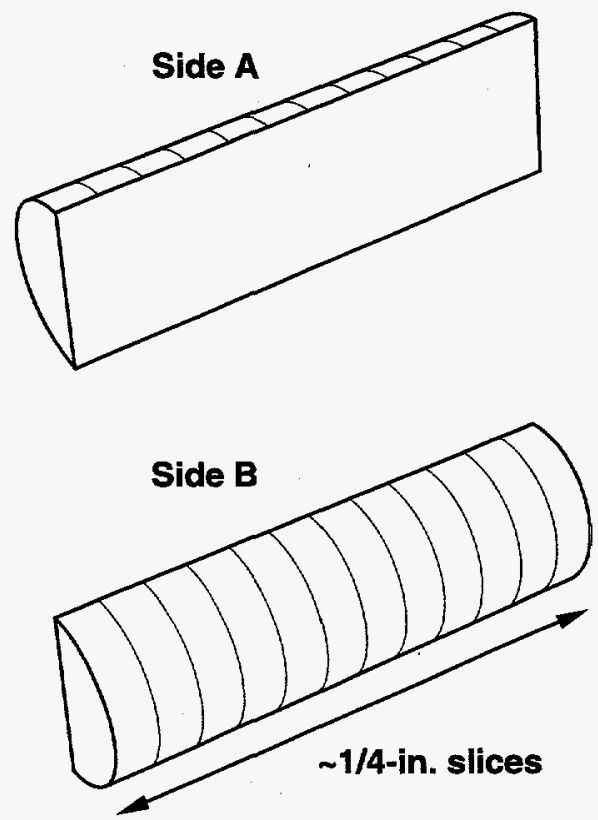

Figure 3.2. Sample preparation techniques. (a) Cross section of prepared water-glass consolidated sample. (b) Sample preparation for cores. 

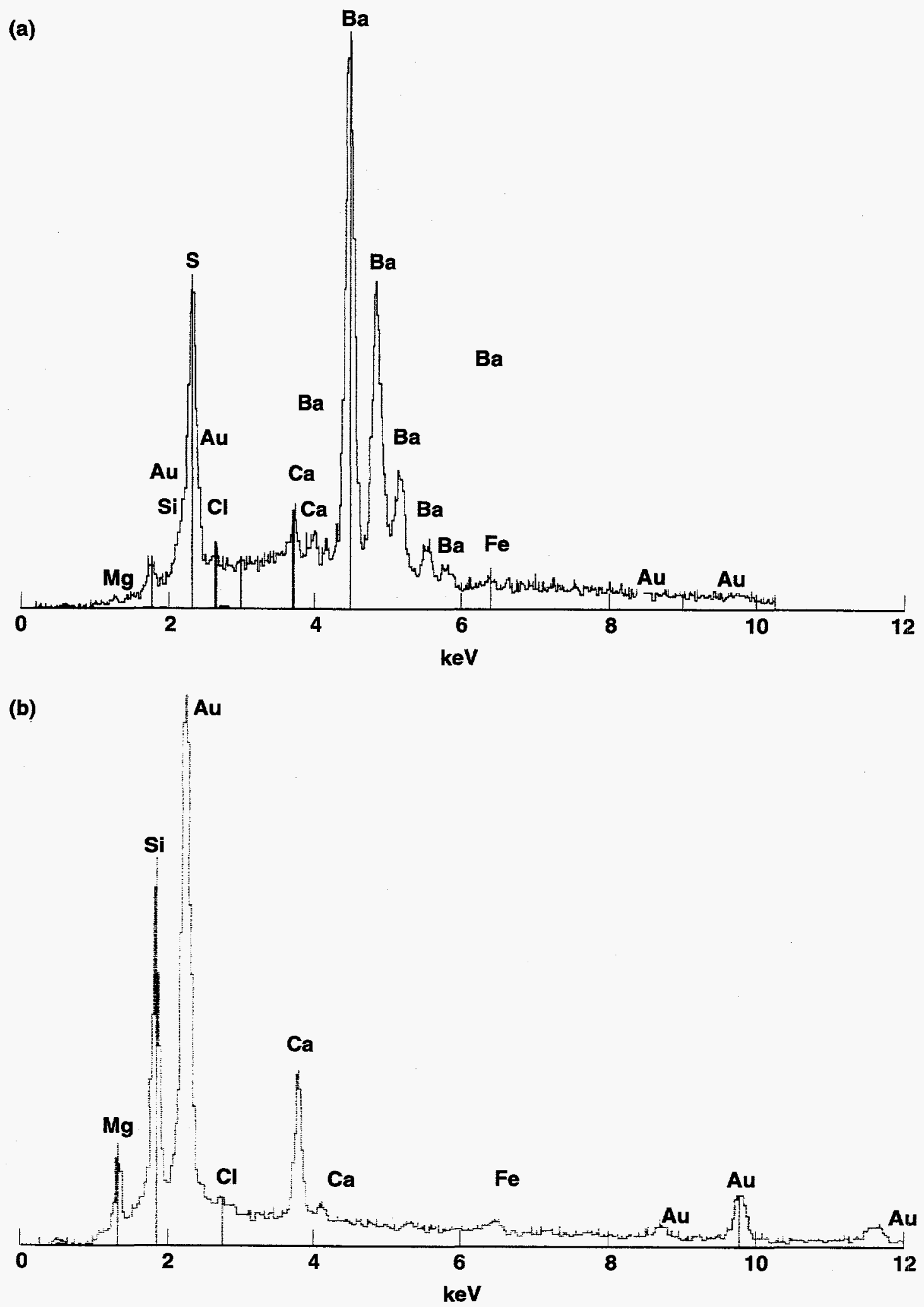

Figure 3.3. (a) SEM EDS analysis of a gold-coated deposit sample collected on "tacky tape," which contains Ba and S. (b) Baseline analysis of a gold-coated tacky tape mount. 

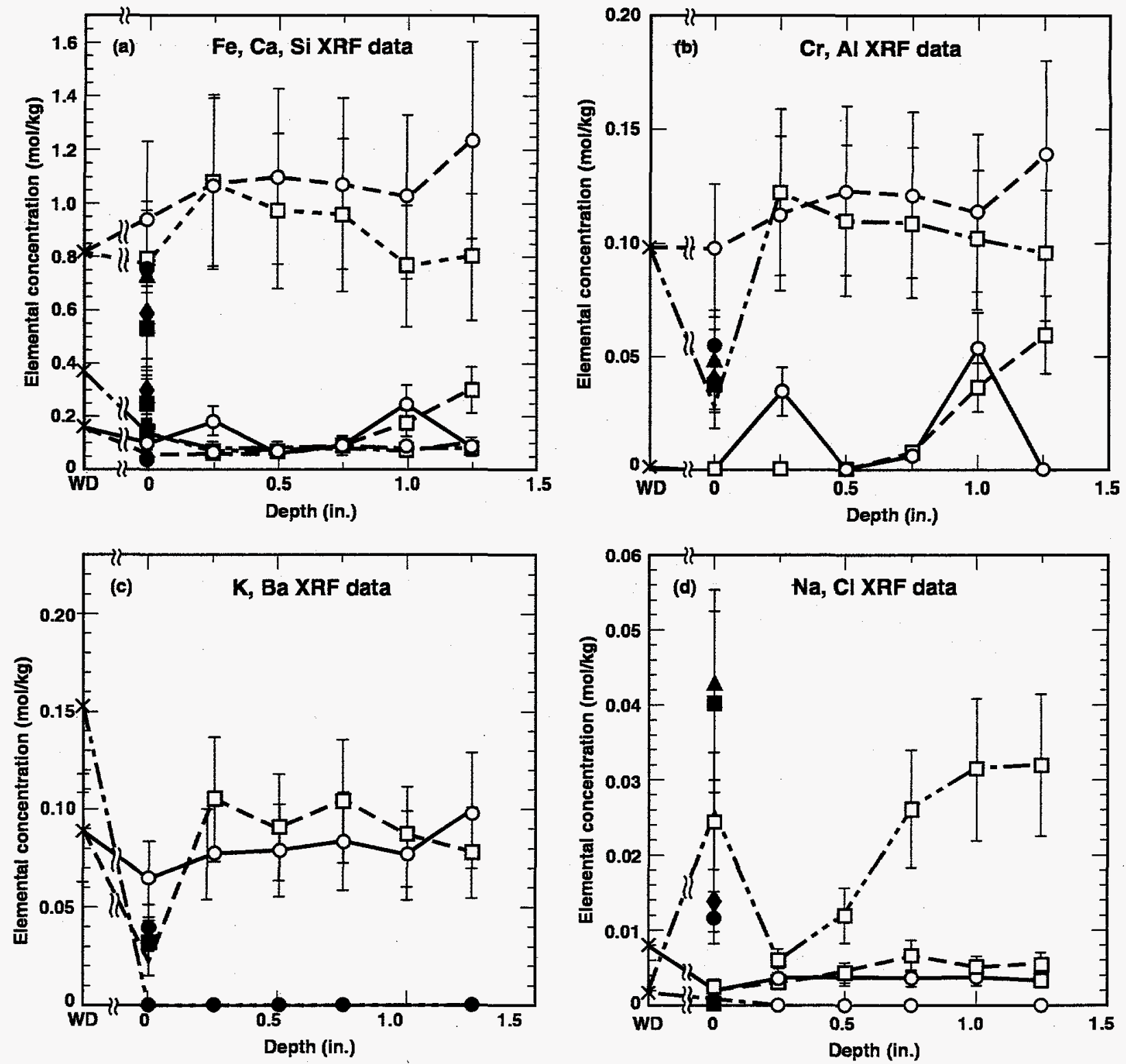

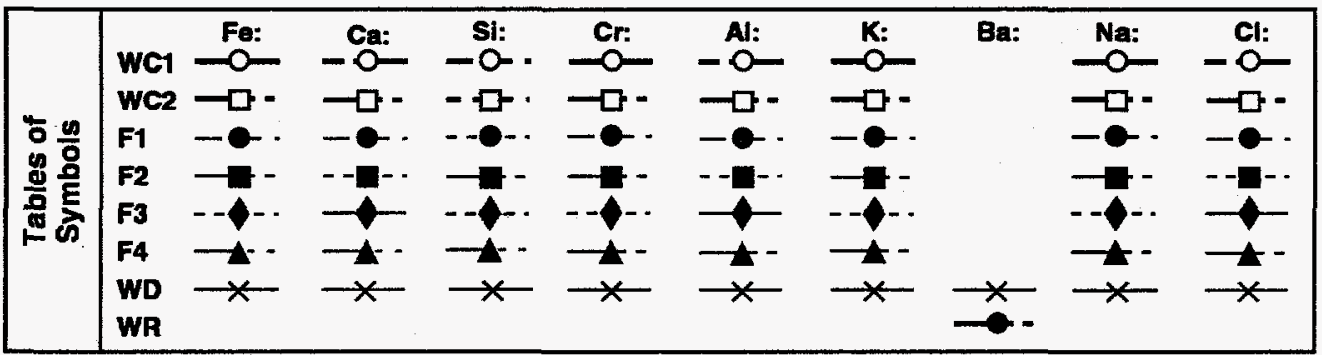

Figure 3.4. Possible chemical trends of (a) $\mathrm{Fe}, \mathrm{Ca}$, and $\mathrm{Si}$ (y-axis scale: $\mathrm{O}-1.6 \mathrm{~mol} / \mathrm{kg}$ ), (b) $\mathrm{Al}$ and $\mathrm{Cr}$ (y-axis scale: $0-0.2 \mathrm{~mol} / \mathrm{kg}$ ), (c) $\mathrm{K}$ and $\mathrm{Ba}$ (y-axis scale: $0-0.2 \mathrm{~mol} / \mathrm{kg}$ ), and (d) $\mathrm{Na}$ and $\mathrm{Cl}$ (y-axis scale: 0-0.06 $\mathrm{mol} / \mathrm{kg}$ ) within the first few inches of the tunnel wall as a function of depth. WD (wall deposit) represents the analysis of the surface deposit, which was extremely variable, but roughly $3 \mathrm{~mm}$ thick. WC1 and WC2 represent data from core samples, and F1-4 represent data from filter samples. 

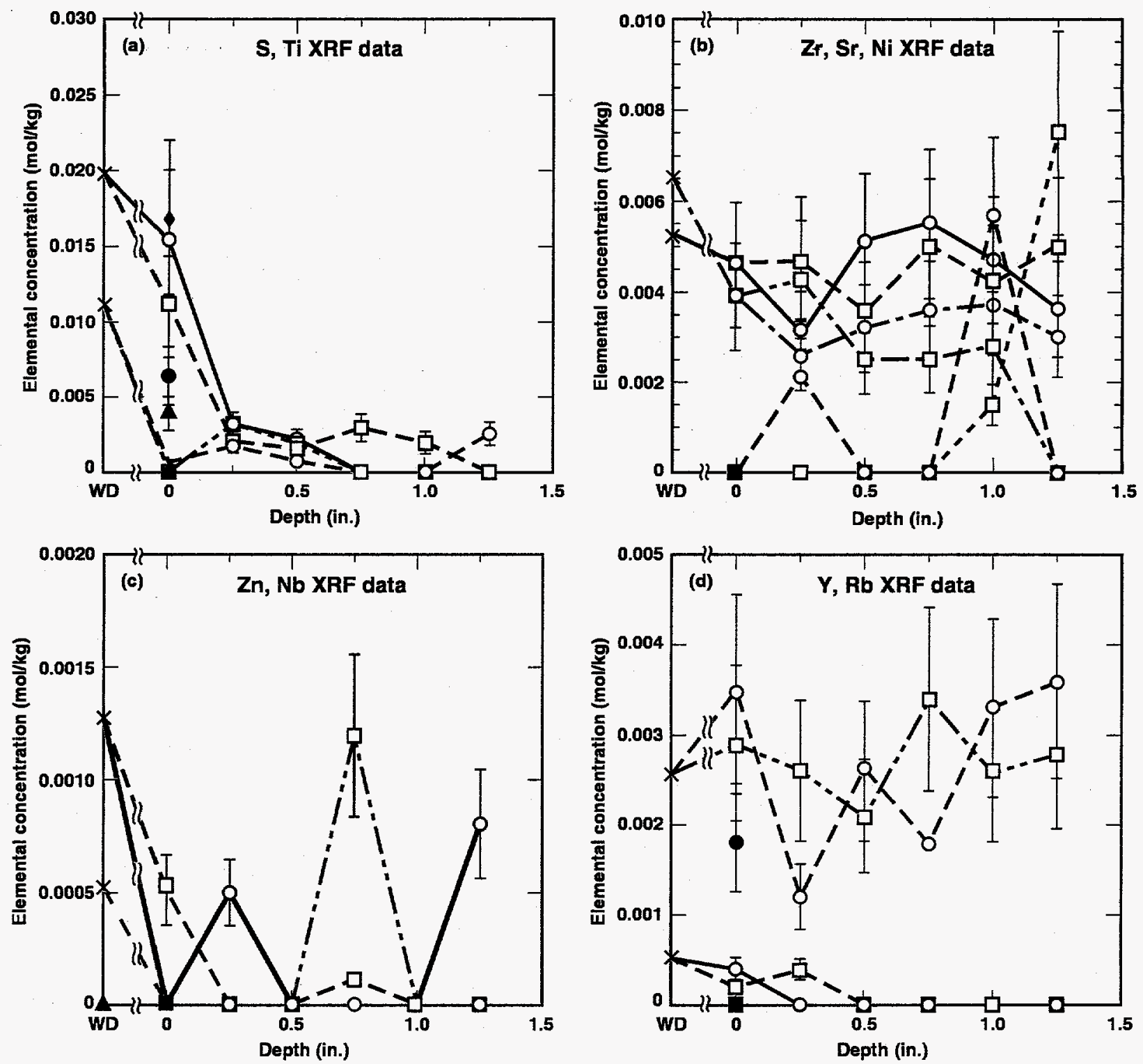

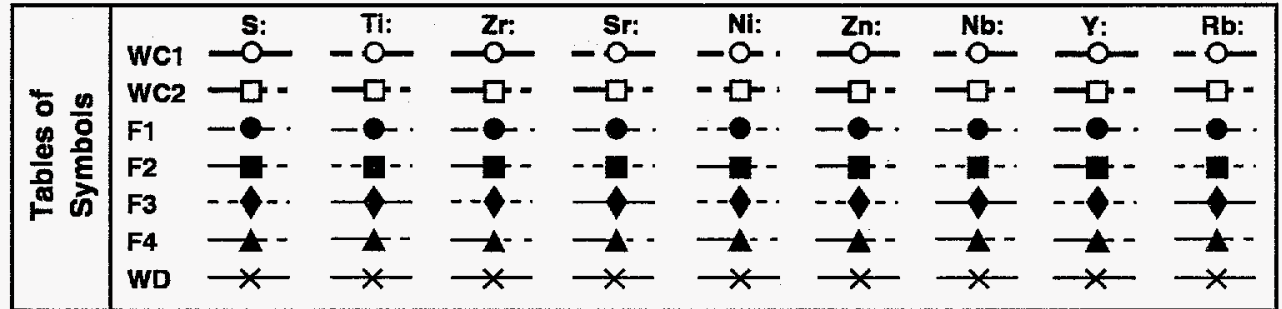

Figure 3.5. Chemical trends of (a) $\mathrm{S}$ and $\mathrm{Ti}$ (y-axis scale: $0-0.2 \mathrm{~mol} / \mathrm{kg}$ ), (b) $\mathrm{Zr}, \mathrm{Sr}$, and $\mathrm{Ni}$ (y-axis scale: 0-0.01 mol $/ \mathrm{kg}$ ), (c) $\mathrm{Zn}$ and $\mathrm{Nb}$ (y-axis scale: $0-0.002 \mathrm{molal}$ ), and (d) $\mathrm{Y}$ and $\mathrm{Rb}$ (y-axis scale: $0-0.005$ $\mathrm{mol} / \mathrm{kg}$ ) within the first few inches of the tunnel wall as a function of depth. WD (wall deposit) represents the analysis of the surface deposit, which was extremely variable, but roughly $3 \mathrm{~mm}$ thick. WC1 and WC2 represent data from core samples, and F1-4 represent data from filter samples. 


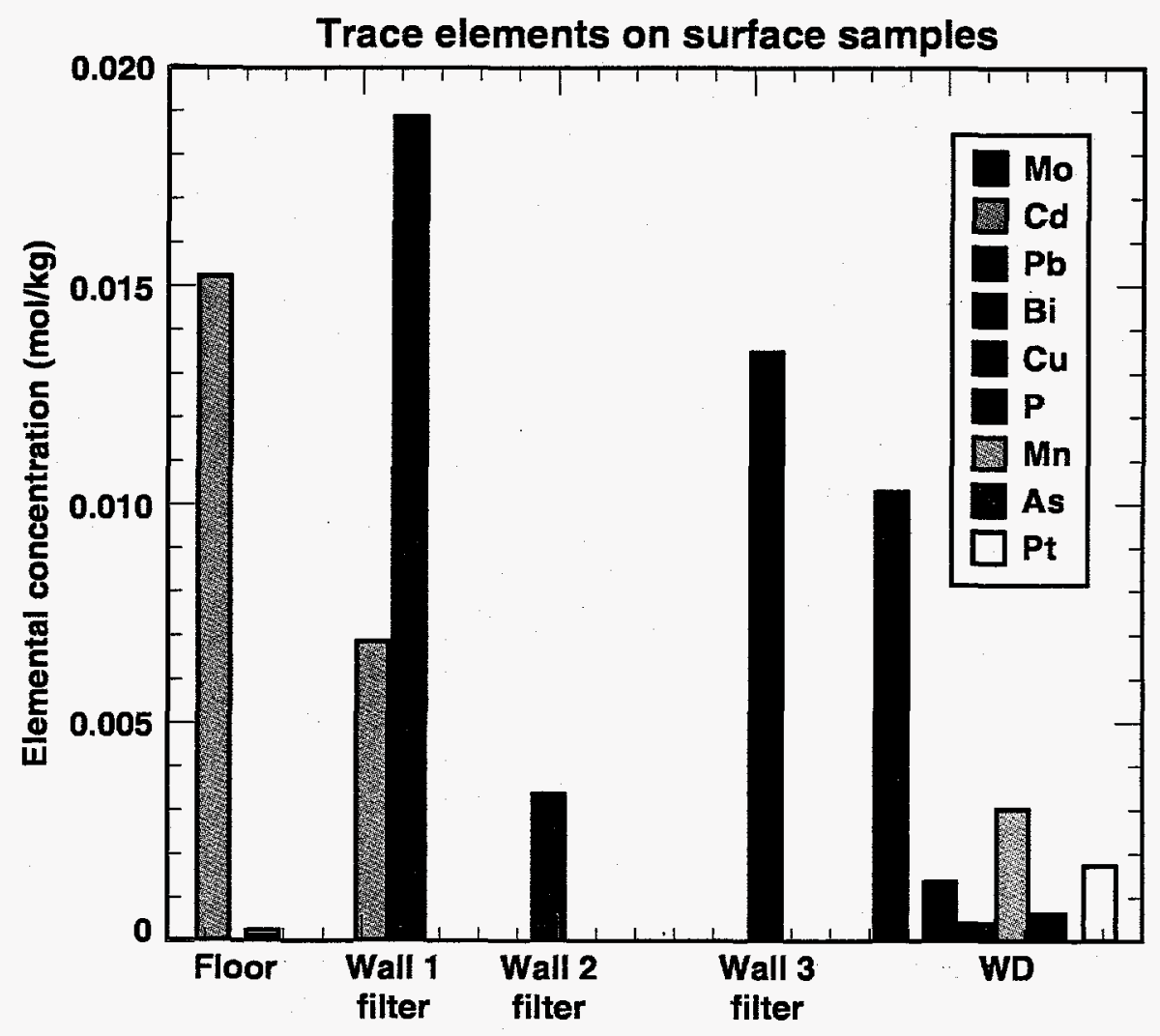

Figure 3.6. Other trace elements only detected within some of the surface deposits are recorded in the bar chart (y-axis scale: $0-0.02 \mathrm{~mol} / \mathrm{kg}$ ). 

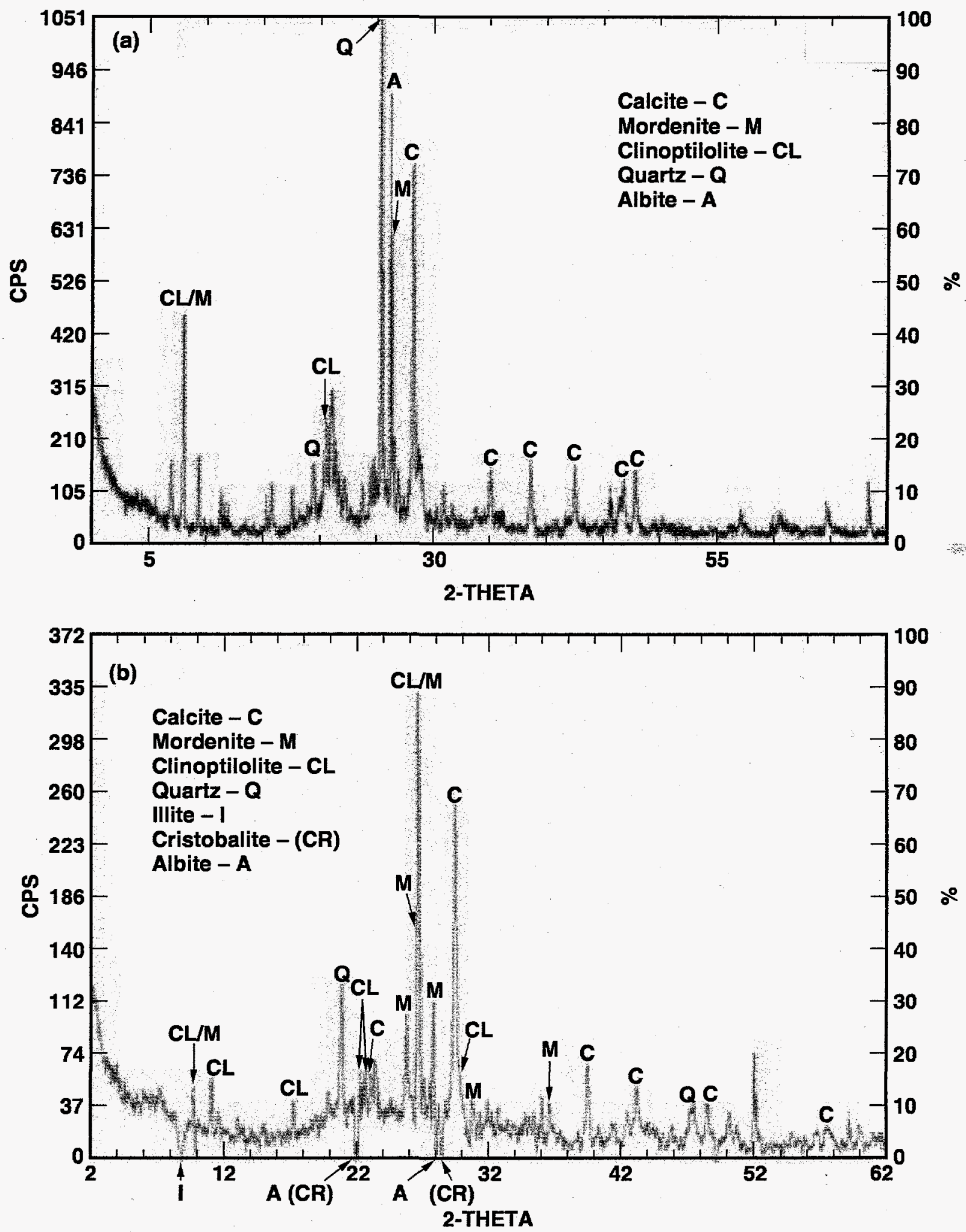

Figure 3.7. Comparison of XRD spectra, which suggests that the less dense mineral constituent of the rock matrix comprises a major fraction of the surface deposit. (a) XRD spectrum of rock matrix.

(b) Synthesized XRD spectrum of rock matrix spectrum subtracted from surface coating spectrum. 


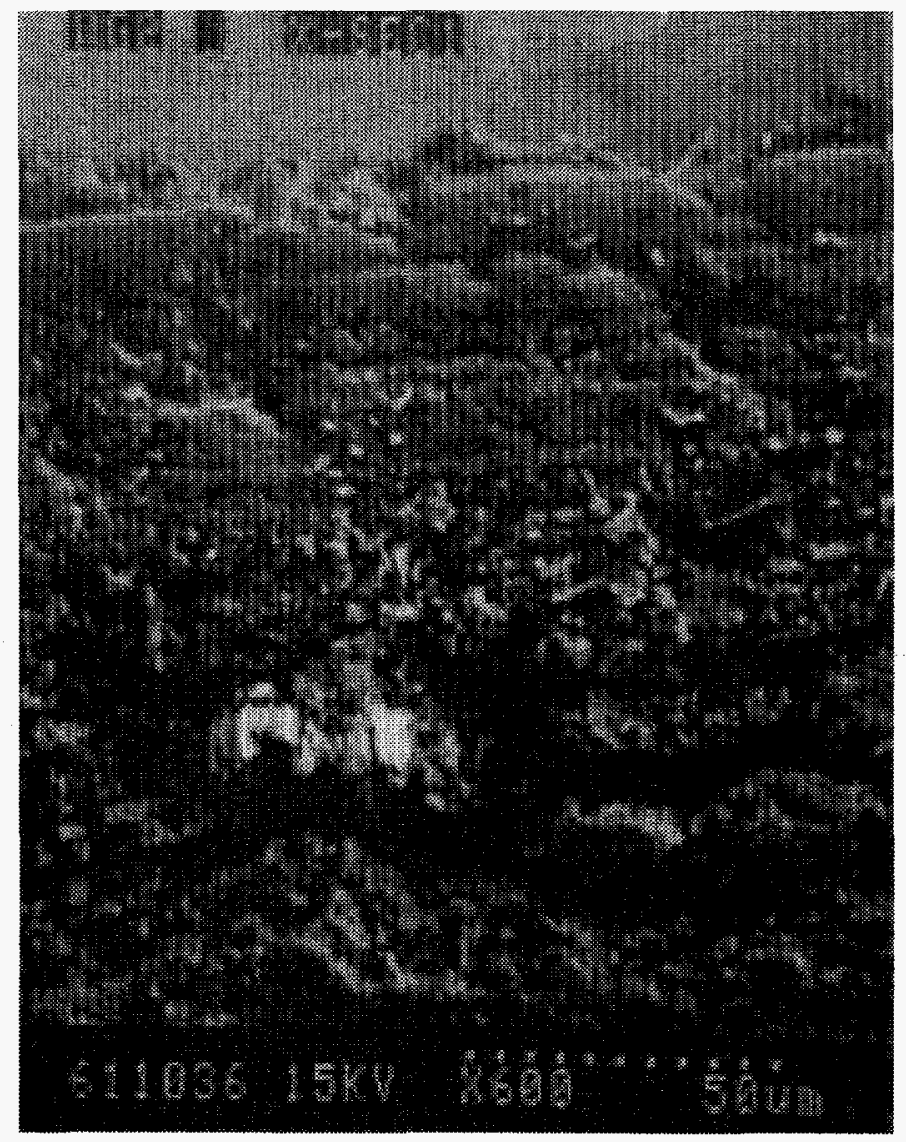

Figure 3.8. SEM backscatter image photomicrograph of a water-glass sample, showing bright Ba particulates that occur sporadically and in connection with the surface deposits. 

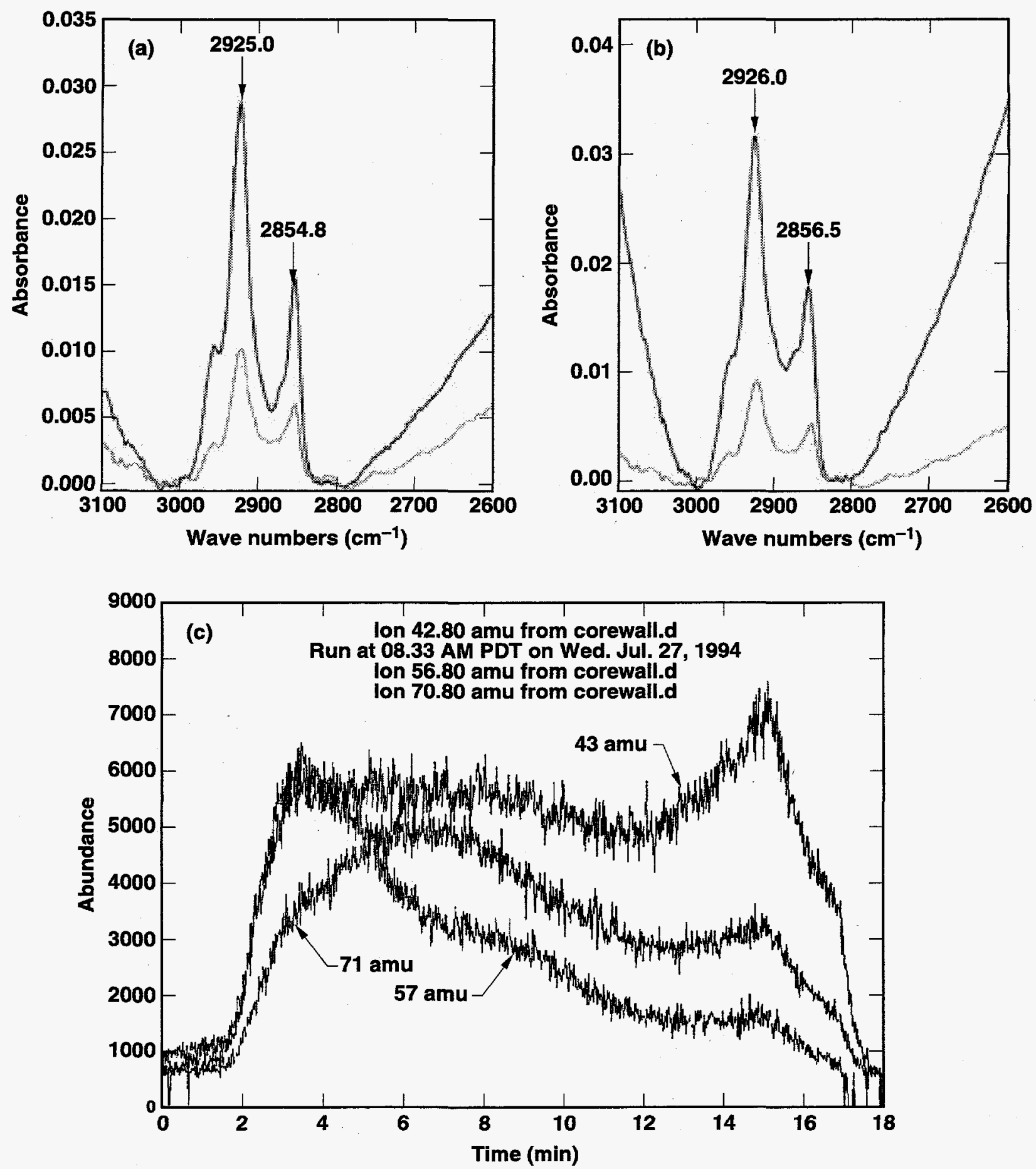

Figure 3.9. Organic content analyses of rock surface. FTIR signature of (a) Core 1-1 (black line) and (b) Core 2-1 (black line), in the area of the spectrum where aromatics are detected, superimposed on the background signature (gray line). (c) Characteristic fragment ions for long chain hydrocarbons at 43,57 , and 71 amu were detected in the SIMS analysis of a core surface. 


\title{
4. Geochemical Modeling of the Interaction between Repository Tuff, Water, and the N-Tunnel Deposit at $150^{\circ} \mathrm{C}$
}

\author{
W. L. Bourcier, A. Meike, and M. Alai
}

\begin{abstract}
The EQ3/6 Geochemical Modeling Package was created to model the complex chemical interactions between water and rock that can occur over time as a function of changing environmental conditions. For discussions of the basis for and development of the code, refer to Wolery (1979, 1983, 1992a, and 1992b) and Wolery and Daveler
\end{abstract} (1992). The Yucca Mountain Site Characterization Project (YMSCP) is sponsoring the development of this package to comply with regulations that require knowledge of repository chemistry through a period of 10,000 years. One mandate of the YMSCP Introduced Materials Task is to evaluate the ability of the code and its database to provide for chemical interactions between materials that have been introduced into the repository as a result of its construction and operation, and host rock, groundwater, waste forms, waste form packaging, and all other repository materials present.

The approach of the present exercise is to investigate the effect of $\mathrm{N}$-Tunnel diesel exhaust deposits on the chemical reactions between the rock wall and host groundwater. This chemical simulation exercise does not show development of the rock and deposits sampled in N-Tunnel. Rather, it evaluates our ability to simulate the interaction between diesel exhaust deposits such as the $\mathrm{N}$-Tunnel deposits and repository rock. To do this, two chemical simulations were performed using the EQ3/6 modeling package. The first simulation is that of the interaction between a model Topopah Spring Tuff and a model J-13 water. The second is the interaction between a model Topopah Spring Tuff, a model J-13 water, and a model soot deposit based on the N-Tunnel deposit analysis described in Sec. 2. A comparison of the two simulations is used to determine the potential for major chemical effects of the reactions of soot on rock-water-repository materials interactions in the repository. Some of the parameters are not strictly representative of the proposed repository environment but were chosen for the ease of this preliminary evaluation. A single temperature of $150^{\circ} \mathrm{C}$ was chosen for this initial calculation to represent an elevated temperature scenario.

This evaluation has exposed the need to expand the modeling capabilities as well as the database. Some of these needs are currently being addressed at LLNL by the Geochemical Modeling Task. The other needs are being addressed by the Introduced Materials Task.

\section{Modeling Parameters}

The EQ3/6 geochemical modeling package is a collection of FORTRAN computer codes designed to be used in succession. The first major chemical modeling code, EQ3NR, is an aqueous phase speciation code. Speciation refers to the equilibrium distribution of a variety of aqueous species and complexes containing a given element. For a given elemental solution composition, EQ3NR calculates what fraction of each element exists in each of several possible aqueous species. For example, Na may be present as free sodium ions $\left(\mathrm{Na}^{+}\right)$or as complexes of sodium such as $\mathrm{NaSO}_{4}{ }^{-}$or $\mathrm{NaHCO}_{3}$. EQ3NR calculates the fraction of $\mathrm{Na}$ in each of these possible species and the mineral saturation states of all relevant solids present in the database. The solution speciation calculation is needed to do the latter calculation. EQ3NR also provides as output a section of the input file needed for EQ6.

EQ6 is the reaction path code. It is used to simulate the chemical effects of reactions between any set of solid, aqueous, and gas phases over a user-defined reaction path. The EQ6 code provides several modeling options that simulate a variety of potential reaction paths that may be relevant to reactions taking place in the repository over time. The two major options are (1) equilibrium mass transfer and (2) kinetically controlled mass transfer. In the first option, the system stays in equilibrium at all points along the reaction path. No disequilibrium in terms of mineral dissolution/precipitation reactions or redox reactions is allowed. In the second option, both mineral and redox disequilibrium are allowed. Both options can be combined with open- or closedsystem conditions. In closed systems, all mass is conserved; no mass transfer out of the system is allowed. In open systems, mass transfer is allowed. The open-system simulation present in EQ6 allows mineral phases produced during the 
reaction path to be removed from the system. This is equivalent to flowing a packet of water along a path through a reacting medium. An alternative open system scenario, in which the reference frame is that of a rock reacting with fluid passing by, is not present in the current version of EQ6 but will be needed for some future modeling work in the Introduced Materials Task.

Typical input to EQ3NR is the elemental composition of the aqueous phase and intrinsic parameters such as $\mathrm{pH}$ and $\mathrm{Eh}$, which further define the fluid. For the Yucca Mountain site, total concentrations of elements present in the J-13 well water are used along with measured $\mathrm{pH}$. For more information on water analysis and geochemical simulation of J-13 water, see Delany (1985). Typical output from the EQ3NR module includes the activities and concentrations of all chemical species and complexes present in the fluid model, the degree of electrical imbalance of the input fluid composition (used as a check on the quality of water analyses), and the mineral saturation indices for the above-mentioned speciation model. In practice, the solution composition entered into EQ3NR includes trace amounts, typically $1 \mathrm{ppb}$ or less (e.g., $\mathrm{Al}^{3+}$ ) of all elements present in the reactants used in the later EQ6 simulation). Trace amounts are included because when EQ6 first reads the thermodynamic database, it excludes any species (solids, aqueous, or gas) that are not representative of the elemental component set input in EQ3NR. If an element is present in the reacting solids that is not present in the fluid, the code will not have picked up the required thermodynamic data to simulate its behavior.

Input required for EQ6 includes (1) the fluid speciation model from EQ3NR; (2) all reactants, including minerals, gases, aqueous species, and special reactant constituents; (3) any kinetic submodels for each reactant; and (4) system parameters such as temperature, pressure, and water/reactant ratio. The system parameters (item 4) can be specified to change as a function of time. In the present simulations, arbitrary reaction progress $\xi$ is used instead of time as a measure of the amount of dissolved reactant. This approach is used because the kinetic models and rate laws required to describe reactions in real time are not available for reactions involving the soot deposit in the rock wall.

Other user input options are available that can have a major effect on simulation results. An important option is the ability to suppress mineral species because, although they may be predicted to precipitate based on their thermodynamic properties, they in fact do not precipitate because of kinetic inhibition. The information needed to make decisions of this sort must be obtained from previous observations from experiments or natural systems. Suppression of some very stable minerals and their replacement with metastable ones can significantly change the predicted solution composition.

Another important user-defined input involves how redox state is calculated for the system. The redox state can be calculated as a function of reaction process from the data entered in the input files. This method is valid if the system is truly closed, and no mass enters or leaves the system. Alternatively, the system can be maintained in equilibrium with an external reservoir that fixes the redox state at some value. This is performed using the fixed-fugacity mode of EQ6. For some Yucca Mountain repository simulations, it may be most accurate to keep the redox state of the system at an oxidized value close to that of equilibration with the atmosphere. This is because the repository is expected to be in contact with air of essentially atmospheric composition during much of its lifetime.

The simulator must make important decisions that affect the outcome of the simulation, such as suppression of species and the choice of oxidation states, discussed above. It therefore requires a significant amount of chemical knowledge, which is used to properly enter the simulation constraints. With the selection of appropriate parameters, database entries, and submodels, EQ3/6 should yield accurate trends and semiquantitative results for chemical processes taking place in the repository. Thus, for the proposed repository, the EQ3/6 code is ultimately expected to simulate the evolution of solution composition, sources and sinks for dissolved species, and local mineral assemblages as a function of repository history. These simulations can provide bounding calculations for repository design.

\section{Modeling Tuff-Groundwater-Rock Deposit Interactions}

For simplicity and as an example of the modeling exercise, the reaction was modeled as a closed system, at $150^{\circ} \mathrm{C}$ and 4.7 bars pressure. In an actual modeling study, cases representing both open and closed systems and a range of pressures would be considered. The temperature was chosen as representative of a potentially more reactive condition than ambient temperature, but 
still well within the range of conditions under consideration for a repository design. In addition, previously published simulation results exist for tuff-groundwater-rock interactions (Delany 1985) for comparison. This comparison is made to verify that the addition of trace species (see below) had a negligible effect on the EQ3NR simulation. The vapor pressure is that of pure water at $150^{\circ} \mathrm{C}$. A physical approximation of the model is as follows. A small amount of solid reactant is dissolved into a constant volume of aqueous phase of known composition. The code then calculates equilibrium relations in the aqueous phase and the saturation state of potential product phases. Any phases that are supersaturated with respect to the aqueous phase are allowed to precipitate, and solid phases that are no longer in equilibrium are allowed to dissolve. At this step, the aqueous phase has obtained a new composition, and more of the reactant is added to the system. These steps are repeated until the defined simulation duration is completed (see Fig. 4.1).

In the present case, two reactants were allowed to react with the predefined aqueous phase (0-13 water). The two reactants used in the present modeling exercise were a standard tuff used in previous rock-water simulations for YMSCP studies (Delany 1985; also see below), and a special reactant including the elements analyzed in the N-Tunnel deposit (see below). The special reactant is assumed to dissolve congruently. This is accomplished in the simulation by releasing elements of the special reactant in proportion to their mole fraction. The minerals making up the tuff were reacted according to the transition theory rate law and experimental rate data collected for each phase (see Delany 1985). In the geochemical model, secondary phases are removed from the solution immediately upon equilibration, which is equivalent to instantaneous precipitation. For further perspective on the usage and assumptions involving a special reactant, see Bruton and Shaw (1987).

Database. Fundamental to a computer simulation that appropriately reflects a complex chemical environment are the databases of internally consistent thermodynamic and kinetic parameters. Evaluation of the modeling package from the standpoint of the Introduced Materials Task consists of examining these databases for the thermodynamic and kinetic parameters of the appropriate constituents. A database adequate for the simulation needs of the Introduced Materials Task has not yet been developed. Therefore, the simulations presented here should be considered more of a method of systems analysis than a realistic simulation of chemical behavior in a repository or mining drift environment.

\section{Summary of Reactants}

Tuff. The Topopah Spring Tuff unit of the Yucca Mountain has been considered as a potential rock horizon from which to excavate the proposed radioactive waste repository. Table 4.1 gives the bulk mineralogy of the proposed repository horizon.

J-13 Water. Well J-13 is the water-producing well from the Topopah Spring Tuff (TPt), which is the delegate repository horizon. As such, it is assumed to approximate the composition of water that may be present within pores in the TPt at ambient conditions. This water, or water of a similar composition, is used for most rock-water laboratory experiments that support YMSCP. The values used for this simulation are mean values reported by Harrar et al. (1990) in their tables 4.1, 4.2 , and 5.1. Delany (1985) gives further discussion of the rationale that supports the usage of this water composition. Table 4.2 gives the average chemical analysis of the J-13 water, characterized by Oversby and Knauss (1983), Knauss (1984), and Oversby (1984a, 1984b).

The composition of this water was modified slightly, as described above, to include trace amounts of all elements present in the special reactant. These modifications to the solution composition are for computational purposes and do not affect the overall solution chemistry.

Table 4.1 Bulk mineralogy used in the simulations of the Topopah Spring Tuff in the proposed repository interval.

\begin{tabular}{lc}
\hline Mineral & $\begin{array}{c}\text { Amount } \\
\text { (vol\%) }\end{array}$ \\
\hline Cristobalite & 44.0 \\
Alkali feldspar & 39.0 \\
Quartz & 14.9 \\
Plagioclase & 1.0 \\
Mg-beidellite & 1.0 \\
Biotite & 0.1 \\
Total & 100 \\
\hline
\end{tabular}


Table 4.2. Composition of LLNL supply of J-13 water $(\mathrm{pH}=7.6)$.

\begin{tabular}{lc}
\hline Element & $\begin{array}{c}\text { Concentration } \\
\text { (ppm) }\end{array}$ \\
\hline $\mathrm{Li}$ & 0.042 \\
$\mathrm{Na}$ & 43.9 \\
$\mathrm{~K}$ & 5.11 \\
$\mathrm{Ca}$ & 12.5 \\
$\mathrm{Mg}$ & 1.92 \\
$\mathrm{Sr}$ & 0.035 \\
$\mathrm{Al}$ & 0.012 \\
$\mathrm{Fe}$ & 0.006 \\
$\mathrm{Si}$ & 27.0 \\
$\mathrm{NO}_{3}$ & 9.6 \\
$\mathrm{~F}$ & 2.2 \\
$\mathrm{Cl}$ & 6.9 \\
$\mathrm{HCO}_{3}$ & 125.3 \\
$\mathrm{SO}_{4}$ & 18.7 \\
\hline
\end{tabular}

Special Reactant. When a chemical analysis of a reactant is available but a complete breakdown of mineral constituents is not, the solids can be incorporated into the chemical code by means of a "special reactant." This is the present case for the rock deposit analysis. A special reactant input consists of the elemental analysis composition in moles. Computationally, a significant difference exists in that the simulation will not achieve equilibrium when a special reactant is included. The input used in the soot simulation shown in Table 4.3 is derived from the XRF analysis of the N-Tunnel deposit. The amount of material given in the table is defined as one mole of rock deposit reactant in the simulation.

The redox state of the elements is determined by specifying the number of moles of oxygen in the reactant. That is, for each element, an oxidation state is chosen that is thought to be representative for that element in the rock deposit. An amount of oxygen is added to the total for oxygen in the special reactant appropriate for that oxidation state. For example, an oxidation state of four was chosen for manganese, so that for each mole of manganese, two moles of oxygen are added. This is equivalent to adding $\mathrm{Mn}$ to the reactants as the oxide $\mathrm{MnO}_{2}$. Until the rock deposit is better characterized, estimated oxidation states for some elements will be used. The
Table 4.3. Special reactant input representing rock deposit analysis.

\begin{tabular}{lc}
\hline Element & $\begin{array}{c}\text { Amount } \\
\text { (moles) }\end{array}$ \\
\hline $\mathrm{Na}(\mathrm{I})$ & 0.0081 \\
$\mathrm{Mg}(\mathrm{II})$ & 0.0124 \\
$\mathrm{Al}(\mathrm{III})$ & 0.0987 \\
$\mathrm{Si}(\mathrm{IV})$ & 0.8138 \\
$\mathrm{~S}(\mathrm{VIII})$ & 0.0196 \\
$\mathrm{Cl}(-\mathrm{I})$ & 0.0018 \\
$\mathrm{~K}(\mathrm{I})$ & 0.0907 \\
$\mathrm{Ca}(\mathrm{II})$ & 0.3648 \\
$\mathrm{Ti}(\mathrm{IV})$ & 0.0110 \\
$\mathrm{Cr}(\mathrm{III})$ & 0.0005 \\
Fe(III) & 0.1604 \\
$\mathrm{Cu}(\mathrm{II})$ & 0.0013 \\
$\mathrm{Zn}(\mathrm{II})$ & 0.0013 \\
$\mathrm{Rb}(\mathrm{I})$ & 0.0026 \\
$\mathrm{Sr}(\mathrm{II})$ & 0.0066 \\
Y(III) & 0.0005 \\
$\mathrm{Zr}(\mathrm{IV})$ & 0.0053 \\
$\mathrm{~Pb}(\mathrm{II})$ & 0.0102 \\
$\mathrm{C}(\mathrm{O})$ & 0.013 \\
$\mathrm{P}(\mathrm{III})$ & 0.0003 \\
$\mathrm{Mn}(\mathrm{IV})$ & 0.0029 \\
$\mathrm{As}(\mathrm{III})$ & 0.0006 \\
$\mathrm{Ba}(\mathrm{II})$ & 0.1541 \\
$\mathrm{O}$ & 2.7364 \\
\hline & \\
\hline
\end{tabular}

a Roman numerals in parentheses give the effective oxidation state assumed for each element in this reactant.

oxidation states are given as roman numerals for each element in Table 4.3. The special reactant can be thought of as a mixture of oxides and salts that have the desired bulk composition.

Because the rock wall deposit was generated at high temperatures in an oxidizing environment, fairly high oxidation states were chosen for most elements. In addition, hydrologic modeling of the Yucca Mountain site suggests that an excess of atmospheric oxygen will be available to oxidize reactive reduced species. For these reasons, we believe that our fairly oxidized characterization of the rock wall deposit is justifiable. 
For the sake of this exercise, the TOC analysis was used to estimate the total mole fraction of carbon. The carbon was initially present in the input file in elemental form $\left(C^{0}\right)$ but could be involved in reactions to form carbonate. Abiotic reactions accounting for this conversion at moderate to low temperatures are very slow. Because soot comes from incomplete combustion in an oxygen-poor environment, these assumptions represent an extreme bounding condition for the interpretation of the available data, and as will be shown below, they have a significant effect on the simulation results.

Suppressed Mineral Phases. The ability to suppress minerals from precipitation in the EQ6 simulation is an essential part of the simulation process. Species are suppressed when, for kinetic or other reasons, it is clear that the code would choose inappropriate minerals for precipitation. This is a common occurrence in geochemical modeling of low-temperature systems. There are numerous phases that commonly only precipitate at very high temperatures and pressure (e.g., in igneous and metamorphic rocks) but are predicted to precipitate in the simulations of low-temperature reactions. These include phases such as andradite garnet, diopside, and tremolite. However, we know from observations of natural systems and short-duration laboratory experiments that phases such as clays and zeolites form instead. Suppression of these phases, when done correctly, has led to much better agreement between modeling results and data both from natural analogs and experiments. Table 4.4 lists species suppressed in the present simulation.

Table 4.4. Solids suppressed in simulations of tuff $+\mathrm{J}-13$ water, and tuff + soot $+\mathrm{J}-13$ water reactions.

\begin{tabular}{ll}
\hline Quartz & Tremolite \\
Pyrophyllite & Wollastonite \\
Talc & Tridymite \\
Garnet & Hematite \\
Dolomite & Diopside \\
Chalcedony & $\mathrm{ZnCr}_{2} \mathrm{O}_{4}$ \\
Microcline & \\
\hline
\end{tabular}

\section{Results}

\section{Evaluation of the Database}

The $\mathrm{NO}_{\mathrm{x}}$ and $\mathrm{SO}_{\mathrm{x}}$ species described in many published diesel emission analyses are not included in the database because they have not been needed until now. This is expected to be the case for many species of interest to the Introduced Materials Task. Therefore, the LLNL Geochemical Task is beginning to incorporate these species into a preliminary database for use by the Introduced Materials Task.

Until such data are available, we cannot model the interactions between water and a diesel emission reactant based on analyses that include these gases. The diesel emission analysis report (CRWMS M\&O Contractor 1993) is based on these types of analyses; however, they measure the exhaust emitted from an engine, not the solid that is deposited on a rock face. We question the utility of such an exercise, since the drifts will be ventilated and much of the gas will escape during the construction and operation of the repository. In time, as the potential for the escape of gases into fractures is better understood, modeling dissolved gases may become useful. For this brief study, we have focused on analyzing the actual deposit taken at $\mathrm{N}$-Tunnel. However, the sulfur and carbon gases $\left(\mathrm{NO}_{x}\right.$ and $\mathrm{SO}_{x}$ species) are expected to be very reactive and to affect both the $\mathrm{pH}$ and the oxidation state of any water they contact. Their effects may be at least as important as those modeled and described here.

Another difficulty in applying the EQ3/6 code to introduced materials is its inability to model the long-term degradation of hydrocarbons, which are metastable but long-lived phases. Because EQ3/6 equilibrates at each step, all hydrocarbons would disappear in favor of their thermodynamically most stable decomposition products, generally some combination of methane, carbon dioxide, and water. To avoid this unrealistic situation, the usual approach is to set the breakdown reaction rates to very large values. This, however, will become an impractical and insupportable assumption for the purposes and needs of the Introduced Materials Task. Part of the work of the Introduced Materials Task will be to develop strategies that will interface with the geochemical codes and suit the modeling needs in this area. 


\section{J-13 Water + Tuff}

Figures 4.2 through 4.4 show the results of the J-13 water + tuff simulations. Although no kinetic rate data were used to determine reaction rates for the rock wall deposit, dissolution rates were used for the minerals making up the tuff (for example, see Delany 1985). For the tuff-water reactions, the value of the reaction progress variable $\log \xi=$ -1.8 corresponds to about 16 months of reaction time. For the rock deposit reaction, the reaction path in the plots corresponds to about $2 \mathrm{~g}$ of rock deposit reacting in $1 \mathrm{~kg}$ of water at a steady rate over the 16-month period. This, of course, represents a completely saturated system. In a rigorous study, in support of a radioactive repository at Yucca Mountain, other modeling scenarios would have to be developed for less than $100 \%$ saturation.

Figure 4.2a shows the change in $\mathrm{pH}$ as the reaction progresses. The $\mathrm{pH}$ is fairly constant and varies within 0.1 units of $\mathrm{pH}=7$. Figure 4.3a shows the predicted aqueous concentrations of several elements, and Fig. 4.4a shows the secondary phases predicted to form during the tuff-water reaction. These simulations differ from those of Delany (1985) in that ours used an updated database and our solutions were doped with trace amounts of additional elements contained in the rock surface reactant. Nevertheless, the results of the present simulation have a qualitative, orderof-magnitude similarity to previous simulation results and thus can be used to establish a baseline for comparing simulations that include the rock surface deposit. Of more interest for the present discussion are differences between simulations performed with and without rock wall deposit present ( $a$ vs. $b$ in Figs. 4.2-4.4). These are discussed below.

\section{J-13 Water + Tuff + Deposit}

Figures 4.2 through 4.4 also show the results of the J-13 water + tuff + deposit simulations where $\mathrm{fO}_{2}$ and $f \mathrm{CO}_{2}$ were fixed at atmospheric values throughout the iterations of the simulations. Figure 4.2 shows that the $\mathrm{pH}$ is increased significantly by the reaction of the rock deposit. This probably reflects hydrolysis reactions involving the metals present in the rock deposit to some extent, but more importantly, it reflects the conversion of elemental carbon to carbonate species. Because the kinetics of the rock deposit-water reaction is not known (including whether, at some temperatures, the biologically mediated reaction will be most significant), we see this simulation as a bounding condition for the chemical analysis of the N-Tunnel deposit and the simulation conditions. We believe that the simulations represent the maximum possible effect. It is likely that the rock surface deposit will be less reactive than we have assumed in this simulation. However, another factor not accounted for is the $\mathrm{pH}$ effect of the metastable sulfur and nitrogen species mentioned above. Their effects on system $\mathrm{pH}$ may be more significant than the effects modeled here.

Figure 4.4 shows the predicted concentrations of dissolved $\mathrm{Si}, \mathrm{Na}, \mathrm{C}, \mathrm{S}$, and $\mathrm{Ca}$ without (4.4a) and with (4.4b) the rock deposit present in the simulation. The concentrations of silicon and sulfur are higher for simulations including the rock deposit reactions; the concentrations of carbon and calcium are lower; and the concentration of sodium is about the same for both simulations. Similar sized changes are observed for many of the other 23 elements present. These effects may be important in dissolution and corrosion reactions of other repository materials. For example, borosilicate glass dissolves faster as the $\mathrm{pH}$ is increased (at neutral $\mathrm{pH}$ or higher) and as dissolved silica is decreased. The fluid that has reacted with rock deposit has both a higher $\mathrm{pH}$ and a higher silica concentration. It is not clear without further analysis which of the two opposing effects is greater and therefore what the net effect on glass dissolution would be.

Figure 4.4 also shows the secondary phases predicted to form without (a) and with (b) the rock deposit included in the simulation. Table 4.5 gives the formulas for minerals predicted to form during groundwater-tuff-rock deposit reaction. In Fig. 4.4, the horizontal lines corresponding to each mineral indicate whether or not the phase is predicted to form during the reaction path. These paragenesis-type plots therefore show only whether each phase is predicted to be present, not the amount. Most of these phases are very minor in terms of mass produced. The dominant phases are calcite (labeled carbonate on the diagrams), smectites (both dioctahedral and trioctahedral), the zeolites mesolite and stilbite, goethite, and antigorite. In the simulations with rock deposit, the same phases dominate plus witherite, cerussite, and zincite.

The number of phases is much larger for the simulation with the rock deposit included because of the greater number and concentrations of elements present in the rock deposit reactant.

Although the simulations predict fairly similar phases whether or not the rock deposit is present, even minor differences in the predicted phases can be significant in terms of radionuclide 
Table 4.5. Names and formulas for minerals predicted to form during groundwater-tuff-rock deposit reaction.

\begin{tabular}{|c|c|}
\hline Mineral name & Chemical formula \\
\hline Alamosite & $\mathrm{PbSiO}_{3}$ \\
\hline Antigorite & $\mathrm{Mg}_{24} \mathrm{Si}_{17} \mathrm{O}_{42.5}(\mathrm{OH})_{31}$ \\
\hline Barite & $\mathrm{BaSO}_{4}$ \\
\hline Carbonate & $\mathrm{CaCO}_{3}$ (solid solution with $\mathrm{Mg}, \mathrm{Mn}, \mathrm{Sr}, \mathrm{Fe}$, and $\mathrm{Zn}$ ) \\
\hline Cerussite & $\mathrm{PbCO}_{3}$ \\
\hline Ferrite-Zn & $\mathrm{ZnFe}_{2} \mathrm{O}_{4}$ \\
\hline Fluorapatite & $\mathrm{Ca}_{5}\left(\mathrm{PO}_{4}\right)_{3} \mathrm{~F}$ \\
\hline Goethite & FeOOH \\
\hline K-feldspar & $\mathrm{KAlSi}_{3} \mathrm{O}_{8}$ \\
\hline Mesolite & $\mathrm{Na}_{2} \mathrm{Ca}_{2} \mathrm{Al}_{6} \mathrm{Si}_{9} \mathrm{O}_{30.8} \mathrm{H}_{2} \mathrm{O}$ \\
\hline Smectite-dia (clay) & $\mathrm{Ca}_{0.165} \mathrm{Fe}_{2} \mathrm{Al}_{0.33} \mathrm{Si}_{3.67} \mathrm{O}_{10}(\mathrm{OH})_{2}$ \\
\hline Pseudowollastonite & $\mathrm{CaSiO}_{3}$ \\
\hline Pyrolusite & $\mathrm{MnO}_{2}$ \\
\hline Smectite-tria ${ }^{\text {(clay) }}$ & $\mathrm{Ca}_{0.165} \mathrm{Mg}_{3} \mathrm{Al}_{0.33} \mathrm{Si}_{3.67} \mathrm{O}_{10}(\mathrm{OH})_{2}$ \\
\hline Stilbite & $\mathrm{NaCa}_{2} \mathrm{Al}_{5} \mathrm{Si}_{13} \mathrm{O}_{36.14} \mathrm{H}_{2} \mathrm{O}$ \\
\hline Tenorite & $\mathrm{CuO}$ \\
\hline Witherite & $\mathrm{BaCO}_{3}$ \\
\hline Zincite & $\mathrm{ZnO}$ \\
\hline
\end{tabular}

a Smectites are complex dioctahedral (smectite-di) and trioctahedral (smectite-tri) solid solution phases. Only one calcium end member composition is given.

release from the repository. The types of secondary phases present affect both the sorption and the inclusion in solid solution of the radionuclides in the repository. Some phases, such as zeolites, can exchange ions and serve to isolate radionuclides such as $\mathrm{Sr}$ and $\mathrm{Cs}$. The radionuclides also may partition in trace amounts into some types of secondary phases such as oxides and carbonates. Therefore, even what appear to be minor differences in mineralogy could have a significant effect on the escape of radionuclides from the repository. This topic is being investigated in other YMSCP activities.

\section{Conclusions}

Simulations of reactions between groundwater, tuff, and rock deposit suggest that potentially significant chemical interactions are possible between the rock deposit and the other repository materials. Two major effects have been identified:
(1) The groundwater $\mathrm{pH}$ increases because of hydrolysis of the metals contained in the rock deposit and oxidation of the reduced carbon in the rock deposit. (2) The rock deposit contributes several elements to the reacting rock-water-deposit system that change the types of secondary phases predicted to form. These phases have differing abilities to isolate radionuclides from the environment through sorption and inclusion as trace or minor amounts in solid solution. The ability of the system to contain radionuclides will therefore change because of the presence of the reacting rock deposit material. The changes in fluid chemistry because of rock deposit interaction also will affect the dissolution rates and corrosion behavior of other repository materials such as the spent fuel and glass waste forms.

Our ability to model the rock-water-deposit interaction accurately will be improved by addressing deficiencies in the database and the lack of some key modeling capabilities in the codes. The database lacks data on metastable 
sulfur and carbon compounds, which must be included and used in future modeling work. Recent improvements to the EQ 3/6 chemical code will provide for redox disequilibrium, which is almost certainly present and persistent for repository time scales. Present modeling work has assumed thermodynamic equilibrium. among all dissolved redox species during the reaction path. With these improvements, future modeling work, combined with experimental work, will be able to better constrain the potential impact of the rock deposit materials on repository behavior. 


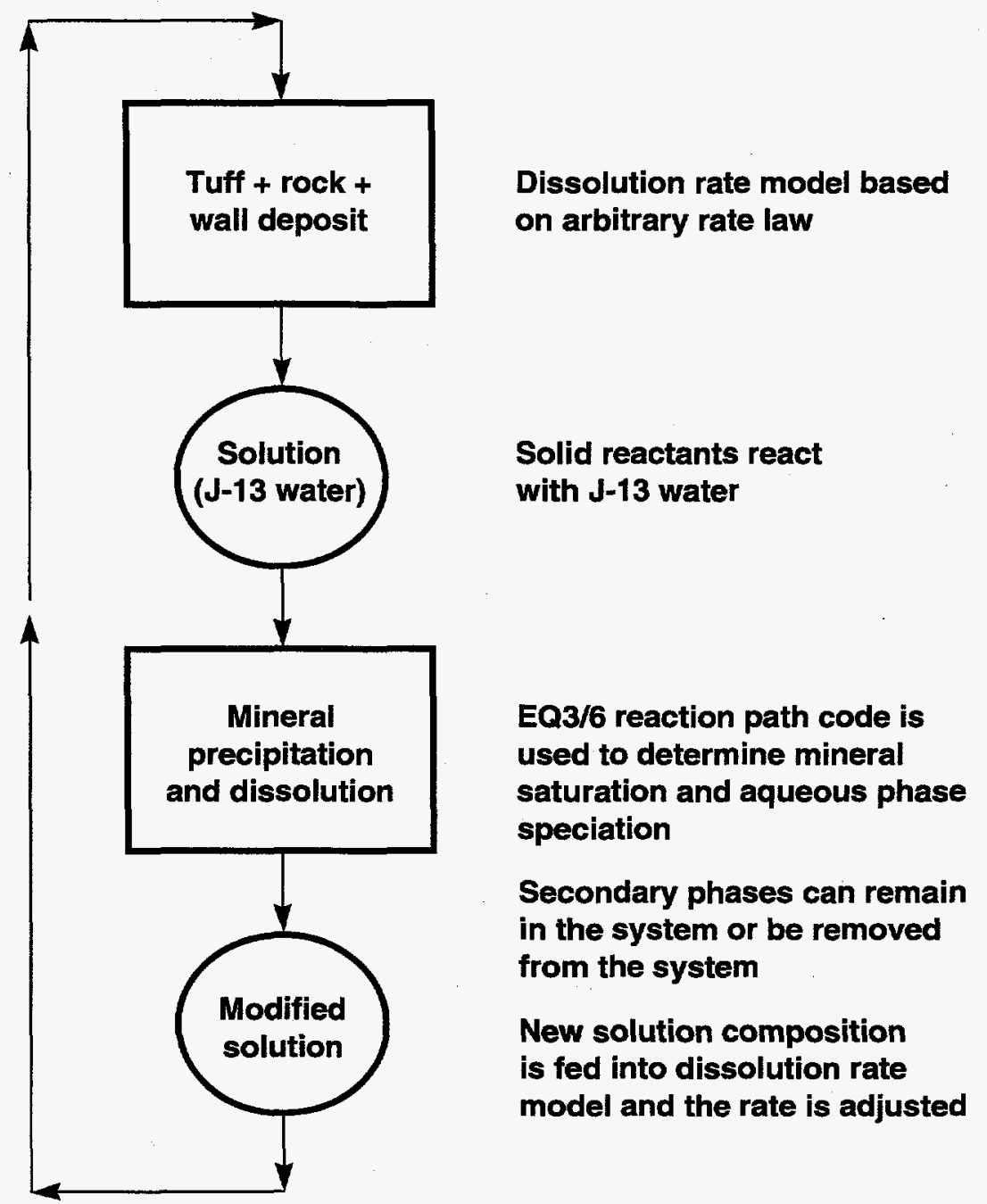

Figure 4.1. Use of EQ3/6 to simulate chemical reactions involving host rock, groundwater, and rock wall deposits. 

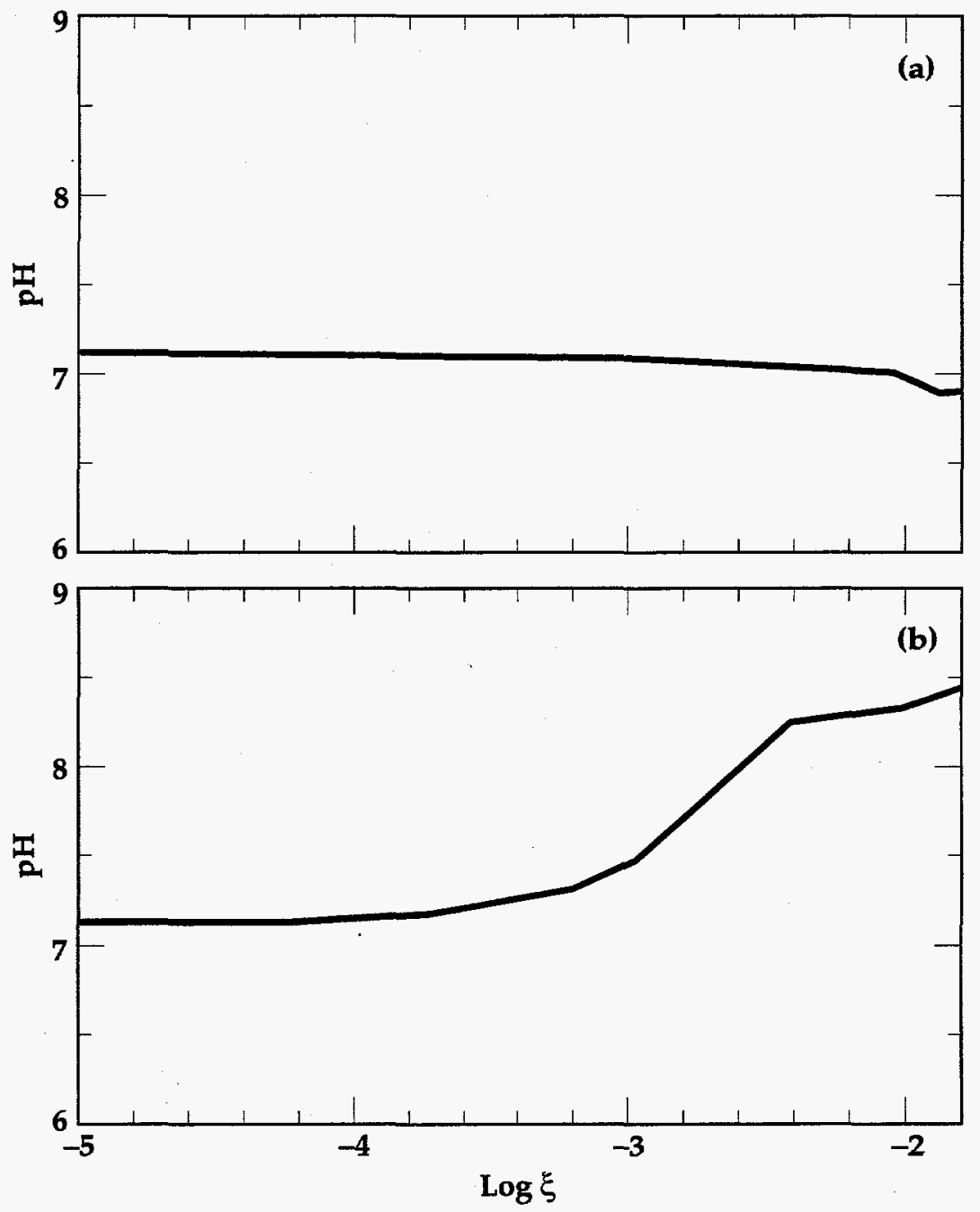

Figure 4.2. Predicted $\mathrm{pH}$ during reaction between (a) tuff $+\mathrm{J}-13$ water and (b) tuff $+\mathrm{J}-13$ water + rock deposit. 


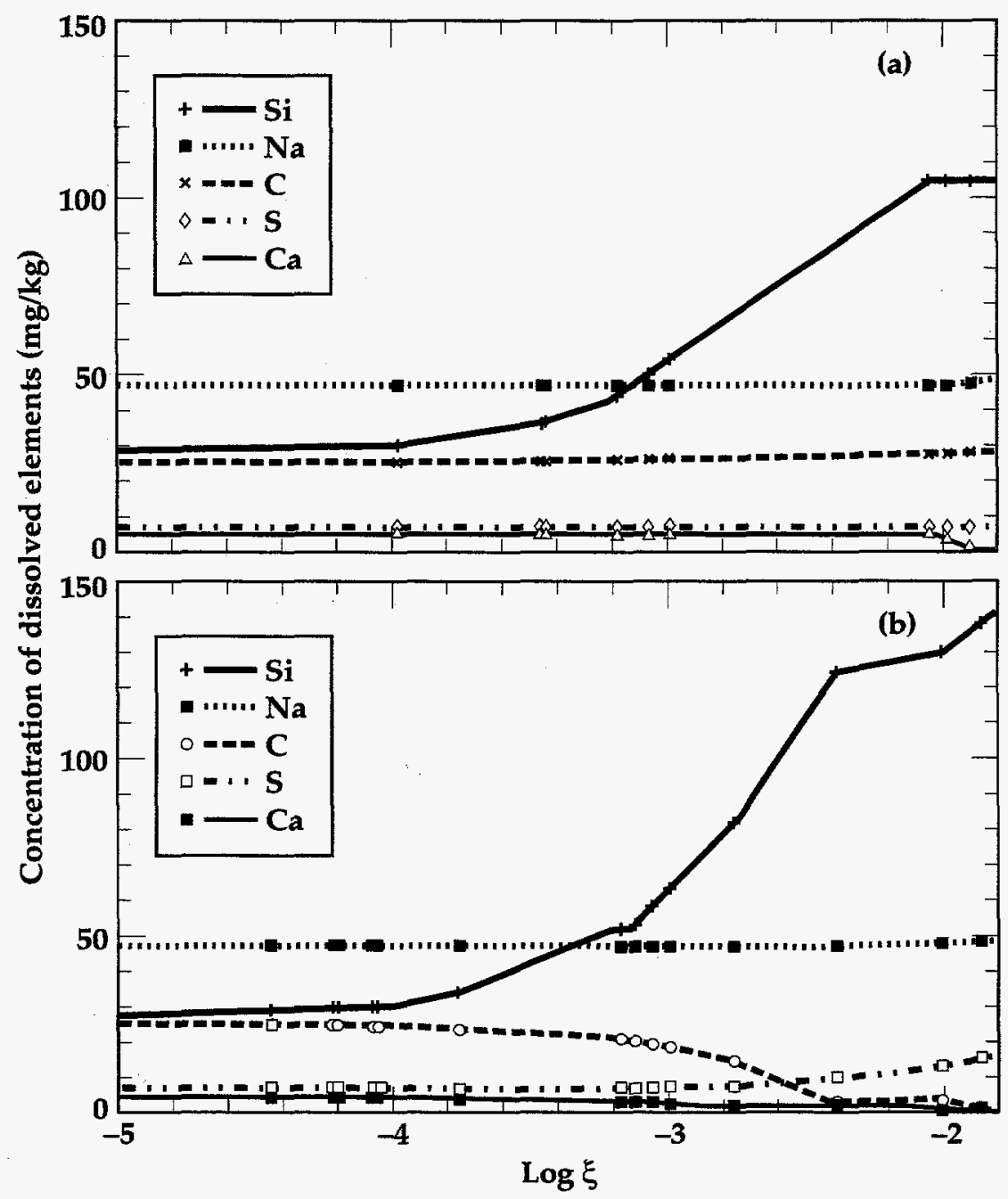

Figure 4.3. Predicted dissolved elemental concentrations during reaction between (a) tuff $+\mathrm{J}-13$ water and (b) tuff $+\mathrm{J}-13$ water + rock deposit. 


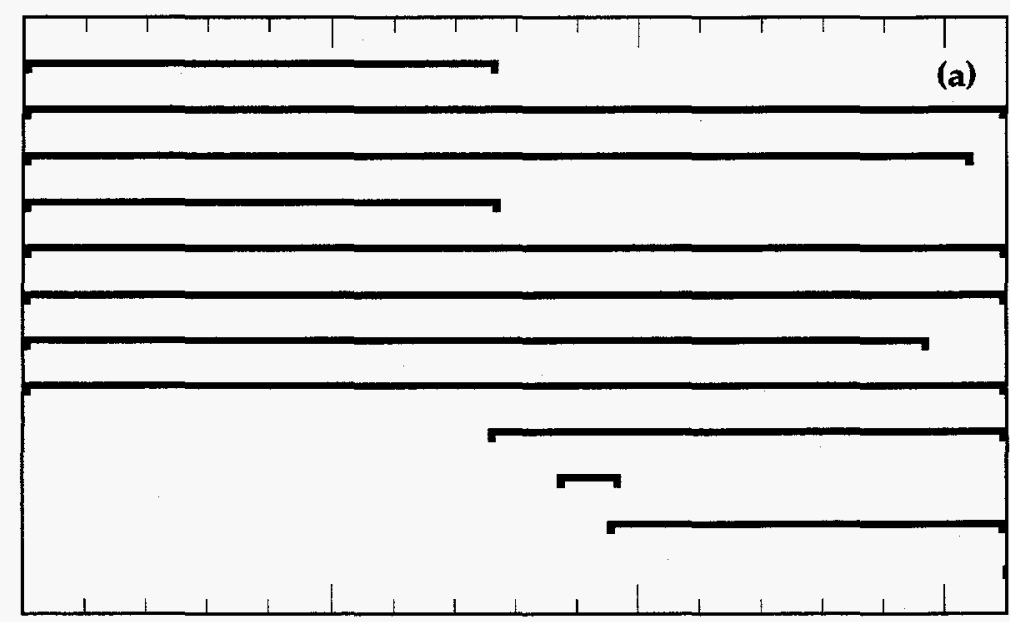

Antigorite

$\mathrm{CaZrO}_{3}$

Fluorapatite

Goethite

Pyrolusite

Tenorite

Carbonate-Ca

Saponite-tri

Smectite-di

Mesolite

Stilbite

K-Feldspar

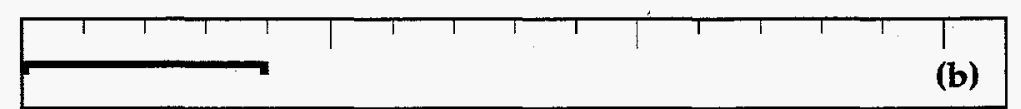

Antigorite

$\mathrm{CaZrO}_{3}$

Fluorapatite

Goethite

Pyrolusite

Tenorite

Carbonate-Ca

Saponite-tri

Witherite

Cerussite

Ferrite-Zn

Smectite-di

Mesolite

Stilbite

Alamosite

Zincite

Pseudowollast

K-Feldspar

Barite

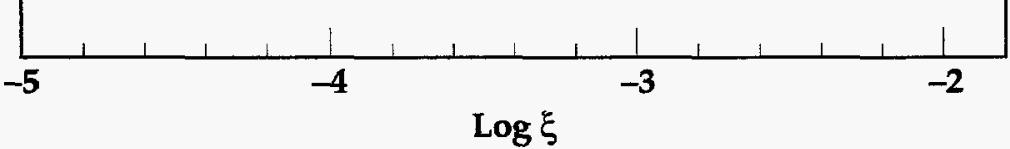

Figure 4.4. Predicted secondary mineral phases forming during (a) reaction between tuff $+\mathrm{J}-13$ water and (b) tuff $+\mathrm{J}-13$ water + rock deposit. 


\title{
5. Effects of Diesel Exhaust on the Microbiota in a Tuffaceous Tunnel System
}

\author{
D. L. Haldeman, T. Lagadinos, L. Hersman, and P. S. Amy
}

The purpose of this investigation was to better understand the effect of diesel exhaust on subsurface microbiota because diesel-powered engines may be used during the construction of the Exploratory Studies Facility (ESF). Many components of diesel combustion, such as short-chain acids, sulfates, and nitrates (Air Pollution Manual 1972) and diesel fuel itself, can be used by microbes as carbon and energy sources (Atlas and Bartha 1992). Thus, the activity of autochthonous subsurface microbes (or allochthonous microbiota) will probably be altered by the introduction of these compounds, and geochemical parameters of the environment may be affected.

Microbiota were sampled from the surface of a tunnel wall in an area impinged on by diesel exhaust, and cores were obtained from the tunnel invert in the same area. The tunnel invert material served as an environment that had been heavily perturbed, by anthropogenic activity since tunnel construction and by periodic water flux. Fluorescently labeled latex microspheres were used to determine the potential for contamination during the sampling of the tunnel walls. Numbers of culturable, aerobic, heterotrophic, diesel-degrading, citrate-utilizing, sulfate-reducing, and denitrifying bacteria were enumerated at all sample locations to determine the abundance of microorganisms capable of using diesel fuel and its combustion products. Diversity, evenness, total cell numbers, and abundances of particular microbial types were determined from samples taken at various depths into the tunnel walls and into the invert to discern possible trends in microbial distribution. To determine the potential for diesel degradation, we incubated microcosms containing sample materials with diesel fuel and determined the disappearance of total petroleum hydrocarbons (TPHs) for each sample. Data obtained from previous research in less impacted areas within the tunnel systems of Rainier Mesa were used to gain insight into probable influences of anthropogenic activity on indigenous microbial communities, and areas needing further investigation were identified.

\section{Sampling and Sample Locations}

Samples were taken from the left rib of tunnel U12n, $\sim 500 \mathrm{~m}$ from the portal. The ambient air temperature was $\sim 13^{\circ} \mathrm{C}$. Samples were taken from the wall at the height of exhaust pipes of dieselburning locomotives and at a location where the trains were often left idling. Black deposits could be seen on the tunnel wall in this area. Approximately $100 \mathrm{~g}$ of rock was taken from wall surfaces $(\sim 10 \times 10 \mathrm{~cm}$ in area). Triplicate samples were taken from the exposed surface of the wall and at depths of $\sim 1$ and $3 \mathrm{~cm}$ (bar code SPCOO503826; Fig. 5.1a). The samples were collected by aseptically chipping rock into sterile containers as previously described (Amy et al. 1992; Haldeman and Amy 1993a; Haldeman et al. 1993). Samples were rapidly transported in coolers containing ice to minimize storage-related effects (Haldeman et al. 1995), and microbiological analysis was begun immediately upon return to the laboratory (less than $6 \mathrm{hr}$ from the time of sample procurement).

Three surfaces of the tunnel wall, $\sim 10 \times$ $10 \mathrm{~cm}$, were painted with one each of three kinds of labeled 1.0- $\mu \mathrm{m}$ latex microspheres (Fluorsebrite carboxy yellow/green, Polyscience; blue and yellow/green colored, polystyrene latex surface free, IDC, Portland OR). Microbead rock faces were located $\sim 1 \mathrm{~m}$ from the microbiological samples, in the same tunnel bed, and samples were taken at the same depths and in the same manner as described above to determine the potential for contamination during sampling (bar code SPCOO503827).

Three floor samples were taken by pounding sterile $15-\mathrm{cm}$ core barrels $(6 \mathrm{~cm}$ diam) into the tunnel invert about $500 \mathrm{~m}$ from the tunnel portal (bar code SPCOO503825). Cores were wrapped in sterile foil and transported to the laboratory as described above. The core material was extruded at the laboratory after first aseptically removing the top $2 \mathrm{~cm}$ of material. The unconsolidated material from the top $(3-5 \mathrm{~cm})$, middle $(6-9 \mathrm{~cm})$ and bottom (11-14 cm) was used for microbiological analysis (Fig. 5.1b). 


\section{Sample Analysis}

Rock and invert material were aseptically ground in sterile mortars and pestles, transferred to sterile containers, and homogenized. Then subportions were taken to determine gravimetric dry weight, total organic carbon (TOC), TPH degradation, and direct bacterial count and to enumerate specific bacterial types (culturable aerobic heterotrophic, sulfate-reducing, and nitrate-reducing bacteria and the numbers of bacteria capable of using acetate or diesel as a sole carbon source).

TOC was determined by Galbraith Laboratories, Inc. (P.O. Box 51610, Knoxville, TN 37950). Total carbon was determined with a Leco induction furnace. Carbonate carbon was determined by titration of $\mathrm{CO}_{2}$ from an acid digest of the sample, and TOC was determined by subtracting the carbonate carbon from total carbon.

Microcosms used to determine TPH degradation were prepared with $5 \mathrm{~g}$ of homogenized rock and $50 \mu \mathrm{L}$ of diesel fuel in sealed serum vials. Acetone was used to stop the reactions after 30 days of incubation at room temperature $\left(\sim 24^{\circ} \mathrm{C}\right)$ and to extract the diesel fuel. Replicate samples were sacrificed at time zero to determine extraction efficiencies. Portions of the diesel fuel/acetone mixture $(0.5 \mathrm{~mL})$ were removed and extracted in 100-mL deionized water to separate diesel fuel and acetone. The remaining diesel fuel was extracted into 1-mL hexane (Sigma). Samples were injected into a Hewlett-Packard 5890 gas chromatograph Ipolydimethyl diphenyl (5\%) siloxanes column (Alltech, RSL-200) with initial and final temperature of $50^{\circ} \mathrm{C}$ and $260^{\circ} \mathrm{C}$, respectively, and a ramp rate of $15^{\circ} \mathrm{C} / \mathrm{min}$ for $25 \mathrm{~min}$ ]. TPHs were determined by integrating all peaks with retention times from 5 to $20 \mathrm{~min}$ and comparing the result with a standard curve.

Portions of rock were made into 1:10 wt/vol slurries with filter-sterilized $0.1 \%$ sodium pyrophosphate and were shaken for $1 \mathrm{hr}$ at $\sim 150 \mathrm{rpm}$. Subsamples of slurry were used to determine total counts, culturable aerobic heterotrophic counts, and most probable number (MPN) enumerations of specific microbial types (Alexander 1965).

For direct counts, portions of prepared slurries $(9 \mathrm{~mL})$ were fixed with $135 \mu \mathrm{L}$ of filter-sterilized formaldehyde and $1 \mathrm{~mL}$ of filter-sterilized noble agar. Smears were prepared by evenly distributing $5-\mu \mathrm{L}$ portions of fixed slurry into $1-\mathrm{cm}-$ diam circles drawn on clean glass slides, and were air-dried before staining. A $0.01 \%$ acridine orange solution containing $5 \mu \mathrm{g} / \mathrm{mL} \mathrm{4}$-6-diamidino-2-phenylindole (DAPI; Sigma) was flooded onto smears and allowed to stand for $2 \mathrm{~min}$. Smears were rinsed with approximately $20 \mathrm{~mL}$ of $1 \mathrm{M} \mathrm{NaCl}$ and deionized $\mathrm{H}_{2} \mathrm{O}$ (filter-sterilized solutions). A drop of oil was placed on smears after they were completely dry, and a cover slip was added for viewing at $1000 \times$ magnification under oil immersion. Twenty fields or 200 cells were counted from each smear with a Nikon. Optiphot epifluorescence microscope fitted with a Nikon Fluor 100 lens, a 100-W mercury bulb, and UV-B and UV-1A filter blocks.

To determine numbers of culturable heterotrophs, we made serial dilutions of unfixed slurry in deionized $\mathrm{H}_{2} \mathrm{O}$ and spread them onto R2A agar plates (Difco; Amy et al. 1992). Shannon diversity and evenness indices (Atlas and Bartha 1992) were determined from $R 2 A$ spread plates as previously described (Haldeman and Amy 1993b; Haldeman et al. 1993). One of each colony morphotype was selected for purification from wall samples, and all colony types were compared to determine whether certain bacterial types were recovered from more than one replicate or rock face. Comparison of colonies by morphotype is a reliable method for selecting bacteria from subsurface tunnel samples that were related at less than the genus level (Haldeman and Amy 1993b).

MPNs of diesel-degrading, sulfate-reducing (SRB), and nitrate-reducing (NRB) bacteria were determined by using $1000-, 100-$, and $10-\mu \mathrm{L}$ portions of slurries to inoculate sets of 5-tube MPN media. Diesel degradation MPN tubes contained $50-\mu \mathrm{L}$ of diesel added to $5 \mathrm{~mL}$ of Bushnell Haus broth (Difco) containing $1 \mathrm{mg} / \mathrm{L}$ filter-sterilized resazurin (Song and Bartha 1990). Tubes were considered positive if they turned pink or clear with respect to purple controls (Song and Bartha 1990). Tubes containing SRB medium (Atlas 1993) were scored as positive if they were black with respect to uninoculated controls. Nitrate-reducing bacteria were determined in $\mathrm{R} 2 \mathrm{~B}$ broth containing $0.1 \% \mathrm{KNO}_{3}$ as previously described (Haldeman and Amy 1993a). Then 10 $\mu \mathrm{L}$ of slurry and 1:10 serial dilutions in deionized $\mathrm{H}_{2} \mathrm{O}$ were struck onto slants (five tubes of each dilution) of Simmon's citrate agar (Difco), so we could determine the MPN of bacteria capable of using citrate as a sole carbon source. A color change from green to blue indicated a positive reaction. All MPN tests were incubated for 30 days at room temperature $\left(\sim 24^{\circ} \mathrm{C}\right)$ before reading. All incubations were 
conducted under aerobic conditions, except SRB tubes, which were incubated in a reducing atmosphere $\left(3 \% \mathrm{H}_{2}, 5 \% \mathrm{CO}_{2}\right.$, and $\left.92 \% \mathrm{~N}_{2}\right)$.

Samples containing microspheres were a septically ground, homogenized, and made into 1:10 wt/vol slurries with filter-sterilized deionized water. Five-microliter portions of slurries were evenly distributed into circles drawn on clean slides. The slides were air dried and were then viewed and counted as described above for direct counting.

A second purpose of the microbiological sampling in Rainier Mesa was to evaluate the sampling procedure and tracer analysis for possible future use in the microbial studies of the ESF. As a result of these prototype tests, we are confident that the sampling procedures and tracers analysis described in this report can be applied to the ESF studies. A detailed procedure (LANL-LS2-DP405) is therefore being written to describe the sampling procedure and tracer analysis.

\section{Results}

Enumerations of latex microspheres at the three sample depths (Fig. 5.2) indicated that introduction of 1-um particles into the tunnel wall by sampling procedures was unlikely. All three types of spheres demonstrated a strong decrease in abundance after the surface sampling face. Statistically significant differences were determined between the 1- and 3-cm faces as well.

Figure 5.3 shows direct counts and the numbers of culturable aerobic heterotrophic bacteria recovered from wall and invert samples. Greater numbers of total and culturable cells were evident in the core samples ( $25.8 \%$ moisture) than in the wall samples ( $4.9 \%$ moisture). Numbers of culturable microorganisms (aerobic heterotrophs) increased with depth into the tunnel wall (Fig. 5.3a) and decreased with depth into the invert (Fig. 5.3b). In the invert, the error associated with direct counting was high, probably in part because of the autofluorescing nature of the rock samples, which precluded the observation of trends in total cell counts at sampling depths (Fig. 5.3c). However, a decrease in total cell number was seen between the surface wall sample and the two subsequent sampling faces (Fig. 5.3c).

The percentage of TOC was significantly higher in the invert samples than in the wall samples (Fig. 5.4). Interestingly, TOC decreased into both the tunnel floor and the wall. Culturable microbial abundance correlated positively with TOC $\left(r^{2}=0.71\right)$ in the core and negatively $\left(r^{2}=0.79\right)$ in the wall samples with depth. Unfortunately, because of the limited scope, we could not take more samples to check the significance of this correlation. It is important to note that black deposits were observed on the face of the tunnel wall but not on subsequent rock faces. Although the composition of the black deposits was not determined, if the deposits were elemental carbon (soot), they would be reflected in the percent TOC by the assay used.

Differences in diversity and evenness could not be demonstrated between invert and wall samples, except for the surface wall face, which had a lower diversity (2.51) than that in the shallowest core samples (3.51). Trends in distribution into the tunnel wall or invert were not discerned in either invert or wall samples based on diversity and evenness indices (data not shown). However, analysis of one of each individual colony morphotype from wall samples demonstrated that, although the numbers and patterns of distribution of distinct colony types in samples may have been similar, the specific colony types recovered were often quite different from each other, even among replicates of a single sample face or depth (Table 5.1). Only 8\%, 15\%, and 5\% of colony types recovered from the three replicate samples taken within a single wall face were found in more than one replicate. The number of actinomycete colony types that were recovered from the wall samples ranged from 15 to 25 , and fungi were recovered only from the first two rock faces. The numbers of polymer-forming bacterial colonies did not show a trend into the tunnel wall (four, three, and four types from the surface, 1-, and $3-\mathrm{cm}$ faces, respectively), but each polymerforming morphotype differed from others in

Table 5.1. Number of bacterial types that were common within a set of replicates.

\begin{tabular}{lccc}
\hline & \multicolumn{3}{c}{ Sample faces } \\
\cline { 2 - 4 } & Surface & $\sim 1 \mathrm{~cm}$ & $\sim 3 \mathrm{~cm}$ \\
\hline Ratio of bacterial types $^{a}$ & $4 / 47$ & $9 / 59$ & $2 / 41$ \\
Percentage $^{b}$ & 8 & 15 & 5 \\
\hline
\end{tabular}

a Number of bacterial types found in more than one replicate/total number of bacterial types in the three replicates.

b Percentage of bacterial types found in more than one replicate. 
some aspect, i.e., relative polymer production and/or colony color, size, or shape. In the wall samples, most colony types were recovered from only a single rock face (Table 5.2). Most of the isolates that were recovered from multiple rock faces were from the 1- and 3-cm faces.

Table 5.3 gives MPN enumerations of SRB, $\mathrm{NRB}$, and diesel-degrading and citrate-utilizing bacteria. Most types of bacteria were more abundant in invert samples than in wall samples. A decreasing trend in distribution in citrate-utilizing bacteria with depth was noted in the invert samples; other MPN tests showed no trend. In the wall samples, the second face had higher numbers of citrate-utilizing bacteria and fewer bacteria capable of reducing $\mathrm{NO}_{3}{ }^{-}$to $\mathrm{NO}_{2}{ }^{-}$.

MPN enumeration demonstrated that more bacteria capable of degrading diesel fuel were present in the invert samples than in wall samples (Table 5.3). No statistically significant trends in distribution were noted into the invert or into the tunnel walls. However, the existence of a trend in the invert cannot be ruled out because all samples exceeded the upper detection limit of the test. Microcosms, used to measure the disappearance of diesel, did not demonstrate a decrease in diesel fuel with respect to fixed controls after 30 days of incubation. It is important to note that in the microcosms, only diesel fuel was added, while the MPN tests for diesel-degrading bacteria contained a medium of mineral salts containing nitrogen and phosphate.
Table 5.2. Distribution of microbial types recovered from multiple rock faces.

\begin{tabular}{lcccr}
\hline & $\begin{array}{c}\text { Surface } \\
\text { and 1-cm } \\
\text { faces }\end{array}$ & $\begin{array}{c}\text { 1- and } \\
\text { 3-cm } \\
\text { faces }\end{array}$ & $\begin{array}{c}\text { 2- and } \\
\text { 3-cm } \\
\text { faces }\end{array}$ & faces \\
\hline $\begin{array}{l}\text { Number of similar } \\
\text { bacterial types }\end{array}$ & 3 & 2 & 11 & 2 \\
$\begin{array}{l}\text { Number of unique } \\
\text { bacterial types }\end{array}$ & 104 & 87 & 90 & 131 \\
\hline
\end{tabular}

\section{Discussion}

The use of microspheres provides a means to determine the effect of sampling procedures on the procurement of representative subsurface material for microbiological analyses. The use of tracers, such as microspheres, provides a control for sample integrity (Colwell et al. 1992; Russell et al. 1992). We successfully applied microspheres as tracers to sampling within the tunnel systems. The results demonstrate that transport of 1- $\mu \mathrm{m}$ sized microspheres is greatly reduced after removing just $1 \mathrm{~cm}$ of surface rock (Fig. 5.2); thus, the probability of introducing exogenous microbes during sampling at greater depths is small.

In previous microbiological research in which samples were obtained at depths into the tunnel walls exceeding $5 \mathrm{~cm}$, fungi served as an indicator of microbial contamination during sampling.

Table 5.3. Average most probable number enumerations of specific bacterial types.

\begin{tabular}{|c|c|c|c|c|c|}
\hline $\begin{array}{c}\text { Sample } \\
\text { designations } \\
\text { (depth in } \mathrm{cm} \text { ) }\end{array}$ & $\begin{array}{c}\mathrm{SO}_{4} \text {-reducing } \\
\text { bacteria }\end{array}$ & $\begin{array}{c}\mathrm{NO}_{3} \text {-reducing } \\
\text { bacteria } \\
\left(\mathrm{NO}_{3} \rightarrow \mathrm{NO}_{2}\right)\end{array}$ & $\begin{array}{c}\mathrm{NO}_{3} \text {-reducing } \\
\text { bacteria } \\
\left(\mathrm{NO}_{3} \rightarrow \mathrm{NO}_{2}\right) \\
\end{array}$ & $\begin{array}{c}\text { Diesel- } \\
\text { degrading } \\
\text { bacteria }\end{array}$ & $\begin{array}{c}\text { Citrate- } \\
\text { utilizing } \\
\text { bacteria }\end{array}$ \\
\hline Invert $(3-5 \mathrm{~cm})$ & 13.50 & 25.33 & 360.00 & $>1600$ & $10,067.00$ \\
\hline Invert $(6-9 \mathrm{~cm})$ & 15.33 & 2.40 & 793.33 & $>1600$ & 3733.33 \\
\hline Invert $(11-14 \mathrm{~cm})$ & 12.25 & $1.80^{\mathrm{a}}$ & $1210^{b}$ & $>1600$ & 1800.00 \\
\hline Wall (surface) & BLD $^{\mathrm{c}}$ & 87.00 & BLD & 19.67 & BLD \\
\hline Wall $(\sim 1 \mathrm{~cm})$ & BLD & 23.33 & $1.80^{b}$ & 20.67 & $450.00^{b}$ \\
\hline Wall $(\sim 3 \mathrm{~cm})$ & BLD & 85.33 & $5.75^{c}$ & 29.60 & $200.00^{d}$ \\
\hline
\end{tabular}

a Two of the three replicates had numbers below the limit of detection.

b Two of the three replicates had numbers greater than the detection limit (>1600). A conservative average was estimated using 1600 for the values of those replicates.

c BLD designates numbers below the limit of detection ( $<1.8$ cells/g wt).

d One of three replicates had numbers below the limit of detection. 
The fungi recovered here, in low abundance on the surface and at $1 \mathrm{~cm}$ into the tunnel wall, were not recovered in samples taken at $3 \mathrm{~cm}$ into the wall rock, which augmented assurance of uncompromised samples by acting as a fortuitous tracer.

Direct counts, although difficult to obtain in the autofluorescing tuffs of Rainier Mesa, were consistently higher than culturable aerobic heterotrophic bacterial counts and MPN estimates of microbial abundance. The discrepancy between culturable and direct counts (Fig. 5.3) is due to nonculturable cells being either dead, dormant, or viable but nonculturable (VBNC). It would not be surprising to find large numbers of dead or dormant cells in wall samples, because zeolitized tuffs experience little or no nutrient flux in unfractured areas (Amy et al. 1992; Haldeman and Amy 1993a). A comparison of phospholipid fatty acid and diglyceride fatty acid contents with acridine orange direct counting of subsurface samples of zeolitized rock from Rainier Mesa, has indicated that this may be the case. However, VBNC cells are also common in natural environments (Rozak and Colwell 1987), and we believe that their presence cannot be ruled out in the subsurface of Rainier Mesa. More investigation is needed to determine abundance, distribution, and in situ functions of nonculturable cell populations and the potential for activity if growth requirements were met. Anthropogenic activity associated with repository construction may provide the necessary environmental conditions and may stimulate dormant microbial populations.

Higher total cell counts were obtained in the cored invert material than in the wall samples (Fig. 5.3). The invert samples were unconsolidated and of higher moisture and total organic content, and they had been periodically perturbed by anthropogenic activities since tunnel construction. All of these factors may have influenced the invert environment in such a way that it supported greater bacterial numbers. Geological and microbiological parameters that have been correlative in the deep subsurface include higher moisture, permeability, and organic carbon content with increased bacterial numbers (Fredrickson et al. 1989; Kieft et al. 1993; Severson et al. 1991), although these correlations have not been demonstrated in the analysis of tuffaceous rock from Rainier Mesa (Russell et al. 1994). Perturbations have been shown to increase microbial abundance and activity in surface and subsurface environments (Brockman et al. 1992; Craswell and Waring 1972; Rovira and Greacen 1957), including samples from Rainier Mesa (Haldeman et al. 1994; Haldeman et al. 1995; Fredrickson et al. 1995). More information on how such factors affect in situ subsurface microbiota is needed.

TOC measurements demonstrate a decreasing trend into both the wall and the invert with depth from the tunnel surface. The TOC measurements demonstrate correlations with heterotrophic plate counts in the wall (negative) and core (positive) samples with depth. In the invert material, the abundance of active heterotrophic microbial communities may be influenced by organic carbon content, while dormant (or dead) microbes are more likely to be present in greater abundance in the wall rock (Amy et al. 1992, 1993; Haldeman and Amy 1993a; Haldeman et al. 1993). Microbial communities in the wall rock may no longer be active because the carbon there is minimal and may not be bioavailable - that is, the carbon may not be available for use by the microbiota. It is also important to note that elemental carbon may have been included in TOC analysis because it was not excluded from the total carbon determination. Blackened material was observed on the wall surface but not on faces created at depth into the tunnel wall. Further analysis is needed to determine whether this material was a major constituent of what was measured as TOC, because inert materials such as elemental carbon are not bioavailable and may explain the contradictory results. Organic hydrocarbon content is further discussed in Sec. 3.

Most measures of microbial communities (diversity, evenness, and-in most cases-direct counts) did not show distinct differences between samples. However, trends were noted in the abundance of culturable heterotrophic bacteria with depth into the tunnel wall and into the invert material, and heterogeneity was observed in the recovery of specific heterotrophic colony types. This was not surprising because heterogeneity has been noted on a larger scale in this and other subsurface environments (Balkwill et al. 1989; Brockman et al. 1992; Colwell 1989; Haldeman and Amy 1993a; Haldeman et al. 1993). The wall rock appeared more homogeneous in microbial composition after the immediate surface was removed, as evidenced by the increased number of colony types in common between the 1- and 3-cm rock faces. This may be due in part to the disparity in numbers of culturable organisms recovered from the $1-$ and $3-\mathrm{cm}$ faces and from the surface. MPN analyses, which enumerate functional groups of microorganisms, 
exhibited few trends in microbial distribution within the wall samples. More complete characterization of heterotrophic isolates may determine that they fulfill similar niches (besides heterotrophy), although they differ in appearance. It is important to stress that these are not in situ measures of microbial activity but reflect the organisms cultivated under enriching conditions. Microbial heterogeneity is an issue that must be addressed in future site characterization.

Although a decrease in the amount of diesel fuel added to the microcosm (see Sec. 3 for hydrocarbon analysis of unamended rock samples) was not demonstrated, diesel-degrading MPN media tested positive. Further experimentation will be needed to resolve these contradictory results. Characterization of isolates will be needed to determine whether the oxidative activity in the MPN tubes was exclusively a result of diesel degradation or whether it was due to nutrients provided in the inoculum, bacteria degrading each other, or gaseous compounds. The addition of a mineral salts medium to microcosms will also determine whether the lack of diesel degradation as measured by TPH was due to a limiting nutrient such as a phosphate or nitrogen source. No studies have been done within the tunnel systems to determine limiting nutrients. These experiments will be important in understanding the effects of perturbations on microbial communities.

Two types of bacteria present within the tunnel system included polymer-forming and sulfate-reducing bacteria, which are known to play roles in the corrosion of metals (Jones 1992; Stroes-Gascoyne 1989; West et al. 1985). Likewise, bacteria capable of degrading diesel fuel and diesel combustion products were present. The presence of these microbiota, whether introduced or naturally occurring, is important because the activity of one group of microorganisms may influence the activity of or select for another group, thus setting off a chain of complex events (Bachofen 1991; Rosevear 1991). Questions concerning the survival, activity, and interaction of subsurface microbes in the presence of each other and their subsurface environment must be considered in decisions regarding the emplacement of a nuclear repository.

\section{Summary and Future Directions}

Various types of microorganisms were recovered from the subsurface of Rainier Mesa, invert material, and tunnel walls in this study and others (Amy et al. 1992; Haldeman and Amy 1993a; Haldeman et al. 1993). As European researchers suggest, whether microorganisms are introduced or indigenous is not a necessary area of investigation because repository construction, especially backfilling procedures, will probably introduce a plethora of microbial types (Bachofen 1991; McCabe 1990; West et al. 1986). Instead, an important focus of research might include understanding general microbial ecology through studies such as the following:

- Determining the effects of perturbations on microbiota and gaining a better understanding of successional changes that will occur.

- Determining the effect of inputs such as moisture and carbon (for example, from diesel fuel exhaust) on survival and activity of microbiota.

- Identifying factors that limit the microbiota in situ.

- Determining what factors protect microbiota (e.g., polymer formation, dormant state).

- Determining the survival characteristics and mutation rates of microbiota exposed to high heat and radiation.

- Gaining a better understanding of dormant and nonculturable bacteria and their importance as a "seed bank" of microbial diversity.

- Determining the in situ role of microbiota in the biogeochemical cycling of elements and how they may alter geological or introduced structures.

- Determining the mobility of subsurface microbiota and their potential effects on the transport of metals. 
(a)

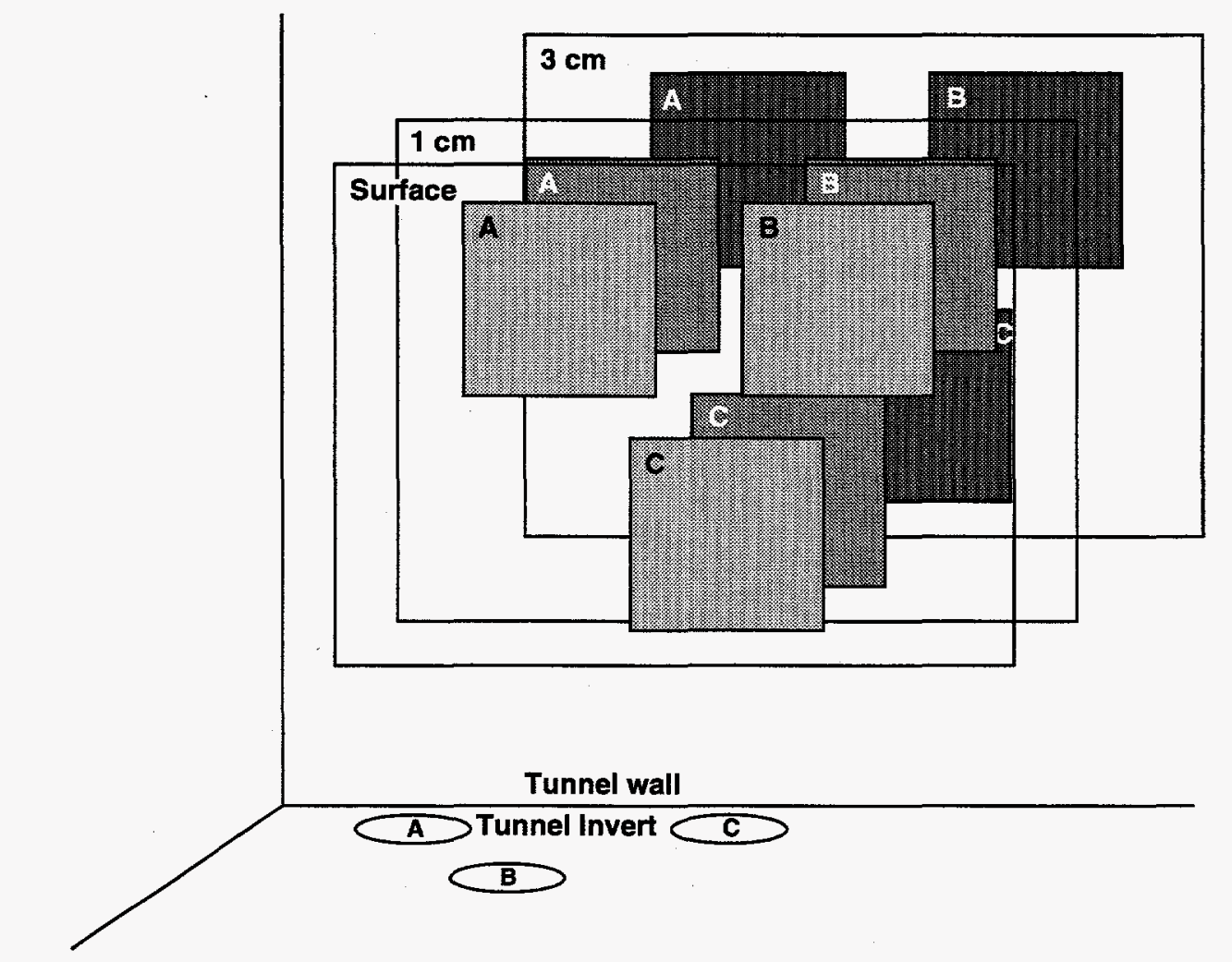

(b)

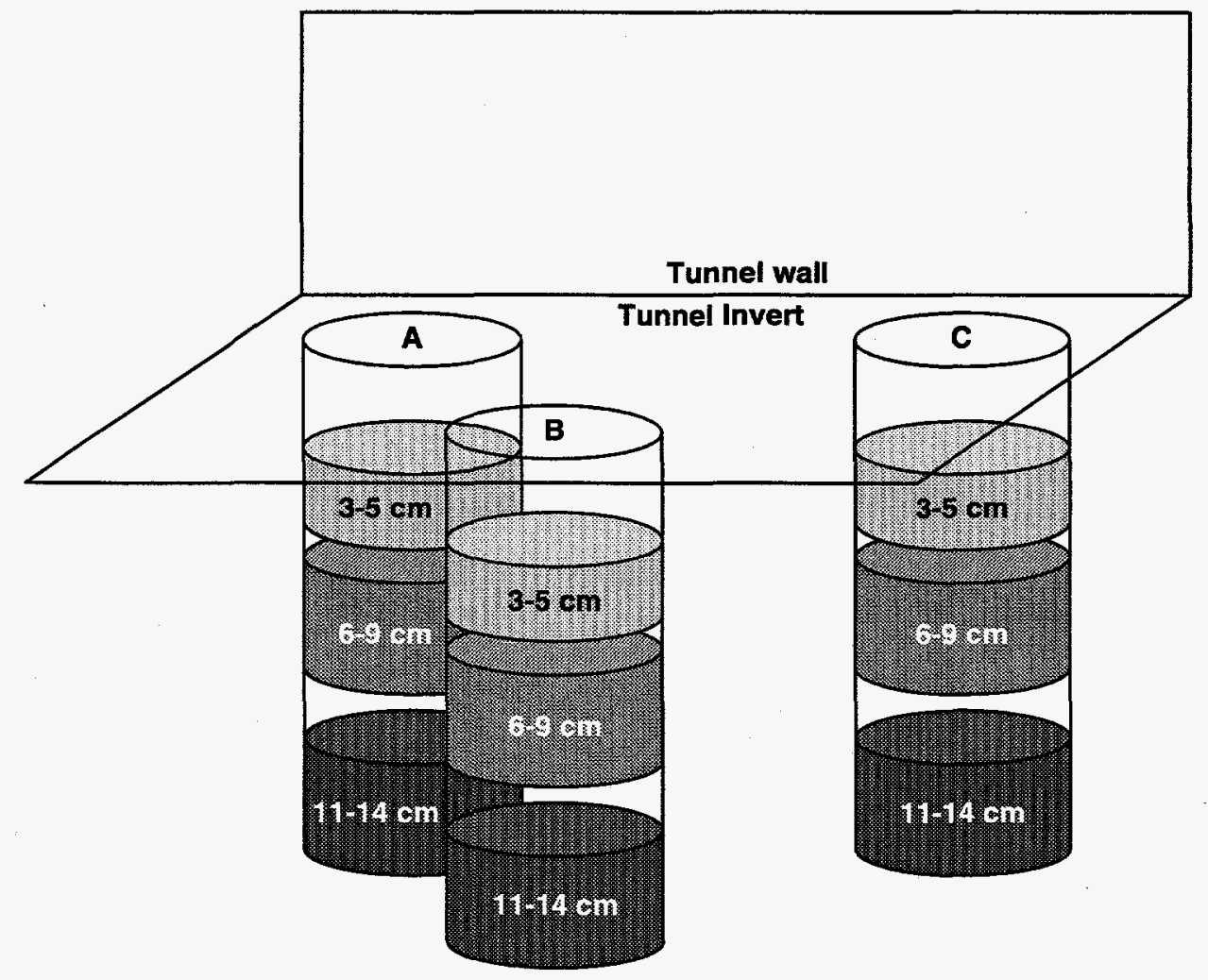

Figure 5.1. Locations of replicate samples. (a) Samples $A, B$, and $C$ taken from three rock faces (surface and at depths of 1 and $3 \mathrm{~cm}$ ) into the tunnel wall. (b) Replicate cores $A, B$, and $C$ taken from the tunnel floor. Subsections of the cores represent the three sampling depths $(3-5,6-9$, and 11-14 cm from the invert surface). 


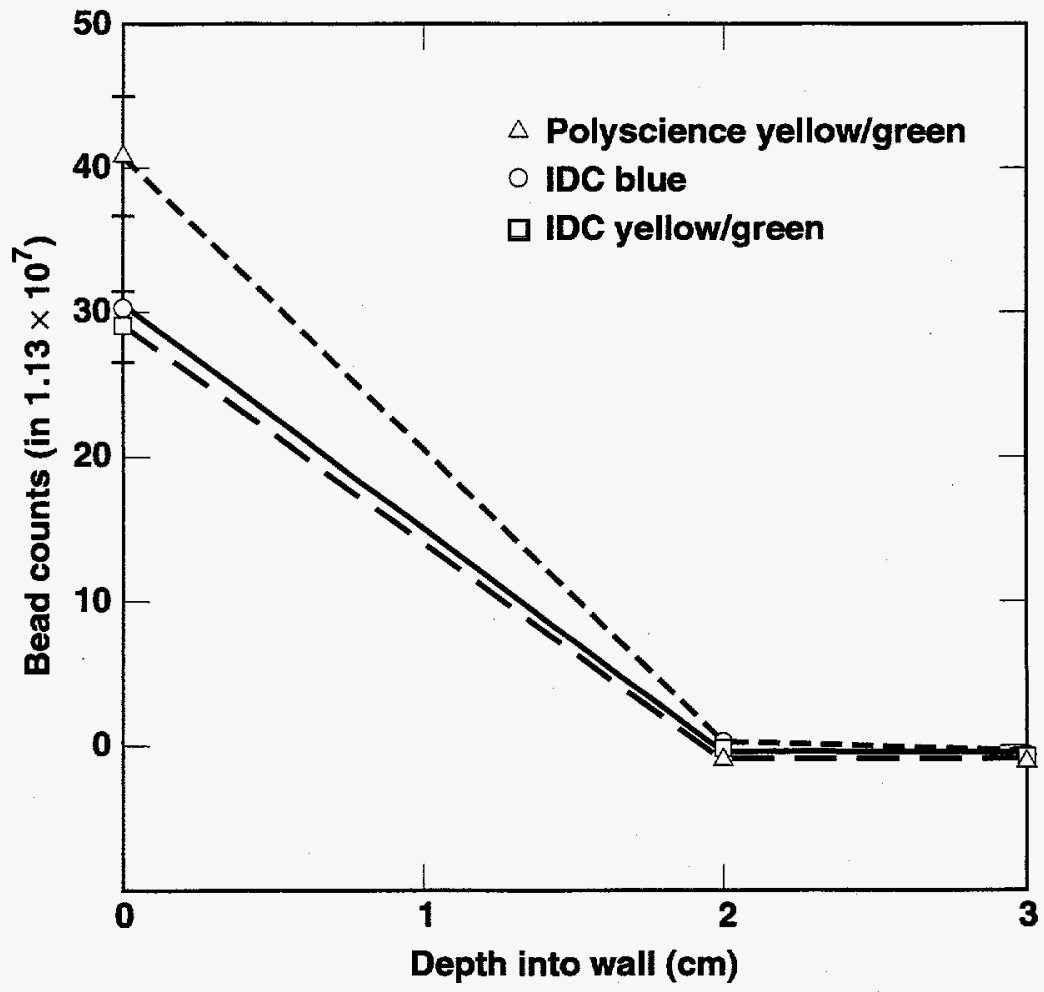

Figure 5.2. Distribution of latex spheres into the tunnel walls. 

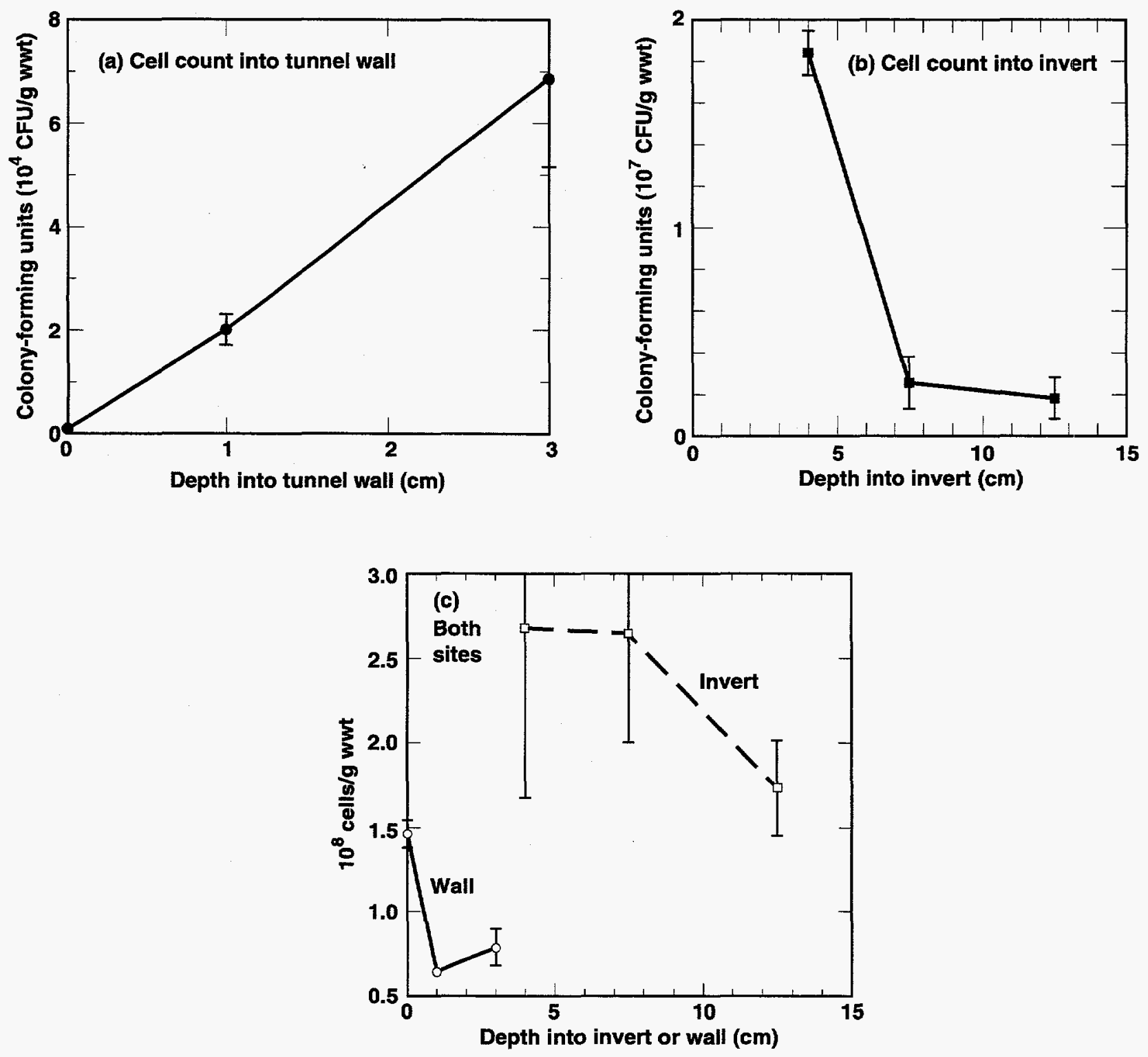

Figure 5.3. Culturable cell counts (a) into the tunnel walls and (b) into the invert. (c) Direct counts at both sites. 


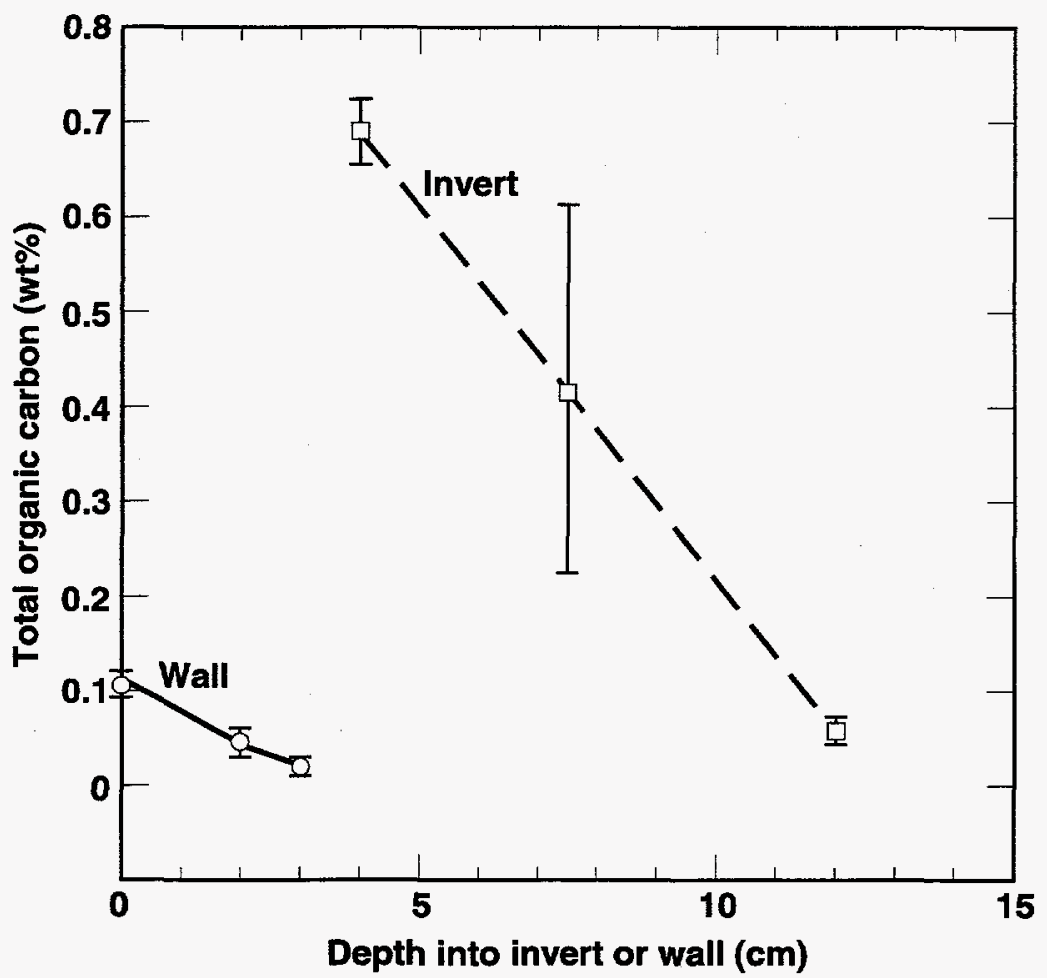

Figure 5.4. Percentage of total organic carbon found at sample depths into the tunnel walls or into the invert. 


\title{
6. Concluding Remarks
}

\author{
A. Meike
}

This study was conducted to determine a general framework for discussing the potential significance of diesel exhaust to the long-term chemistry of a subsurface environment. As the first historical analog study conducted by the Introduced Materials Task, it has demonstrated the possibly complex interaction of some of the factors of interest: (1) the many factors (e.g., engine load, engine wear, exhaust modification system, engine usage schedules) that determine the concentration, quantity, and dispersion of the diesel deposit; (2) some of the other materials (e.g., crushed or powdered rock, metal and PVC pipe, paint) that could be associated with the exhaust deposit in a tunnel setting; (3) two of the potential chemical processes (chemical and biochemical reactions) that could be affected by diesel exhaust.

Other potential chemical processes, such as sorption and colloid formation and the mutation of microbial species, were beyond the scope of this small investigation but will be investigated in the future. Sorption by exhaust deposits may be a significant issue because diesel particulates have high surface areas $\left(\sim 100 \mathrm{~m}^{2} / \mathrm{g}\right)$ and large isosteric heats of adsorption ( $>15 \mathrm{kcal} / \mathrm{mole}$ ) (see, e.g., Herr et al. 1982). Thus, diesel particulates can act as preferred sites for the condensation or sorption of other partially combusted reaction products, such as polynuclear aromatic compounds (PACs) (Herr et al. 1982). PACs have been shown by Herr et al. (1982) to be products of diffusion-controlled combustion of any hydrocarbon fuel, and not simply fuel components that have passed unaltered through the combustion zone, which must be considered in addition to diesel fuel components. Because of the sorption capacity, the formation of colloidal material from this particulate matter will be investigated by the Introduced Materials Task.

The soluble organic fraction (SOF), which was obtained by the dichloromethane Soxhlet extraction of diesel particulate matter, is known to exhibit direct microbial mutagenic activity. The presence of direct-acting mutagens appears to be unique to diesel particulates among particulates collected from combustion sources generally
(Santodonato et al. 1978; Pederson and Siak 1981a,b; King et al. 1981; Dukovich et al. 1981). In the presence of water vapor, nitrogen dioxide can modify PACs to produce these direct-acting mutagens. The source of the nitrogen appears to be the oxidant for the combustion reaction (Herr et al. 1982). The mutagen studies were conducted with an interest in potential human health hazards. From the perspective of the Introduced Materials Task, the formation of mutagens potentially increases the numbers of species that may reside in the repository environment.

The preliminary findings from this study indicate no immediately obvious source of significant chemical modification to subterranean water chemistry. The effects of trace amounts of heavy metals and sulfur are not known at present. The single marked modification that we have simulated is a change in $\mathrm{pH}$, and it represents an extreme bounding condition that reflects the set of assumptions used for the exercise. We expect the carbon particulate matter to be far less chemically reactive than is indicated by that bounding calculation. A more complete analysis would include further simulations to provide further bounds for potential chemical modifications. However, as discussed above, all possible avenues of potential chemical modification have not been pursued in this study. One of these avenues, sorption and formation of colloids, may be particularly important for retardation or transport of radionuclides.

The study establishes that further information. is required and indicates the directions in which further work is needed. We strongly suggest that if diesel is to be considered at all for the main body of the repository, it should be used in the initial portions of the ESF so as to conduct tests in a more controlled testing environment that more clearly represents aspects of a repository environment (e.g., use of the appropriate diesel fuel, and adherence to modern exhaust emission standards and ventilation conditions). In addition, experiments should be conducted at elevated temperatures on the soot and rock to characterize and identify thermal breakdown products in order to determine potential influences on water chemistry and transport properties. 


\section{References}

Alcock, K. (1977), "Safe Use of Diesel Equipment in Coal Mines," Mining Congress Journal, 53-62.

American Industrial Hygiene Association (1972), Air Pollution Manual. Part 1. Evaluation, 2nd ed.

Amy, P. S., D. L. Haldeman, D. Ringelberg, D. H. Hall, and C. Russell (1992), "Comparison of Identification Systems for Classification of Bacteria Isolated from Water and Endolithic Habitats within the Deep Subsurface," Appl. Environ. Microbiol. 58, 3367-3373.

Bachofen, R. (1991), "Microorganisms in Nuclear Water Disposal," Experentia 47, 583-584.

Baumgard, K. J. and K. L. Bickel (1987), "Development and Effectiveness of Ceramic Diesel Particle Filters," U.S. Bureau of Mines Information Circular 9141, pp. 94-102.

Birch, L. D., and R. Bachofen (1990), "Effects of Microorganisms on the Environmental Mobility of Radionuclides," Soil Biochemistry 6, 483-527.

Brockman, F. J., T. L. Kieft, J. K. Fredrickson, B. N. Bjornstad, S. W. Li, W. Spangenburg, and P. E. Long (1992), "Microbiology of Vadose Zone Paleosols in South-Central Washington State," Microb. Ecol. 23, 279-301.

Bruton, C. J., and H. F. Shaw (1987), Geochemical Simulation of Reaction between Spent Fuel Waste Form and J-13 Water at $25^{\circ} \mathrm{C}$ and $90^{\circ} \mathrm{C}$, Lawrence Livermore National Laboratory, Livermore, CA, UCRL-96702, 10.

Calabrese, E. J., and P. T. Kostecki, Eds. (1991), Hydrocarbon Contaminated Soils. Vol. 1 (Lewis Publishers, Chelsea, MI).

CRWMS M\&O Contractor, 1993, Calculation: Underground Diesel Emission Analysis, Rev. 0, Yucca Mountain Project, Las Vegas, NV, B00000000-AA-12-00002-00, 36.

Dainty, E. D., E. W. Mitchell, and G. H. Schakenberg, Jr. (1986), Organization, Objectives and Achievements of a Three-Government Collaborative Program on Diesel Emissions Reduction Research and Development, Mineral and Energy Technology, Mining Research Lab, Division Report M\&ET 86-19 (OP,J).

Delany, J. M. (1985), Reaction of Topopah Spring Tuff with J-13 Water: A Geochemical Modeling
Approach Using the EQ3/6 Reaction Path Code, Lawrence Livermore National Laboratory,

Livermore, CA, UCRL-53631, 46.

Doyle-Coombs, D. M. (1987), "Survey of Gaseous Diesel Products in Underground Coal Mines," Proceedings of U.S. Bureau of Mines Technology Transfer Seminar, 66-72.

Dukovich, M., R. E. Yasbin, S. S. Lestz, T. H. Risby, and R. B. Zweidinger (1981), "The Mutagenic and SOS-Inducing Potential of the Soluble Organic Fraction Collected from Diesel Particulate Emissions," Environ. Mutagen. 3, 253.

Fredrickson, J. K., S. W. Li, F. J. Brockman, D. L. Haldeman, P. S. Amy, and D. L. Balkwill (1995), "Time-Dependent Changes in Viable Numbers and Activities of Aerobic Heterotrophic Bacteria in Subsurface Samples," J. Microbiol. Meth., in press.

Gadd, G. M. (1990), "Heavy Metal Accumulation by Bacteria and Other Microorganisms," Experentia 46, 834-839.

Haldeman, D. L., and P. S. Amy (1993), "Bacterial Heterogeneity in Deep Subsurface Tunnels at Rainier Mesa, Nevada Test Site," Microb. Ecol. 25, 183-194.

Haldeman, D. L., P. S. Amy, D. Ringelberg, and D. C. White (1993), "Characterization of the Microbiology within a $21 \mathrm{~m}^{3}$ Section of Rock from the Deep Subsurface," Microb. Ecol. 26, 145-159.

Haldeman, D. L., P. S. Amy, D. Ringelberg, and D. C. White (1994), "Changes in Bacteria Recoverable from Subsurface Volcanic Rock Samples during Storage at $4^{\circ} \mathrm{C}, "$ Appl. Environ. Microbiol., in press.

Haldeman, D. L., P. S. Amy, C. Russell, and R. Jacobson (1995), "Comparison of Drilling and Mining as Methods for Obtaining Microbiological Samples from the Deep Subsurface," J. Microbiol. Meth., in press.

Hare, C. T., K. J. Springer, and R. L. Bradow (1979), "Fuel Additive Effects on Diesel Particulate Development and Demonstration of Methodology," in The Measurement and Control of Diesel Particulate Emissions (Society of Automotive Engineers, Warrendale, PA), 177-205. 
Harrar, J. E., J. F. Carley, W. F. Isherwood, and E. Raber (1990), Report of the Committee to Review the Use of J-13 Well Water in the Nevada Nuclear Waste Storage Investigations, Lawrence Livermore National Laboratory, Livermore, CA, UCID-21867, pp. 112.

Hartman, H. L. (1992), "Diesel Exhaust Control," in The SME Mining Engineering Handbook, 2nd ed., Vol. 1 (Society of Mining Engineering, Littleton, CO), pp. 1040-1051.

Herr, J. D., M. Dukovich, S. S. Lestz, J. A. Yergey, T. H. Risby, and S. B. Tejada (1982), "The Role of Nitrogen in the Observed Direct Microbial Mutagenic Activity for Diesel Engine Combustion in a Single-Cylinder DI Engine," in Diesel Engine Combustion, Emissions, and Particulates, Publication P-107 (Society of Automotive Engineers, Warrendale, PA), pp. 311-314.

Jackson, K. J., and S. A. Carroll (1994), "Experimental Investigation of Hydrous Pyrolysis of Diesel Fuel and the Effect of Pyrolysis Products on the Performance of the Candidate Nuclear Waste Repository at Yucca Mountain," in A. Barkatt and R. Van Konynenburg, Eds., Proceedings of the Materials Research Society, Scientific Basis for Nuclear Waste Management XVII, Vol. 333 (Materials Research Society, Pittsburgh, PA),pp. 841-847.

Khatri, N. J., J. H. Johnson, and D. G. Ledy (1979), "The Characterization of the Hydrocarbon and Sulfate Fractions of Diesel Particulate Matter," in The Measurement and Control of Diesel Particulate Emissions, Progress in Technology Series No. 17 (Society of Automotive Engineers, Warrendale, PA), pp. 73-96.

Kieft, T. L., P. S. Amy, F. J. Brockman, J. K. Fredrickson, B. N. Bjornstad, and L. L. Rosacker (1993), “Microbial Abundance and Activities in Relation to Water Potential in the Vadose Zones of Arid and Semiarid Sites," Microb. Ecol. 26, 59-78.

King, L. C., M. J. Kohan, A. C. Austin, L. C. Claxton, and J. L. Huisingh (1981), "Evaluation of the Release of Mutagens from Diesel Particles in the Presence of Physiological Fluids," Environ. Mutagen. 3, 109.

Knauss, K. G. (1984), Hydrothermal Interaction Studies of Bullfrog Member Tuff Core Wafers in J-13 Water at $1500^{\circ} \mathrm{C}$ : Quantitative Analyses of Aqueous and Solid Phases, Lawrence Livermore National Laboratory, Livermore, CA, UCRL53521, 24.
Lee, L. S., M. Hagweall, J. J. Delfino, and P. S. C. Rao (1992), "Partitioning of Polycyclic Aromatic Hydrocarbons from Diesel Fuel into Water," Environmental Science and Technology 26(11), 2104-2110.

Lipkea, W. H., J. J. Johnson, and C. T. Vuk (1979), "The Physical and Chemical Character of Diesel Particulate Emissions: Measurement Techniques and Fundamental Considerations," The Measurement and Control of Diesel Particulate Emissions (Society of Automotive Engineers, Warrendale, PA), pp. 1-57.

Mason, G., J. Gustafsson, R. N. Westerholm, and H. Li (1992), "Chemical Fractionation of Particulate Extracts from Diesel Vehicle Exhaust: Distribution of Ligands for the Dioxin Receptor," Environmental Science \& Technology, 26(8), 1635-1638.

McClure, B. T. (1992), "Laboratory Evaluation of the Effectiveness of Oxidation Catalytic Converters," in Diesel in Underground Mines-Measurement and Control of Particulate Emissions (U. S. Bureau of Mines), pp. 60-61.

Meike, A. (1994), "Chemical Implications for the Presence of Introduced Materials in the Post-Emplacement Environment," in A. Barkatt and R. Van Konynenburg, Eds., Proceedings of the Materials Research Society, Scientific Basis for Nuclear Waste Management XVII, Vol. 333 (Material Research Society, Pittsburgh, PA), pp. 835-839.

Meike, A., and C. Wittwer (1994), "Introduced Materials and Colloid Formation: A Report on the Current State of Knowledge," in A. Barkatt and R. Van Konynenburg, Eds., Proceedings of the Materials Research Society, Scientific Basis for Nuclear Waste Management XVII, Vol. 333 (Material Research Society, Pittsburgh, PA), pp. 783-789.

Oversby, V. M. (1984a), Reaction of the Topopah Spring Tuff with J-13 Well Water at $90^{\circ} \mathrm{C}$ and $150^{\circ} \mathrm{C}$, Lawrence Livermore National Laboratory, Livermore, CA, UCRL-53552, 69.

Oversby, V. M. (1984b), Reaction of the Topopah Spring Tuff With J-13 Water at $120^{\circ} \mathrm{C}$, Lawrence Livermore National Laboratory, Livermore, CA, UCRL-53574, 29.

Oversby, V. M., and K. G. Knauss (1983), Reaction of Bullfrog Tuff with J-13 Well Water at $90^{\circ} \mathrm{C}$ and $150^{\circ} \mathrm{C}$, Lawrence Livermore National Laboratory, Livermore, CA, UCRL-53442, 51. 
Pederson, T. C., and J.-S. Siak (1981a), "The Activation of Mutagens in Diesel Particle Extract with Rat Liver S9 Enzymes," J. Appl. Toxic. 1, 61.

Pederson, T. C., and J.-S. Siak (1981b), "The Role of Nitro Aromatic Compounds in the DirectActing Mutagenicity of Diesel Particle Extracts," J. Appl. Toxic. 1, 54.

Santodonato, J., D. Basu, and P. Howard (1978), Health Effects Associated with Diesel Exhaust Emissions. Literature Review and Evaluation, U.S. Environmental Protection Agency, Cincinnati OH, EPA-600/1-78-063.

Springer, K. J., and T. M. Baines (1979), "Emissions from Diesel Versions of Production Passenger Cars," in The Measurement and Control of Diesel Particulate Emissions (Society of Automotive Engineers, Warrendale, PA), pp. 207-231.

Stewart, D. B., E. D. Dainty, and J. P. Mogan (1976), "Diesel Emissions with Respect to Mine Environment," in A Review of Technology, Can. Bur. Mines Bull. 765, 85-89.

Watts, W. F., Jr (1987), "Industrial Hygiene Issues Arising from the Use of Diesel Equipment in Underground Mines," in Proceedings of U.S. Bureau of Mines Technology Seminar, pp. 4-8.

West, J. M., N. Christofi, and I. G. McKinley (1985), "An Overview of Recent Microbiological Research Relevant to the Geological Disposal of Nuclear Waste," Radioactive Waste Management and the Nuclear Fuel Cycle 6, 79-95.

Westerholm, R. N., J. Almen, H. Li, J. U. Rannug, K. Egeback, and K. Gragg (1991), "Chemical and Biological Characterization of Particulate-, Semivolatile-, and Gas-Phase-Associated Compounds in Diluted Heavy-Duty Diesel Exhausts: A Comparison of Three Different Semivolatile-Phase Samplers," Environmental Science \& Technology 25(2), 332-338.

Westerholm, R., and H. Li (1994), “A Multivariate Statistical Analysis of Fuel-Related Poly- cyclic Aromatic Hydrocarbon Emissions from Heavy-Duty Diesel Vehicles," Environmental Science \& Technology 28(5), 965-972.

Williams, K. L., E. J. Chilton, D. P. Tuchman, A. F. Cohen (1987), Measuring Gaseous Pollutants from Diesel Exhaust in Underground Mines, U.S. Bureau of Mines Information Circular, pp. 41-51.

Wolery, T. J. (1979), Calculation of Chemical Equilibrium between Aqueous Solutions and Minerals: The EQ3/6 Software Package, Lawrence Livermore National Laboratory, Livermore, CA, UCRL-52658, 39.

Wolery, T. J. (1983), EQ3NR: A Computer Program for Geochemical Aqueous Speciation-Solubility Calculations, User's Guide and Documentation, Lawrence Livermore National Laboratory, Livermore, CA, UCRL-53414, 191, (HQS.880517.2912).

Wolery, T. J., and S. A. Daveler (1992), EQ6, A Computer Program for Reaction Path Modeling of Aqueous Geochemical Systems: Theoretical Manual, User's Guide and Related Documentation (Version 7.0), Lawrence Livermore National Laboratory, Livermore, CA, UCRL-MA-110662, Pt. IV, 338.

Wolery, T. (1992a), EQ3/6, A Software Package for Geochemical Modeling of Aqueous Systems: Package Overview and Installation Guide (Version 7.0), Lawrence Livermore National Laboratory, Livermore, CA, UCRL-MA110662 , Pt. I, 66.

Wolery, T. (1992b), EQ3NR, A Computer Program for Geochemical Aqueous Speciation-Solubility Calculations: Theoretical Manual, User's Guide and Related Documentation (Version 7.0), Lawrence Livermore National Laboratory, Livermore, CA, UCRL-MA-110662, Pt. III, 246.

Zeller, H. W. (1990), Fuel Additive and Engine Operation Effects on Diesel Soot Emissions, U.S. Bureau of Mines Information Circular, USBM IC 9238. 


\section{Glossary of Terms}

Aerobic heterotrophs: Microorganisms that use organic carbon compounds as carbon and energy sources in the presence of oxygen.

Allochthonous: Describes microorganisms introduced into an environment; i.e., organisms carried into the subsurface as a result of human activity.

Autochthonous: Describes microorganisms extant in a natural environment; in situ or indigenous communities.

Bioavailable: Describes the availability of compounds for use by microbiota as carbon or energy sources; e.g., a compound may contain needed phosphates but may be toxic to microbiota, or a compound that might be readily usable by microbiota may be bound by minerals in pore spaces distal to microbe locations and is thus not bioavailable.
Diversity: A measure of the distribution of microbial communities based on both the number of different kinds of microbiota and the relative abundance of each kind; e.g., a community with a high diversity might have 10 each of 30 colony types, while low diversity might indicate a community dominated by a particular bacterial type.

Evenness: Diversity divided by the natural logarithm of the number of colony types; normalizes diversity indices so that samples containing different numbers of colony types can be compared.

Invert: Describes the unconsolidated material that has been brought into the tunnel system and placed on the floor.

Microcosms: Artificial environments created in the laboratory to simulate particular environmental conditions; in this case, diesel fuel was added to rock or invert material that contained in situ microbial communities. 


\section{Acknowledgments}

We thank K. Jackson and W. Glassley for their reviews, as well as $\mathrm{P}$. Murphy and C. Middleton for their editorial work. We especially appreciate the work of $R$. Pletcher and M. Owens in providing the equipment for sampling and preparing samples for analysis. We also thank Sue Martin, Hugh Gregg, Russ Sanborn, and J. Yoshiyama for sample analysis, and A. Simmons, K. Kinter, A. Mitchel, N. Elkins, and B. Harris-West for arranging sampling at $\mathrm{N}$-Tunnel. This work was performed under the auspices of the U.S. Department of Energy by Lawrence Livermore National Laboratory under Contract No. W-7405-Eng-48. This work was prepared by Yucca Mountain Site Characterization Project (YMSCP) participants as part of the Civilian Radioactive Waste Management Program. YMSCP is managed by the Yucca Mountain Site Characterization Project Office of the U.S. Department of Energy, Las Vegas, Nevada. 